\title{
AN EXPLORATION OF SOCIAL PARTICIPATION FOR YOUNG ADULTS FOLLOWING A FIRST PSYCHOTIC EPISODE
}

\author{
Valerie Fox
}

A dissertation submitted to the faculty of the University of North Carolina at Chapel Hill in partial fulfillment of the requirements for the degree of Doctor of Philosophy in the Department of Allied Health Sciences (Occupational Science).

Chapel Hill

2016

Approved by:

Antoine Bailliard

Nancy Bagatell

Virginia Dickie

Sue Estroff

Debbie Laliberte Rudman 
(C) 2016

Valerie Fox

ALL RIGHTS RESERVED 


\begin{abstract}
Valerie Fox: An Exploration of Social Participation for Young Adults Following A First Psychotic Episode

(Under the direction of Antoine Bailliard)

Individuals with mental illness continue to be among the most excluded in society.
\end{abstract} Adolescents and young adults with psychotic disorders often fare worse than their peers in areas such as education and the adoption of adult social and occupational roles. Although various factors have been identified that influence this exclusion and impairment, studies have predominantly focused on stigma with insufficient attention paid to other societal factors influencing participation (e.g., socioeconomic status, normative age expectations, and social institutions). In addition, there is a notable gap in the literature studying participation beyond that of employment for individuals with first episode psychosis (FEP). Numerous studies have shown that the ability to participate and interact with others is vital to recovery for people with mental illness. Indeed, participation and social interaction promote the development of social networks to support the recovery process, encourage engagement in meaningful activity, and foster community integration. A thorough understanding of how social participation shifts for individuals following their first psychotic break is needed to develop interventions targeting social integration and participation. The objective of this collaborative ethnography was to explore participation in social life for young adults following their first psychotic episode. To meet this objective, the study adopted two specific aims: 1) explore the sociocultural mechanisms that facilitate or hinder the experience of social participation for young adults following FEP; and 2) explore perceived opportunities for participation for young adults following FEP. The transactional perspective, in conjunction with the life course model and theories of action, were used as 
guiding theoretical frameworks for this study. Semi-structured interviews, participant observations, and discourse elicitation were used for data collection. Seven factors were revealed that impacted consultants' social participation: 1) social norms and expectations; 2) a sense of responsibility to others; 3) consultants' occupational histories and prior routines, including their relationships prior to the illness; 4) change in the physical and social environment; 5) the types of participation available; 6) the need to manage the illness; and 7) consultants' self-perception and the associated perception of occupational possibilities. These factors transacted in a complex way to impact consultants' experiences of belonging and their life trajectories following FEP. Consultants reported experiencing a space of liminality, wherein they struggled with new identities and negotiated new life trajectories. Participation in occupation facilitated movement through the liminal space and promoted belonging after FEP. The study findings offer new insights into theories of belonging, including how belonging is impacted in varying spaces of belonging. Implications for occupational science and occupational therapy are discussed, including recommendations for continued research related to belonging and the use of occupation as a conduit for identity work and movement through liminal spaces. 


\section{ACKNOWLEDGEMENTS}

At times our own light goes out and is rekindled by a spark from another person. Each of us has cause to think with deep gratitude of those who have lighted the flame within us.

\section{-Albert Schweitzer}

To be honest, I did not plan to pursue a doctoral degree, but as has happened numerous times, the people in my life saw a potential and opportunity that I did not see. I am beyond blessed to have the support and mentorship that I currently have and have had in the past. First and foremost, I extend expense gratitude to my husband and true partner, Kyle Fox. He did not hesitate to support me when I decided to pursue a doctoral degree and he has been my rock throughout this experience. To have the unwavering support and confidence of someone like this is a blessing beyond compare. In addition, my family, friends, and supportive cohort have been immensely helpful through their encouragement and guidance. From the early life lessons to the regular check-in phone calls, my parents have been an unending source of support. One of their many lessons was one of commitment in that once you commit to something, quitting is not an option. That lesson has helped me through this process and many other journeys throughout my life. I am thankful for those lessons, many of which were not easy but helped me develop the discipline and strength I needed to succeed. And to my cohort, the community that has been developed over these last few years will forever be treasured; I am thankful for your camaraderie, collaboration, and most of all your friendship.

A special thank you to Dr. Ruth Humphry for seeing my potential and encouraging me to consider the $\mathrm{PhD}$ in Occupational Science. Ruth, as have all of my professors at the UNC Division of Occupational Science and Occupational Therapy, fostered an intense love 
for occupational therapy and a drive to continue to expand the field. I will be forever grateful for the knowledge they shared, for challenging me to always be a better clinician and scholar, and equipping me with the tools I needed to make a difference in the world. Thank you to Dr. Virginia Dickie for being my mentor and guide throughout the masters and doctoral program, whether she knew it or not. I have always admired her ability to imagine new pathways for occupational science, her passion for mental health and continued learning, her honesty and directness in sharing her ideas, and her ability to foster challenging, mind-expanding discussions that left me pondering ideas for days and weeks later. Lastly, thank you to Dr. Antoine Bailliard and my doctoral committee. Thank you to Antoine for being open to trying new research processes with me, for providing a listening ear as I thought out ideas in often non-linear ways, and for challenging me to think outside of the box when it came to my research and findings. You pushed me outside of my theoretical comfort zone and challenged me to think deeper about the ideas. Though there were frustrating moments during this process, these are the moments I will most remember as periods of growth as a researcher and as a person who now knows that her perceived limits are only guidelines. I cannot thank you enough for that. Thank you also for not shying away from my non-traditional career and research path and assisting me with getting to where I want to be and helping me to envision my future career. You have been a truly wonderful advisor. I look forward to continuing our collaborative research relationship in the future as I hope to see many of our discussions and ideas for expanding mental health research come to fruition in the near future. And to my committee, Dr. Sue Estroff, Dr. Debbie Laliberte Rudman, Dr. Virginia Dickie, and Dr. Nancy Bagatell, thank you deeply for agreeing to be a part of my committee, sharing your expertise, and giving of your time to help council me and support me throughout this process. 
It is truly impossible to thank everyone who has impacted my life over the years and led me to this place. To those unnamed individuals, I thank you for both the large moments of guidance and support, as well as the small moments you influenced my life that you may never know mattered. I promise you, it did. 


\section{TABLE OF CONTENTS}

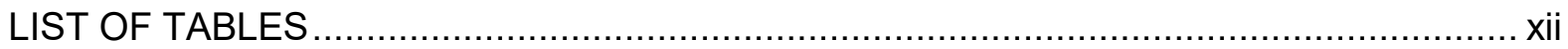

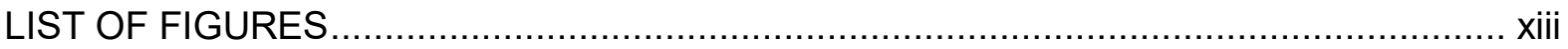

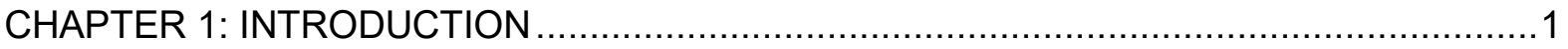

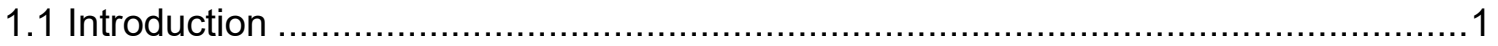

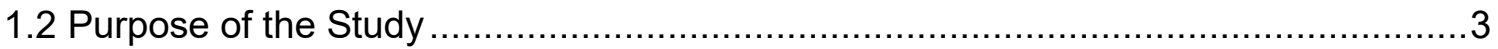

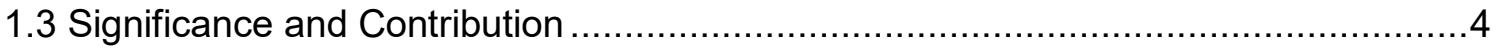

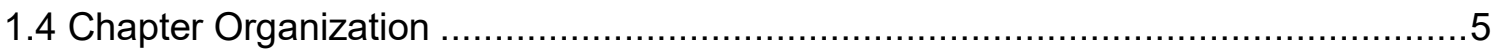

CHAPTER 2: THEORETICAL FRAMEWORKS AND LITERATURE REVIEW ..................7

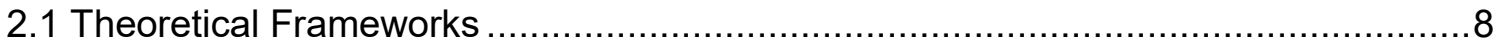

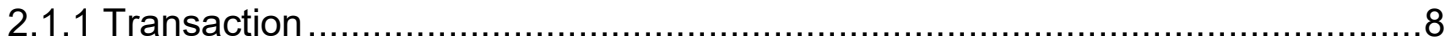

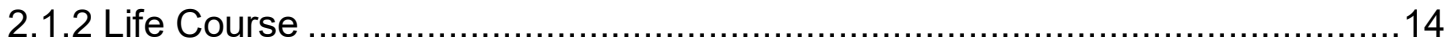

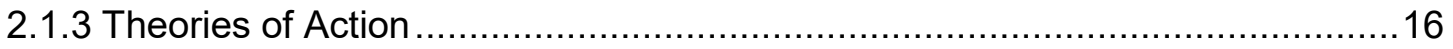

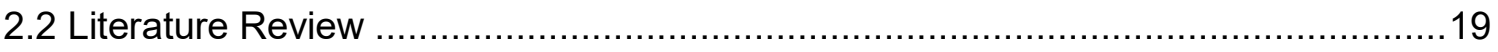

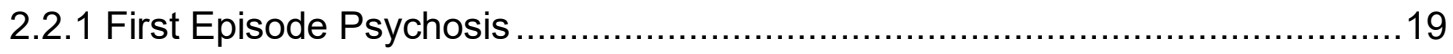

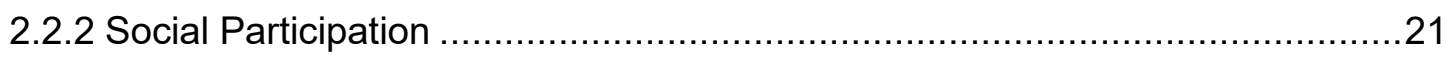

2.2.3 Factors Impacting Social Participation .................................................. 25

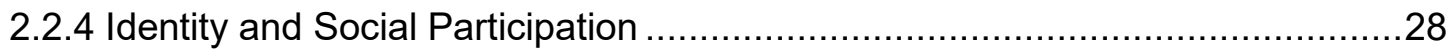

2.2.5 Occupational Science's Stance on Identity and Participation .......................32

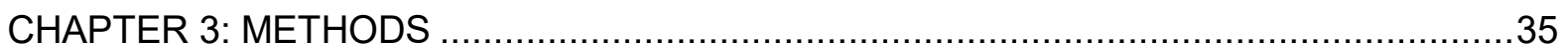

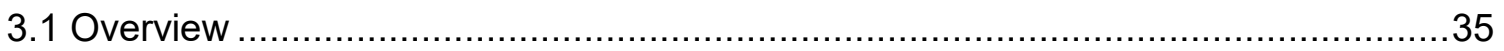

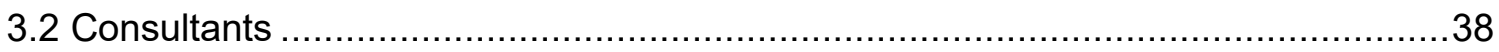

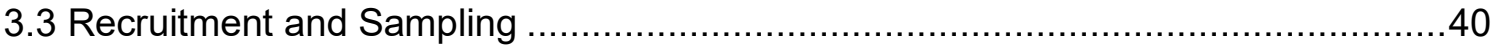


3.4 Data Collection, including Benefits and Drawbacks to each Approach

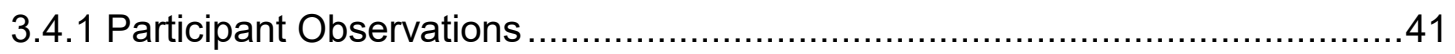

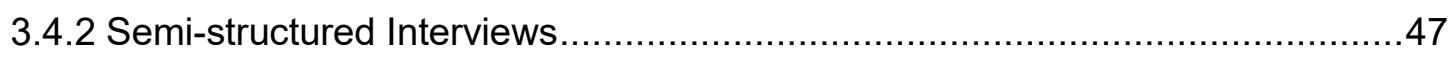

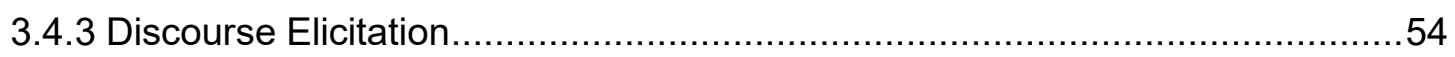

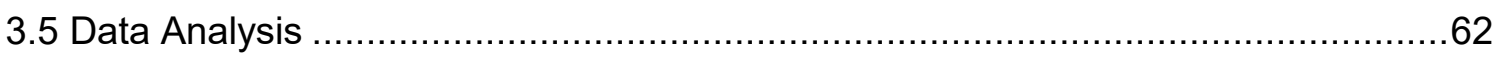

CHAPTER 4: EXPLORATION OF SOCIAL FACTORS IMPACTING SOCIAL PARTICIPATION...

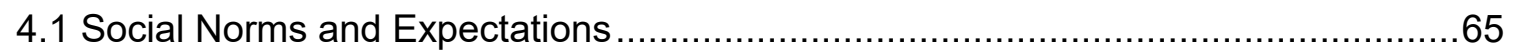

4.1.1 Stuck in a Liminal Space of Dealing with Mental Illness ............................68

4.1.2 Normative Expectations for Determining Socially Appropriate

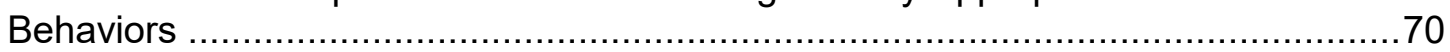

4.1.3 Impact of Social Norms and Age Expectations on Belonging ........................71

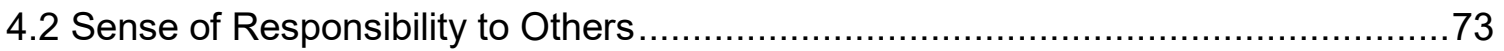

4.2.1 Impact of Sense of Responsibility on Belonging .....................................74

4.3 Occupational History and Prior Routines ................................................... 75

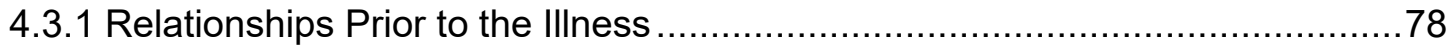

4.3.2 Impact of Occupational History and Prior Routines on Belonging ...................82

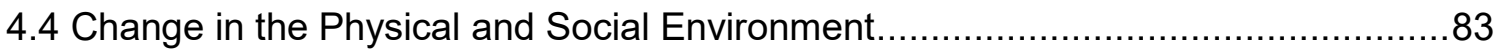

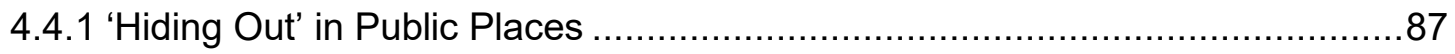

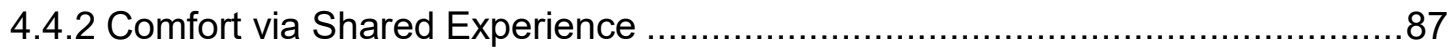

4.4.3 Impact of Changes in the Physical and Social Environment

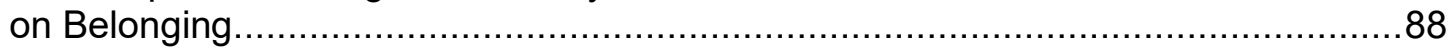

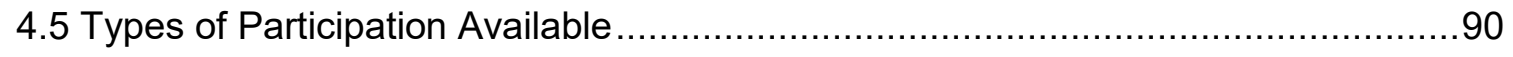

4.5.1 Adapting Participation Styles at Various Stages of the IIlness ......................93

4.5.2 Impact of Varied Types of Participation on Belonging ...............................94

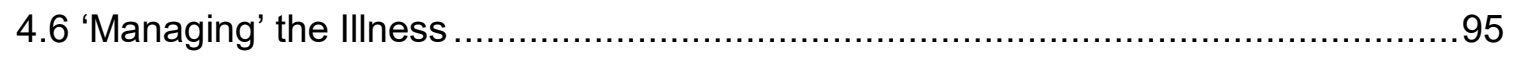

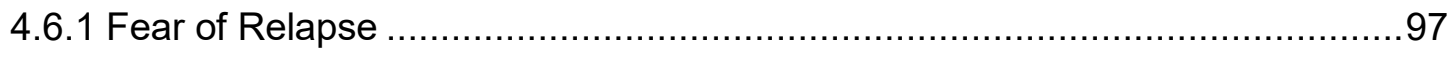


4.6.2 Impact of Managing the IIIness and Fear of Relapse on Belonging

4.7 Self-perception and Perceived Occupational Possibilities... 100

4.7.1 Impact of Self-perception and Perceived Occupational Possibilities on Belonging ....

4.8 Summary of Findings.

CHAPTER 5: OCCUPATION AS MEDIUM FOR IDENTITY WORK

5.1 Hospitalization Experience as Initial Identity Construction Period:

"Feeling like a Waste to Our Society" 103

5.2 Emotional Link with Identity ..... 106

5.3 Power to Define Oneself. .112

5.4 Role of Media in Integrating IIIness Identity 114

5.5 Identity Work: Drawing Intra-group Distinctions .116

5.6 Intersectionality of Identities .119

5.7 Positive Factors of Adopting the 'Mentally III' Identity. 122

5.8 Summary. 123

CHAPTER 6: DISCUSSION .125

6.1 Summary of Findings. .125

6.1.1 Social Participation and Belonging.... 125

6.1.2 Rethinking the Experience of FEP Relative to Belonging 134

6.1.3 Reframing FEP as a Problematic Situation 135

6.1.4 Belonging and Identity 137

6.1.5 Liminal Space of FEP: Importance to Identity Work and Social Participation

6.2 Limitations

6.3.1 Future Avenues for Research 148

CHAPTER 7: CONCLUSION .153

7.1 Conclusion 153 


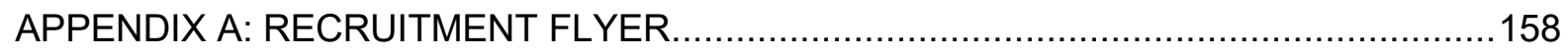

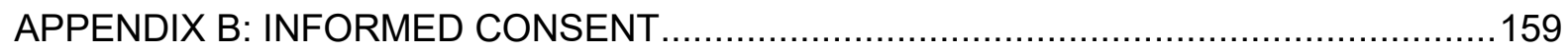

APPENDIX C: LIST OF CONSULTANT OBSERVATIONS ..................................... 163

APPENDIX D: SEMI-STRUCTURED INTERVIEW QUESTIONS ................................ 166

APPENDIX E: PHOTOS USED DURING DISCOURSE ELICITATION ........................168

APPENDIX F: CONSULTANT IDENTIFIED DISCOURSE ....................................... 169

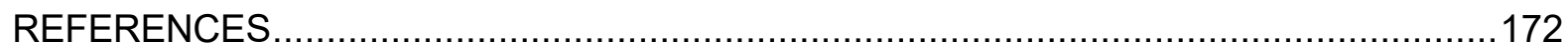




\section{LIST OF TABLES}

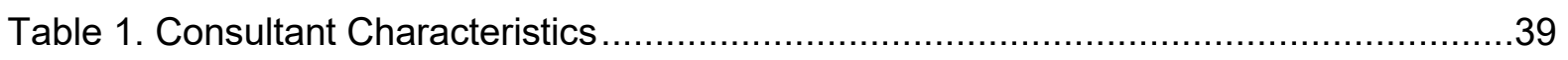




\section{LIST OF FIGURES}

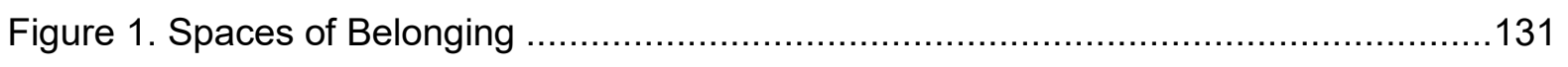

Figure 2. Liminal Space of FEP: Belonging Through Occupation .............................141 


\section{CHAPTER 1: INTRODUCTION}

\subsection{Introduction}

Mental illness affects one in five adults in the US, accounting for $13 \%$ of the global burden of disease (SAMSHA, 2012; WHO, 2012). The nature of mental health problems and stigma, as well as limitations in income and employment, have detrimental effects on interpersonal relationships for individuals with mental illness, leading to reduced opportunities for social contact and occupational participation (Huxley \& Thornicroft, 2003). Prince and Gerber (2005) found that although individuals with psychiatric disabilities living in the community were able to access basic resources, they remained socially isolated and only minimally interactive with others in their community. In addition, cognitive deficits (e.g., executive function, memory, attention, and verbal learning), as well as social impairments resulting from positive and negative symptoms lead to significant functional impairments for individuals with psychotic disorders (Sharma \& Antonova, 2003).

The rate of mental illness is much higher for young adults aged 18-25, which is the typical age of onset for psychosis. In Western cultures, this age corresponds to a time in life when increased independence and self-sufficiency is expected and life trajectories and career pathways are chosen (Henry \& Coster, 1996; McGorry et al., 2007). 'First episode psychosis' is the term generally used to describe individuals who have experienced a short duration of psychotic illness (i.e., 2-5 years) (Breitborde, Srihari, \& Woods, 2009). Examining first episode psychosis (FEP) is important because this population would provide more informative data regarding the course and trajectories of the illness and its effects (Malla \& Payne, 2005). This 'critical period' between 3 to 5 years after onset of psychosis is when interventions will likely have the greatest effect on future trajectories of functional outcome 
(Birchwood et al., 1998; Harrison, et al., 2001). There is a need to develop treatment that is more suitable to the earlier phases of illness and to younger client populations (Malla \& Payne, 2005).

As a mental health clinician, it has become apparent in my clinical practice that traditional individual-based interventions are inadequate to foster significant change in social and occupational functioning. There is a paucity of available intervention strategies that address the social barriers that limit participation for adults with FEP. Understanding the impact of social factors on participation and life trajectories following FEP can inform the development of interventions and policies to effectively target the early stages of mental illness to mitigate long-term effects on health and well-being.

To date, clinical interventions and research have primarily focused on the individual and experiences of stigma with little regard to how social forces impact recovery and community participation. While psychopathology is important for understanding experiences of mental illness, it is equally important to study how mental illness affects quality of life, participation in occupation, and social functioning (Malla \& Payne, 2005). According to these authors, research must study the complex relationships between factors that predict functioning and actual outcomes following a first episode of psychosis. Research on first episode psychosis has predominantly used quantitative, biomedical methodologies that isolate variables to study without integrating the holistic interplay of factors or studying the relationships themselves (Boydell, Stasiulis, Volpe, \& Gladstone, 2010). Due to the isolation of variables typical in quantitative research, a systematic understanding of the FEP situation continues to be limited. Qualitative research is able to fill this gap and address the need for a relational examination of FEP and its impact on function. Although qualitative FEP research is growing, there are still many avenues left unexplored, in particular, the social mechanisms that affect participation in community activities and life roles. In addition, qualitative research that examines areas of activity outside of employment are significantly 
lacking (Boydell et al., 2010). Boydell et al. called for an extension of the scope of qualitative research to examine the full trajectory of FEP. Occupational science nor the broader social science literature have focused on occupation and pathways for participation for FEP; this is a current gap in research.

\subsection{Purpose of the Study}

The objective of this collaborative ethnography was to explore participation in social life for young adults following their first psychotic episode. To meet this objective, the study adopted two specific aims: 1) explore the sociocultural mechanisms that facilitate or hinder the experience of social participation for young adults following FEP; and 2) explore perceived opportunities for participation for young adults following FEP. It was anticipated that social elements played at least an equally important role as individual factors in facilitating or hindering community participation for young adults following a first psychotic episode. Identifying those social factors, in addition to exploring the interplay between the individual and social components, is important for improving clinical outcomes and participation in meaningful life roles. The purpose of aim 2 was to understand how social factors and perceptions impact individual function and were adopted by the individual. It was assumed that individuals adjusted their life goals and pathways following first episode psychosis based on social stereotypes, perceived opportunities available to them, and anticipated success in future life roles. Using discursive examples to examine social beliefs and factors impacting participation served three purposes: 1) to explore the social messages being produced in a local context; 2) determine how each individual responded to such messages, and 3) ascertain whether these discursive examples impact an individual's perceived possibilities for participation in particular contexts.

The intent of this study was two-fold. First, this study filled a gap in qualitative research exploring participation in areas outside of employment for people with first episode psychosis. Second, this study identified social factors that impact social participation and 
provided preliminary data to focus early intervention practice and research, program development, and improve functional outcomes on a broader scale for those with mental illness.

\subsection{Significance and Contribution}

This research contribution is significant for two reasons. First, this research increased knowledge of sociocultural elements that influence social participation, which is an area of focus in the President's New Freedom Commission on Mental Health and vital to community and societal well-being. Without a holistic understanding of the societal factors that influence individual action, intervention is limited in its scope and may not be as effective if the most significant barrier to participation is beyond the individual. When the individual is the focus of attention, broader sociocultural elements are often left unaddressed (Whiteford \& Hocking, 2012). Because individual participation occurs through social environments, interventions that address social factors will consequently impact individual participation. While outside of the scope of this particular study, this study generated preliminary data to inform early intervention practice, specifically focused on the social elements influencing participation, which could lead to better functional outcomes and reduce the need for chronic management of illness.

Second, this research is significant to occupational science because it extended understandings of sociocultural factors impacting occupational participation, while also expanding application of existing occupational concepts to new populations. Occupational science research on older adults has examined how social structures and neoliberal governance support policies and practices that create possibilities for some, while excluding others (Laliberte Rudman, 2012). This research needs to be applied to those with mental illness, specifically how individuals with mental illness perceive opportunities for social participation after diagnosis. While the concepts are applicable, the ways in which occupational deprivation and exclusion occur are profoundly different for individuals with 
mental illness, in part due to the social perceptions and elements influencing social engagement. Prior to this research, occupational science has not explored the experience of first episode psychosis and how this population negotiates occupational participation. Understanding occupation is central to the experience of FEP. Research examining FEP has not explored the role occupation serves in supporting well-being, quality of life, and role expansion. This study filled this gap both within the occupational science literature, as well as the broader mental health literature. In addition, this study discussed the ways to expand occupational therapy's role in early intervention for FEP via a focus on occupation as central to the experience of FEP.

\subsection{Chapter Organization}

This chapter has served to provide an overview of the current state of affairs for first episode psychosis research, including gaps in the research and limitations in clinical interventions. In addition, the importance of this study in filling those gaps and offering preliminary data to expand more effective clinical and social interventions has been underscored. In the next chapter, I present my philosophical perspective and the theoretical frameworks that guided the design and analyses of this study. Subsequently, I will review the current body of literature in occupational science and other social sciences in relation to social participation and identity. In the third chapter, I present the study design and methodology. I will discuss the innovative combination of methods used to garner a holistic understanding of the array of social factors impacting social participation for young adults following FEP. In addition, I examine the benefits and drawbacks of each method from a researcher and consultant perspective. I make methodological recommendations for future research on FEP. Chapters four and five present the major findings of this research study. In chapter four, I present findings related to social participation, focusing on the social factors that impacted the participation of the consultants in the study. In chapter five, I present findings related to identity and participation, emphasizing occupation as inherent to the 
process of identity work. In chapter six, I apply the findings to broader concepts, specifically belonging and liminal space. I discuss these concepts in relation to existing occupational science literature and depict three models that represent belonging and liminal spaces in relation to the experience of FEP. I also discuss the implications of these findings for occupational science and occupational therapy and suggest avenues for future research. Lastly, in chapter seven, I provide a summary of my findings and analyses and examine the limitations of this research study. 


\section{CHAPTER 2: THEORETICAL FRAMEWORKS AND LITERATURE REVIEW}

The philosophical assumptions underlying a researcher's work have strong implications for the type of research conducted and the knowledge produced. Science is fundamentally a social construct and values and beliefs are inherent to scientific work (Bishop, 2007); there are "no theory-free approaches or methods...they all presupposed a number of things about what the world is really like, what truth about it would resemble, and what is worth knowing in the first place" (p. 50). I have adopted the social constructionist paradigm, which assumes that knowledge is socially constructed and shaped, often through interactions. This view requires questioning the taken-for-granted assumptions and opposes the idea that knowledge is objective and unbiased (Burr, 2015; Crotty, 1998; Daly, 2007). Through our interactions with our world, meanings and interpretations are constructed and shaped by shared societal and cultural beliefs, values, and perceptions. Daly (2007) affirmed, "We don't simply create idiosyncratic meanings of behavior, but we construct meanings on the basis of socially available, shared understandings of reality" (p. 32). Because meaning is constructed from being in the world, it is contingent on interactions with others (Daly, 2007). Accordingly, reality or truth can be represented or interpreted in multiple ways and there is no one way, objective truth or way of seeing the world. This philosophical orientation framed the design of this study including methods for data collection and analysis.

For the remainder of this chapter, I will discuss key theoretical frameworks that have shaped my thinking and research approach. Specifically, I will focus on the transactional perspective, the life course perspective, and theories of action. I will highlight key ideas from 
each theoretical perspective that specifically relate to this study and how I understand the findings.

\subsection{Theoretical Frameworks}

\subsubsection{Transaction}

A holistic examination of the experience of FEP requires a broad theoretical theory that highlights society as much as the individual while blending them into a unified observable relationship: action. The transactional perspective on occupation (Dickie, Cutchin, \& Humphry, 2006) offers such a theory. The perspective suggests an "ever-present and always changing interpenetration of humans and their world" (p. 88) wherein all entities are co-defining and continuous. The transactional perspective is a relational perspective; the focus is on the relationships or the interplay of elements that constitute any given situation. Interaction and self-action imply a duality between a person and their world; though a person may interact with their world, these two concepts are viewed as distinct entities. Transaction transcends interaction and self-action, highlighting that focusing on the interaction between elements is insufficient for understanding the way in which people and their environments co-define and co-constitute each other (Cutchin \& Dickie, 2013). According to Humphry and Wakeford (2013), "A transactional perspective serves as a metatheory and reflects a different view of what can be known. It realigns our focus, away from the individual and onto the relationships among all elements of a life situation" (p. 216). They termed this holistic system the occupational situation, "comprised of multiple interpenetrating elements, including the person, the occupation, and temporal, cultural, social, and physical contexts, but which is also more than the sum of those parts" (p. 219).

The transactional perspective is grounded in Deweyan philosophy. Dewey emphasized that the relationship of individuals and their environment is achieved and necessitated by 'functional coordination' (Cutchin \& Dickie, 2013; Garrison, 2001). 
Functional coordination is a "dynamic, coordinated restructuring of relationships of person and situation" (Cutchin \& Dickie, 2013, p. 27). Functional coordination results in a harmonious balance or fit of a person and their situation where all parts work together towards a functional outcome: the ability to act and participate in their world. According to Dewey, when a situation becomes problematic, there is a loss of coordination amongst the elements in a given situation. To resolve this, individuals must coordinate their action with their environments to again achieve functional coordination of the situation. Individuals do this by imagining new possibilities for action and restructuring their habits.

Dewey claimed that habits dominate transactions, "operating subconsciously to foster basic functional coordination of the person-context relationship" (Aldrich, 2008, p. 152). For Dewey, habits are "social tools...functions acquired from both natural and social dimensions of our habitats...that are at the ready as potentialities and only actualized through transactional coordination with a situation" (Cutchin, 2007, p. 525). They are the building blocks of all action. Habits allow individuals to act in their world more efficiently, leaving more energy available for creative thinking and action. People act, think, or feel according to a more or less stable, foreseeable pattern of behavior; these patterns of behavior are largely influenced by past experiences and historical events (Fesmire, 2003). The automaticity of habits can be very helpful in moving through daily life if the habits used are effective; they can provide stability and "serve as a platform for exploring additional ways of being in the world" (Fritz, 2014, p.167). However, when they become ineffective and are not adapted, habits can be detrimental.

Habits remain largely invisible, until they are disrupted (Garrison, 2001). People with psychotic disorders have habits in place prior to the development of their illness. Following FEP, these habits may no longer be effective in helping people to functionally coordinate their actions in daily life, thereby creating a need for new habits. Thus, it is helpful to think of a first psychotic episode as a 'problematic situation' that requires functional coordination of 
the individual and their environment. Examining psychosis in this way encourages understandings of the illness as a relational issue that extends beyond the individual. In addition to the habits disrupted by the illness, new habits may be acquired through the experience of mental illness and these must be coordinated with other habits while participating in certain social settings (Davidson, 2007). For example, new medication habits or routine medical appointments will have to be coordinated with habits already operating in certain contexts, such as work or school. Individuals may have to take time off of work, schedule appointments in the evening, or receive adaptations to utilize habits needed for illness management, while also coordinating the habits of the environment in which they are participating. They may have group projects that require evening meetings that interrupt medication routines or sleep habits needed for symptom management.

The ability to functionally coordinate, and thus recover, requires opportunities for action and inquiry. It is through action that people "express the habits of the present self and form the future self" (Garrison, 2001, p. 16). For Dewey, participation in community is the primary mode through which humans grow their capabilities (Cutchin \& Dickie, 2012). Opportunities for growth are revealed through contact with others and their ways of being (i.e., habits) (Fesmire, 2003). Habits emerge from participation in the world and exist only through the relationships that support or limit the use of habits; they can never be viewed as internal to or deriving from the individual (Cutchin \& Dickie, 2012). While social factors condition and limit us, Dewey also emphasized that through social participation, we generate the habits, or social tools, needed to act on the world (Cutchin, 2007). But how can someone adapt their habits and act on the world if they are unable to participate in their community as others do? Without interactions in social and cultural arenas of practice, individuals with FEP experience limited opportunities to compare their actions to others and subsequently adjust their habit configurations for functional coordination following their FEP. As Garrison (2001) acknowledged, "Habits cannot stand alone, they are nested 
relationships within a context, subfunctions of larger functions" (p. 125). Dewey acknowledged the relationship between habits and the broader environing conditions and social structures, as well as the limited impact of agency in changing habits. Indeed, Fesmire (2003) noted, "[Habits] cannot magically be changed simply by will or coercion" ( $p$. 21). Thus, focusing on how habits are adjusted following FEP, including how these habits are shaped via social factors, could offer new insights to understand the situation of FEP and how to assist individuals with FEP to functionally coordinate their situation following a psychotic episode. According to the transactional perspective, all elements comprising a situation (e.g., person, environment, policies, etc.) can have an impact on the actions generated by that situation. Consequently, the environment, policies, organizations, and cultural attitudes can limit possibilities for action and thus possibilities for functional coordination.

The transactional perspective is a useful framework for exploring the relationship of broad sociocultural factors and participation and its impact on individuals with first episode psychosis. In thinking about participation, research needs to move away from a focus on individual performance to investigate the array of factors that impact an individual or group's participation. A focus on individual performance overemphasizes individual responsibility for recovery, while undervaluing the impact of social factors that influence individual functioning and ability to engage in social life. As Dickie et al. (2006) asserted "an understanding of individual experience is a necessary but insufficient [emphasis in original] condition" (p. 83) for understanding the complexity of occupation. The transactional view encourages occupational scientists to consider the complex array of relationships affecting opportunities for participation. This view simultaneously considers the continuous changes that occur in terms of social, physical, temporal, and cultural demands, as well as variations in personal interest, meaning, and self-efficacy inherent in any one occupational situation (Humphry \& Wakeford, 2013). 
Participation in social life is the primary way humans expand their capacities and grow as both individuals and societies (Cutchin \& Dickie, 2013). Occupation is the primary mode through which participation occurs in communities. It is a form of relational action through which functional coordination between person and environment is achieved (Cutchin, Aldrich, Bailliard \& Coppola, 2008). Through occupation, experience and meaning are realized, identities are formed, societal interaction occurs, and habits are modified for improved living (Cutchin, 2013; Hasselkus, 2002; Laliberte Rudman, 2002; Wilcock, 2006). Given occupation's position as the relational glue (Cutchin et al., 2008), it is logical and essential to focus on occupation when attempting to study a complex, interdependent system. In utilizing the transactional perspective, the focus of inquiry shifts away from substances comprising a situation to focus on the relationships joining those substances. In the case of first episode psychosis, it refocuses attention to the relationships between determinants of participation and allows for examination and intervention at the social level, which was the goal of this study. As Cutchin and Dickie (2013) underlined, "It is the relationships among things, not what takes place within things, which should hold a scientist's attention" (p. 27). Utilizing a transactional perspective to examine occupation and participation for individuals with FEP provides a way to achieve insight into the social and cultural processes that shape situations and the actions that influence those situations. According to Cutchin, Dickie, and Humphry (2006), such an approach empowers occupational scientists to address broad sociocultural concepts and concerns that limit engagement in occupation.

\subsubsection{Anti-dualism}

The relational nature of transaction emphasizes an anti-dualistic approach to research and clinical practice. The transactional perspective denies the existence of a dualism between individuals and their physical or social environments. Rather, it emphasizes the relationship of person and their environment; one cannot exist without the 
other and they continuously influence each other. This anti-dualistic stance is important for examining first episode psychosis and social participation and fully understanding the complex situation of FEP. Many dualisms exist in the health field, especially when examining mental illness. Dualisms, such as mind-body or person-context fail to acknowledge the fluid transactional relationship between elements. Container metaphors continue to exist when discussing the person, the environment, and health as if they could be separated into distinct entities. Aldrich and Cutchin (2013) highlighted the traditional view of the body in the health sciences:

To speak of the body in the health sciences is to speak of a physical form: a corporeal, fixed object encapsulating organs, bones, and the mind. Implicit in this idea of the body is the idea of separation, of an individual figure whose shape and contents are restricted and apart from the rest of the world... When the body is viewed only as a physical container for the human being, it becomes challenging to deal with the non-physical features of human life. For example, the question of how culture and environment affect the body arises only when the body's separation from the world is taken as a starting point. (p. 14)

This same notion can be applied to the mind when discussing how traditional research has examined mental illness. For example, medication adherence is a common term amongst mental health providers. Clinicians often focus on why clients are medication non-adherent despite physician recommendations without consideration of social and environmental factors that impact this behavior (e.g., education level, socioeconomic status, history and past experiences of family members who have taken medications, power dynamics between clients and mental health providers, or spiritual beliefs about medication). Adopting a nondualistic approach could facilitate creative thinking about a person's recovery and shift treatment towards more holistic interventions that address various aspects of the situation of mental illness.

Though client-centered practice is currently used as the best model for recoverybased clinical practice, this model continues to adopt a dualistic perspective. Client-centered practice places emphasis on the individual person assuming that the point of intervention is 
the client, without fully addressing the relationship of the person and their environment (Garrison, 2001). A transactional view replaces this dualistic framework and instead focuses on the relationship of things. Aldrich and Cutchin (2013) argued that adopting a transactional view of the body and mind refocuses science to examine the process of embodiment whereby humans actively live through non-bodily aspects of the world. These authors accentuated that embodiment is always a collective process due to the social and communal aspects involved in the process of embodiment; thus, the more integrated an individual is into social life, the more potential there may be for growth and recovery.

Adopting the transactional perspective in examining first episode psychosis offers vast potential for expanding the social and health sciences. First, the transactional perspective replaces the dualistic view of person and environment with a view of active embodiment whereby all elements in a given situation are related and should be examined as such. Second, focusing on first episode psychosis as a problematic situation that requires functional coordination through engagement in occupation expands occupational sciences' role with this population and could serve to enhance social programs and less-stigmatized approaches towards mental health treatment. And third, adopting a transactional perspective expands the various lines of inquiry to be examined with the goal of deepening and widening our knowledge of the role occupation plays in health and well-being.

\subsubsection{Life Course}

While the transactional perspective is the integral framework informing my theoretical stance, the life course perspective informed by the foundational work of Elder (1999) adds an additional theoretical layer that informed my study of FEP and social participation. This theory shares many of the same assumptions inherent to the transactional perspective, specifically the focus on relationships throughout the life span and the social nature of living. However, the life course perspective also emphasizes social positions and roles as they change throughout life. The life course theory recognizes that systematic changes occur 
throughout the life-span and emphasizes that living is a highly contextualized, social process in which individuals change social positions and roles across the course of their lives (Diewald \& Mayer, 2009). The life course theory moves beyond an emphasis on the physical, mental, social, and emotional changes occurring within an individual to study the broader factors impacting roles acquired during the life course. There are five principles of life course theory (Elder, 1999): 1) Human development and aging are life-long processes (accumulated experiences with past occupations impact current forms of engagement); 2) Antecedents and consequences of life transitions and events vary according to their timing in a person's life (i.e., normative expectations, age cohorts); 3) Lives are linked interdependently and social-historical influences are expressed through this network of shared relationships; 4) Historic events and times shape the life course of individuals; and 5) Individuals construct their own life course through the choice and actions they take within the opportunities and constraints of history and social circumstances.

Humphry and Womack (2014) affirmed, "The life course perspective encourages us to acknowledge the intertwined factors leading to the complexity of any one person's occupational engagement...life course perspective illustrates what people do is simultaneously individual, interpersonal, social and historical" (p. 11). Examination of changes in the life course enables investigation of the links between macro-level elements and occupational possibilities; increased understanding of the political, social, cultural, and historical influences on occupation can help to shape environments that maximize occupational possibilities (Laliberte Rudman, 2010).

\subsubsection{Application of Life Course Perspective to FEP}

In applying the life course theory to the idea of occupational participation for individuals with mental illness encourages consideration of life transitions, historic events, normative expectations, and social-cultural forces. While adapting to a mental illness is a transition in and of itself, young adults recently diagnosed with FEP are also dealing with 
other major life transitions such as expectations for increased independence and career planning. Typical onset of FEP occurs at a life stage that is fraught with normative age expectations and social demands that impact self-perception and confidence in managing their health. By adopting a life course perspective, occupational scientists are encouraged to examine the experience of FEP from a variety of perspectives, including the ways normative age expectations impact occupational choices and self-efficacy; how societal, cultural, and individual histories impact current function and future occupational possibilities; and the shared relationships inherent to mental health treatment that impact occupational function.

\subsubsection{Theories of Action}

There are two primary action theorists who have drastically shaped how I have approached this research study: Pierre Bourdieu and John Dewey. John Dewey's perspective on transaction has already been discussed. This section will focus on Bourdieu's theory of action. A central component underlying Pierre Bourdieu's philosophical work are social systems of hierarchy and domination that ultimately reproduced inequality, often without the awareness of members involved in its reproduction (Swartz, 1997). He emphasized the role of power and how power is displayed through cultural processes, resources, and institutions. Three primary concepts structured the cultural sphere for Bourdieu: field, capital, and habitus. Fields are "arenas of struggle for control over valued resources" (p. 122), or capital. Fields outline the social structure through which habitus operates. For example, individuals desiring to integrate into the employment field must compete with 'normal' individuals for the same jobs. They may not have as much capital to assist them in acquiring employment (e.g., gaps in employment due to hospitalization; lack of job experience and variety; limited education; fewer vocational, financial, or transportation resources); in addition, there are particular risks for pursuing employment such as potential loss of disability income and disclosure of their illness. Entry into a field requires the tacit acceptance of the rules structuring the field, and an individual or group's position in the field 
is determined by the unequal distribution of capital versus the characteristics of players in the field. The game, which was a powerful metaphor used by Bourdieu, epitomizes the domination, competitiveness, and power associated with given fields. Social rules are created by specific social groups, often more dominant groups, who then apply those rules and labels to particular individuals or groups (Becker, 1963). We enter the game knowing the rules. We are competitive. We buy into the rules as being legitimate, but we all play the game a little differently based on the skills we possess, the capital we have accumulated, and most importantly, the habitus that we have (Swartz, 1997). We all develop a sense of the game in our fields based on our positions and habitus.

Bourdieu emphasized institutions, social hierarchy, class structure, and social customs and traditions as important in shaping habitus and opportunities for action (Swartz, 1997). Habitus, which is a system of predisposed ways of being, builds on the notion that "actors respond in terms of deeply ingrained past experiences to the opportunities and the constraints offered by present situations" (Swartz, 2002, p. 625). Habitus tends to shape individual and group action towards anticipated chances of success or failure that have been internalized from past experiences. It involves an unconscious calculation of what is possible and impossible for individuals or groups in their specific position in a certain field or social hierarchy. Anticipated outcomes and social rules are transmitted and absorbed via social discourse. Through the use of symbols and language, social expectations, rules, norms, and ideas of power are communicated (Blumer, 1969; Schwalbe et al., 2000). Discourses position individuals and hinder opportunities for participation in certain fields, partly based on the capital afforded them in those fields, and shape habitus towards anticipated outcomes. Action is not predetermined; however, habitus tends to reproduce behaviors, perceptions, and attitudes consistent with the conditions under which they were initially produced (Swartz, 1997). Human action ultimately originates from the combination of habitus, capital, and field. 
Bourdieu argued that social classes are contested identities that are constructed through struggles over legitimacy, and internalized through habitus (Swartz, 1997). While mental illness is not necessarily a class in the traditional sense, the same principles apply. The 'mentally ill' identity is defined in terms of similar positions in social spaces that provide similar conditions of existence and similar dispositions, or habitus, which in turn lead to similarities in all cultural and social practices. People with mental illness often have low cultural and economic capital, and the collective habitus formed through past experiences and interactions with others informs what opportunities are available, beyond the role of the disability in their lives. Thus, in exploring social participation for people with mental illness, it is important to fully assess the social field and to realize that there will inherently be constraints, as well as opportunities for participation. However, their ability to participate socially will not be based solely on the disability. Instead, their ability to participate will more likely be based on an individual or group's social position within a given field, the amount of capital available, as well as the habitus that has developed that will ultimately predispose someone to act and engage in certain ways.

The shared situation of having a mental illness has led to the creation of shared habitus and predisposed ways of acting in the world. While clinicians and treatment providers often blame social isolation and withdrawal, lack of social skills, and inability to interact appropriately with others as typical behaviors for a person with mental illness, these actions and behaviors are equally molded through social structures, available resources and capital, constraints and opportunities in certain fields, and the habits formed as a result of the internalization of the successes and failures associated with previous experiences. Broad social structures and hierarchies are often forgotten when someone is diagnosed with a mental illness, and the blame for isolation and apathy is frequently imposed on the individual. Bourdieu's notions of habitus, field, and capital led me to question clinical use of individually-based interventions that focus solely on individual characteristics with no 
acknowledgement of social structures, predisposed ways of being, and other situational elements besides the person and their strengths and deficits. Based on Bourdieu's theory, this study aimed to explore the social structures that impact social participation and recovery to garner a more holistic understanding of the situation of FEP and how to adapt interventions to address particular areas of the situation.

The aforementioned theories of action emphasize the social nature of habit development and identify opportunities for change through transaction. These theories have encouraged me to focus on social participation and use methods that rigorously but effectively look at the lived experience holistically. Occupation is a primary mode through which participation occurs and social relationships are formed; thus, it is important to fully explore how occupation is used by individuals with FEP as a facilitator of social participation and belonging. These theoretical perspectives have provided guidance as to the social factors that could play a role in the occupational situation of young adults with FEP.

\subsection{Literature Review}

\subsubsection{First Episode Psychosis}

There is currently no operational definition for what constitutes first episode psychosis. Definitions for 'first episode psychosis' generally fall into 3 categories: 1) first treatment contact; 2) duration of antipsychotic medication use; and 3) duration of psychosis (Breitborde et al., 2009). Breitborde et al. (2009) recommended that FEP be defined as lasting 2-5 years since the onset of psychotic symptoms when most functional deterioration occurs. The third definition was used to recruit consultants for this study as this definition possesses the most construct validity.

This population is distinct from individuals with chronic mental illness in many ways. First episode psychosis occurs at a younger age, typically during adolescence or young adulthood, when expectations of independence and responsibility are increased, independent role exploration is encouraged, and life trajectories and career paths are 
determined (Henry \& Coster, 1996; McGorry, Killackey, \& Yung, 2007). The stress of these life transitions is heightened for those with the added challenge of dealing with first episode psychosis, which often interrupts the achievement of vital educational, occupational, and social milestones (Ramsey et al., 2011). The onset of illness interrupts a crucial developmental phase, that of transitions to adulthood; this developmental transition often goes unaddressed in clinical treatment (Judge et al., 2008). Active symptoms are often missed or 'normalized' as part of the self because they become associated with developmental changes (e.g., teenage 'acting out'), or linked to less stigmatized syndromes, such as affective disorders or physical disorders. Thus, there is often a delay in seeking treatment; it typically takes 1-2 years for someone experiencing their first psychotic episode to seek treatment (Lieberman \& Fenton, 2000). During this period of adjustment to psychosis, individuals experience high levels of hopelessness (Perry, Taylor \& Shaw, 2007), as well as reduced participation in daily life roles. Researchers have consistently found that young people with psychotic disorders fare poorer than their peers in education and the adoption of adult social and occupational roles (Pottick et al., 2008). For example, Stoep et al. (2000) found that young adults diagnosed with psychiatric disorders were less likely to complete secondary education, less likely to secure gainful employment, tended to have more unplanned pregnancies, were more likely to have criminal issues, and struggled with developing relationships, often living alone.

Schulenberg, Sameroff, and Cicchetti (2004) also stressed that it is especially important to examine this transition period from a systems perspective. As development is viewed as a function of person-context transactions, it is understood that the social environment in which a person participates will impact their development and growth and thus, must be taken into account. For example, Hopper, Wanderling, and Narayanan (2007) found that the stigma of being unmarried in the Indian context trumped that of having a mental illness. As a result, more individuals were involved in sustained relationships even 
after an episode of psychosis because of the significant social pressure. In their study, Hopper et al. (2007) acknowledged the importance of the sociocultural context in social participation. Iyer, Mangala, Thara, and Malla (2010) called for further "identification of factors that contribute to these differences in outcomes and participation" (p. 232). These studies suggest that an examination of the whole situation enveloping FEP is needed to fully flesh out the factors impacting social participation following a first psychotic episode. A complete understanding of the situation is vital to fostering successful interventions. Without a clear understanding of this transition period and how opportunities for participation shift following a diagnosis, potential avenues for intervention are limited. For example, social programs that target integration of individuals with and without psychiatric disabilities could be developed to develop social skills, relationships, and networking, which may improve social and occupational roles, while potentially reducing social perceptions about individuals with psychiatric disabilities. However, for these interventions to be developed, it is critical that we fully understand the many social dynamics impacting the situation of FEP.

\subsubsection{Social Participation}

There is currently no consensus on a definition of social participation. Piskur et al. (2014) completed a broad literature review on how social participation is conceptualized in academia. Their review found that social participation is referred to in three ways: 1) consumer participation, which involves the individual's right to self-determine their engagement in society; 2) social activity, which restricts social participation to interactions between people and involvement in social activities with others; and 3) levels of involvement in society, which emphasizes that social participation can be both an objective and a subjective outcome on a continuum from relatively passive to very active. In occupational science, Whiteford and Hocking (2012) linked social participation with social inclusion, arguing that inclusion requires that people have the resources, opportunities, and capabilities needed to learn, work, engage and have a voice (i.e., the ability to influence 
decisions affecting them). In this study, I define social participation as 'engagement in social activities and roles in ways that foster a sense of belonging or connection within social groups for the individual(s) participating'. This concept of social participation requires that there be some level of intent to engage and interact with others, in addition to opportunities available for such engagement.

\subsubsection{Benefits of Social Participation}

The positive benefits of social interaction and participation have been well established in social science and health research. Social participation has been shown to improve health and mortality rates, enhance quality of life, and assist with building social relationships and community (Bratun \& Asaba, 2008; Dalgard \& Håheim, 1998; Wenger, 1998; Wilcock, 2006). According to Dalgard and Håheim (1998), lack of social participation is among one of the most studied psychosocial factor in relation to health. When examining the role of social support and social participation on mortality rates, Dalgard and Håheim found that social participation was found to be the most powerful predictor of mortality, when other sociodemographic and biological factors were controlled for. Lee, Jang, Lee, Cho, and Park (2008) also found social participation to be an important factor in maintaining health throughout the life span, especially for those more involved in their communities of practice. These authors acknowledged that the mechanism by which social participation improves health has not yet been fully identified; the emotional support, personal fulfillment, and protection from the negative effects of isolation are factors that appear relevant to promoting this health benefit through participation. In regards to young adults explicitly, Cicognani et al. (2008) found a positive correlation between social participation, sense of community, and identification with community, indicating that social participation not only enhances a sense of belonging in a given community, but also provides opportunities for identity work and selfdefinition. 
Research in occupational science has also identified many benefits of social participation for health and well-being, while also more recently acknowledging the repercussions on health through limitations in participation. Hasselkus (2002) stated, "Research on the human state of well-being is permeated by the belief that a person's ability to engage in life's daily activity is a key ingredient" (p. 60). Hasselkus synthesized many authors' works to underscore the importance of participation in occupations to well-being. One such paper by Ryff and Singer (1996) claimed that well-being was defined by two core features: 1) leading a life of purpose, and 2) quality connections to others, emphasizing that positive health requires social engagement. Wilcock (2006) also linked participation or 'doing' as important to individual and social health. Wilcock claimed that doing with others is important to the development of communities to support one another for the common good or human survival. However, she acknowledged that for participation to contribute to wellbeing and health, it must offer meaning, choice, satisfaction, a sense of belonging, purpose, and socialization. Wenger (1998) also found that engagement in social practice is how we become who we are and learn about ourselves and our world. Through communities of practice that are developed via participation in shared pursuits, individuals begin to negotiate meanings with one another, they develop their identities, and find spaces of belonging. Without opportunities for social participation and interaction with others, learning, growth, and overall health is limited.

\subsubsection{Hindrances to Social Participation}

Despite acknowledgments of the benefits of social participation to individual and social well-being, the ability to 'do' and participate in daily life are largely taken-for-granted rights for many of us. Equal opportunities do not exist for all and are even more limited at times by disability, economic status, age, and race. Laliberte Rudman (2010) termed these avenues for participation "occupational possibilities". According to Laliberte Rudman, "The construct of occupational possibilities... attends to the subtle and various ways power is 
taken up, and how that influences the ways we come to think about what we, and others, can and should do in our occupational lives" (p. 58). By understanding how occupational possibilities have been shaped over time, occupational therapists and scientists can better examine how occupations are negotiated, enacted, and constrained in given contexts. This knowledge could lead to better social advocacy movements, changes to discriminatory policies and cultural procedures, and better targeting of the elements that hinder occupational function across the individual-social spectrum.

Social injustice, exclusion, and occupational deprivation continue to be dominant themes in mental health research and treatment (Townsend, 2012). Occupational deprivation was defined by Whiteford (2000) as a "state of preclusion from engagement in occupations of necessity and/or meaning due to factors that stand outside the immediate control of the individual" (p. 201). While occupational deprivation is not unique to those with mental illness, the combination of impairments, social stigma and prejudice, and shifts in opportunities for participation play a critical role in the occupational pathways open to those with mental illness (Wilcock, 2006). The impairments in self-concept and daily function caused by psychiatric disorders are often more devastating than those of chronic physical illnesses and have been shown to truncate educational attainment, increase risk of teenage pregnancy, lower family income, hinder employment, and limit social supports (Hecht \& Wittchen, 1988; Kessler, Walters, \& Forthofer, 1998). With the additional deprivation that occurs as a result of having a stigmatized identity and the notable impairments in daily function mentioned above, opportunities for occupational participation are further reduced, which leads to greater occupational impairment and deprivation for this population. Despite research demonstrating it to be a biological disease just like other physical disabilities, generational knowledge, policies and laws, and cultural beliefs continue to lead to stigmatization and social exclusion for individuals with mental illness (Huxley \& Thornicroft, 2003). 
It is vital for occupational science and occupational therapy to begin examining and providing early intervention for first episode psychosis. As stated in the introductory chapter, early intervention for psychosis has the potential to affect clinical and life trajectories earlier and more significantly (Birchwood et al., 1998; Harrison et al., 2001; Malla \& Payne, 2005). A focus on occupational trajectories for this population could enhance overall functioning and lead to greater social participation. Malla and Payne (2005) argued that it is important to examine occupational and social functioning, including the elements impacting function, especially in the early phases of psychosis to understand the impact of the illness on future life trajectories, as well as identify ways to reduce the chronicity and impairment often associated with mental illness.

\subsubsection{Factors Impacting Social Participation}

Several studies have identified factors that impact participation in social life for individuals with FEP. Woodside, Krupa, and Pocock (2007) described young people's experiences prior to FEP by focusing on activity performance, in areas such as employment, education, self-care, recreational pursuits and social participation. They developed a conceptual model that highlighted several factors that hindered activity performance and social participation: competency struggles; loss of interest and weakening of commitment; and sense of being different, including social anxiety, immaturity, and passivity. In regards to employment, which is one avenue for social participation, Gioia (2006) found that those with FEP were hesitant to return to work if they were experiencing symptoms, and this in turn increased the severity of disability. They found that return to work was delayed due to cautious messages from mental health professionals, ongoing effects of positive symptoms on function, and early application for disability benefits. Bassett, Lloyd, and Bassett (2001) also identified several factors that influenced gaining and maintaining employment: the loss of job prospects, stigma regarding disclosure to employers and work colleagues, lack of 
strategies to manage symptoms in the workplace, and difficulties articulating realistic goals and plans.

Eklund, Hermansson, and Hakansson (2012) found that societal attitudes contributed extensively to their informants' feelings and sense of meaning in life; belonging in a social context and feeling accepted promoted positive emotions and occupational meaning. Schon, Denhov, and Topor (2009) noted that interpersonal relationships were crucial to recovery; past friends and social supports and feeling needed were important to their participants. Past friendships helped constitute a connection between the individual's current situation of psychosis and their past, when the individual did not have to manage the illness. Perry, Taylor, and Shaw (2007) also found that feeling a sense of belonging and being able to continue to 'do' activities normal for their age group were important to maintaining hope in their participants. Lastly, Sakiyama, Josephsson, and Asaba (2010) found that participation was positively and negatively influenced by extrinsic (physical space, social attitudes/supports) and intrinsic (personal motivation, skills) factors. They found that participation often required a level of interdependency, or balance between agency and social support. This interdependency, or shared social support, was often achieved through interconnecting occupations. Social and economic realities (e.g., availability of jobs, social supports, age, social expectations) played a key role in what occupations could be pursued or chosen by those with mental illnesses.

In sum, these studies identified several factors supporting participation including feeling a sense of belonging and connection with others, which often occurred through occupational engagement. They also discussed several barriers to participation. For instance, ongoing social and self-stigma led to concerns about disclosure and subsequent withdrawal from prior occupations. In addition, the need to manage symptoms, feeling less competent to engage in occupations, and loss of interest in prior occupations and relationships served to hinder social participation for individuals with FEP. 
These studies have begun to acknowledge the role of social structures as influencing social participation. The determinants of participation in and of themselves have not been well-examined in first episode psychosis, especially in regards to the social mechanisms by which participation in social activities are limited. Although social inclusion, normalization, resilience, and hope are emphasized in recovery and psychiatric rehabilitation (Drake, Green, Mueser, \& Goldman, 2003), the focus remains on how an individual can overcome societal barriers to make a life for themselves. Occupational deprivation and dysfunction persists, in part because the recovery process continues to be viewed as a reductionist, individually focused system with some environmental supports thrown into the mix. By shifting the focus towards participation and the 'doing' and 'belonging' aspect (Wilcock, 2006), and away from the individual as the center of study and intervention, we broaden our scope of inquiry and potential intervention to include environmental and social targets. Occupational science can examine the multiple layers through which people participate and how social structures impact recovery, exploring how individuals or groups negotiate these layers through 'doing'. By examining occupation itself, which has been advocated by Hocking (2009), we can better grasp the entirety of the system influencing the occupation and the person engaging in the occupation, including the barriers and supports to engagement and participation. An occupational perspective could contribute significantly to the understanding of participation and experience of individuals with early psychosis by: 1) integrating the importance of 'doing' and 'belonging' with experience and identity; 2) stressing the importance of relationships and interconnection; and 3) understanding how to utilize occupation as a mechanism for facilitating participation and bridging the individualsocial continuum. 


\subsubsection{Identity and Social Participation}

\subsubsection{Social-Constructivist Framework of Identity}

Identity is a formative construct in understanding human development, function, and action. It is an important factor in understanding social participation, especially in stigmatized and marginalized populations. The social-constructivist framework holds great promise for examining identity as it relates to participation for individuals following FEP and fits well with my philosophical foundations and theoretical perspective. The socialconstructivist framework states that identities are constructed through interaction and social discourse (Holland, Lachicotte, Skinner, \& Cain, 1998), and do not exist a priori from participation. People are not born with identities to be discovered; they are formed through interaction and participation. Thus, through participation, people present themselves to others and are influenced by others. Identity is conceived as a joint accomplishment (Schwalbe \& Mason-Shrock, 1996). The power to define oneself, or what Schwalbe and Mason-Shrock termed identity work, is dependent on 4 parts: 1) defining the identity (i.e., creating a shared social representation of this identity); 2) coding (i.e., applying set rules for signifying that identity); 3) affirming the identity, which relies on opportunities to enact the identity; and 4) policing (i.e., establishing and maintaining boundaries between those who can claim the identity and those who cannot). Through identity work, individuals define who they are and want to be and present this to the social world. Identity work is also a social process because identities are labeled using the language available in society and assume particular meanings created in society. Identities themselves are not meanings, but rather signs that invoke meaning (Schwalbe \& Mason-Shrock, 1996). Identities are understood in terms of signs, symbols, and descriptors that convey particular meanings to others. For example, a doctor may be identified as such by his or her clothing (e.g., white coat, badge), demeanor, gait pattern, speaking habits (e.g., medical jargon, etc.). Schwalbe \& MasonShrock argued, "Social life is made up of connected dramatic reenactments through which 
people communicate their dispositions and coordinate action. It is in and through these dramatizations that selves are signified and affirmed, both to others and reflexively to one's self" (p. 114). In creating the codes and shared representations of particular identities, a group creates possibilities and constraints for people to express certain kinds of selves. People with mental illness may be limited in the identities they are able to code and share based on historical understandings, media depictions, and social perceptions of what signs and symbols constitute the identity of mental illness, which impacts their participation in social life.

Social identities are formed through action and participation in figured worlds. Figured worlds are culturally and socially constructed arenas of practice in which particular characters are recognized and particular outcomes are valued over others (Holland et al., 1998). In these worlds, people are positioned differently, assigned positional identities, and subsequently, are afforded different opportunities for participation. This concept highlights the importance of context in identity work, emphasizing that participation may vary between contexts depending on the identities and meanings that are triggered through those specific contexts. Holland et al. also emphasized that action is motivated by the desire to validate and reinforce one's perceived identities, which leads to the pursuit of certain activities and opportunities to enact one's claimed identities. The ability to do this is dependent on opportunities for participation. In sum, identities are formed through doing; without the ability to 'do' or participate, identity work is restrained and the ability to adopt positive, meaningful identities that foster function and well-being is limited. Limited opportunities for social participation for individuals with mental illness will reduce their ability to adopt identities outside of the illness identity and could significantly impede recovery.

Powerful, dominant groups are able to create codes and signs that limit the ability of less powerful groups to express themselves fully, which ultimately leads to inequality and marginalization (Schwalbe \& Mason-Shrock, 1996). Goffman (1963), in his early book on 
stigma, underlined the importance of identity and meaning as it relates to participation and action in the broader social sphere:

In all of these various instances of stigma, the same sociological features are found: an individual who might have been received easily in ordinary social intercourse possesses a trait that can obtrude itself upon attention and turn those of us whom he meets away from him, breaking the claim that his other attributes have on us. He possesses a stigma, an undesired differentness from what he had anticipated. (p. 5)

Goffman highlighted the stigmatizing process wherein through the use of symbols that mark prestige or stigma, attention is drawn to the 'different other' in a manner that devalues the individual. Language, signs, and symbols are used to label and classify individuals based on certain traits; individuals assume these identities based on their positions in society and the language used to describe them. Holland et al. (1998) termed these identities 'socially positioned identities'. Socially positioned identities are defined as "identities attributed or imputed to others in an attempt to place or situate them as social objects... based primarily on information gleaned on the basis of appearance, behavior, and the location and time of action" (Snow \& Anderson, 1987, p. 1347). These identities are shaped by local attitudes, stereotypes, and broader sociohistorical beliefs and views (Holland et al., 1998; Snow \& Anderson, 1987).

\subsubsection{The Relationship between Doing and Identity}

Several studies in mental health have acknowledged the importance of 'doing' in recovery and identity formation. Romano, McKay, Goering, Boydell, and Zipursky (2010) found that individuals with FEP were able to endure a positive sense of self and reshape their identities following a diagnosis by continuing to pursue life interests and goals. They were able to hold on to parts of themselves they valued prior to the illness and adapt other parts of their identity that were deemed more negative following the diagnosis through engagement in valued occupations. According to Estroff (1981), individuals with mental illness are positioned, and position themselves, into a viable 'crazy identity', due to their similarities in clinical settings and as a result of their negative encounters with 'normals' 
outside of the treatment environment. Estroff expressed that more opportunities for positive engagement with others was needed for individuals with mental illness. Davidson (2007) claimed that for recovery to occur, individuals needed opportunities to participate and act to form new habits and achieve a functional coordination with their situation. Davidson argued that shared clinical environments, routine appointments with mental health providers, and strategies for illness management instill an identity of mental illness in individuals with a recent psychotic episode. Without opportunities to participate in arenas of practice outside mental health treatment, identities related to chronic impairment flourish. Lastly, in Boydell et al.'s (2010) descriptive review of qualitative studies in FEP, 'achieving identity' was a common theme for this population. These studies highlighted the importance of ongoing identity work for those experiencing psychosis for the first time, including how they "anticipate, project, define, interpret, assess, accept, resist, and modify images of their selves and of others in their daily encounters" (Boydell et al., 2010, p. 17). McCay et al. (2006) claimed that the stress associated with managing a first episode of psychosis may "predispose young people to the phenomenon of illness engulfment, whereby personal identity is lost and replaced with a sense of self defined entirely by the illness" (p. 105). The authors stated this is particularly concerning for individuals with first episode psychosis because of the timing of the onset of illness. Typical onset occurs during a developmental phase when identity is fluid and more vulnerable to change. Those who become engulfed by the illness become increasingly demoralized, depressed, and emotionally numb. They lead progressively more restricted lives, and "all activities of daily life gradually revolve around being a psychiatric patient, with accompanying alienation from others and loss of previous social roles" (p. 106). Thus, limitations in opportunities to define oneself, which often occur through participation in occupations, can inherently lead to worsening function and withdrawal from life roles. 


\subsubsection{Occupational Science's Stance on Identity and Participation}

Identity is significantly understudied in the occupational science literature, especially in regards to mental illness. Although the discipline has long acknowledged the role of occupation for health and well-being, few scholars have discussed the link between identity and occupation, or specifically the role participation itself plays in identity formation. Christiansen (1999) articulated a direct connection between occupation and individuals' social and personal identity. He suggested that participation in occupation is how identities are constructed and communicated to others, and these identities help create meaningful lives and promote well-being. Similarly, Hasselkus (2002) also proposed occupation as a vehicle by which internal and exterior dimensions of one's self are integrated and united, which emphasizes the fundamental role occupation plays in constructing and crafting identities. Kielhofner (2002) followed Christiansen's original concepts and coined the term 'occupational identity', which is defined as who one is and wishes to be as an occupational being; this identity is developed through one's history of participation in occupation. These views focused too heavily on the person as the core of identity. Phelan and Kinsella (2009) claimed that these concepts assume free choice and autonomy are universal constructs. Instead, they suggested examining identity from a broader sociocultural perspective could significantly expand the notion of occupational identity. Phelan and Kinsella (2014) applied this perspective in a collective case study of children with disabilities. They found that collective and individual occupations shape occupational identities, while social and cultural discourses shape what occupations are deemed valuable and attainable for children with disabilities. This in turn serves to further shape their identities. Their research supported the codependent relationship between occupation and identity noted by Laliberte Rudman (2002). Laliberte Rudman stated that occupation influences one's sense of identity, and an individual's sense of identity also influences his or her occupations. 
Laliberte Rudman (2002) also took a sociocultural approach to examining the link between identity and occupation. She identified five themes: 1) occupation was a means through which participants expressed who they were to themselves and others; 2) limitations in occupation may limit the ways in which participants perceived themselves and manage their social identities; 3) participants made choices about their occupations in ways that would allow them to maintain a satisfying sense of personal identity, which was helpful in maintaining a sense of continuity of identity; 4) participants used or avoided occupations to avoid stigmatizing labels, or to acquire socially valued identities and higher social status; and 5) for the positive benefits of occupation to be realized, participants needed to feel a sense of control over their occupation. Laliberte Rudman's research began to highlight the ways in which constraints on occupational engagement could limit the acquisition of certain personal and social identities. Laliberte Rudman (2010) coined the term "occupational possibilities" to identify and discuss how social control and social organizations perpetuate and support policies and practices that create occupational possibilities for some, while marginalizing or excluding others. The construct of occupational possibilities "attends to the subtle and various ways power is taken up, and how that influences the ways we come to think about what we, and others, can and should do in our occupational lives" (p. 58). This idea underlines the role of sociocultural factors in impacting our perceptions of ourselves and what we are capable of doing. Asaba and Jackson (2011) identified authoring as one way in which social discourses are integrated within the self: "People draw from socially formed and perpetuated discourses circulating within the worlds of which they are a part, and over time they internalize some of these discourses while rejecting others" (p. 143). These authors argued that we reflect discourses in our occupations and identities and it is through engaging in occupations that people simultaneously perceive themselves, are seen by others, and understand how others view them. 
However, with the exception of a few scholars, occupational science has not fully integrated action theory or the transactional perspective into its theories about identity and occupation. And to date, no one has studied the relationship between occupation and the specific identity demands for young adults with first episode psychosis. This is important for several reasons. Examining occupation and identity related to early experiences of psychosis could provide a more holistic understanding of how recovery and management of the illness occurs, which could expand clinical treatment and occupation-based interventions. Utilizing existing occupational constructs, such as occupational deprivation and occupational identity to understand how the label of mental illness consumes all other individual differences or identities and reduces access to certain forms of participation in particular communities of practice could lead to greater interventions for social inclusion and acceptance. It will allow us to look past the mental illness identity to view the person as an occupational being with many facets to their person, including their daily routines, occupations, and roles to understand what they were able to continue doing and how to facilitate continued function in their social worlds. It will also help the therapist and the person be able to envision identities that are not bound by the label of mental illness thereby enhancing participation in other areas and minimizing the impact of 'managing the illness' as an occupation on their identity formation. By examining occupation itself, which has been advocated by Hocking (2009), we can better grasp the entirety of the system influencing the occupation and the person engaging in the occupation, including the barriers and supports to engagement and participation. By focusing on the 'doing' and 'belonging' aspect, we can also examine the multiple layers through which people operate, and we can begin to explore how individuals and groups negotiate these layers, and the identities that are performed through these layers. 


\section{CHAPTER 3: METHODS}

\subsection{Overview}

This multi-method qualitative study was designed to explore how participation in social life shifts for young adults following their first psychotic episode. To achieve this exploration, two research aims guided this study: (1) explore the sociocultural mechanisms that facilitate or hinder the experience of social participation for young adults following FEP; and 2) to explore perceived opportunities for participation for young adults following FEP. Study aims were met using semi-structured and open-ended interviews, participant observations, and discourse elicitation. Due to the complexity of social participation, the need to move between layers of understanding where multiple realities exist (Daly, 2007), and a desire to research the lived experience itself, qualitative methodologies were chosen for this study. The chosen methods were grounded in my theoretical perspective, which emphasizes the need to examine relational aspects of human action in a holistic manner. Study procedures and confidentiality measures were approved by the Institutional Review Board (IRB) at the University of North Carolina at Chapel Hill (\#14-1313). This study combined elements of collaborative ethnography and critical discourse analysis to examine the experience of first episode psychosis as it relates to engagement in social occupations.

Ethnography, specifically collaborative ethnography, is a useful way to examine social participation for individuals with FEP for three reasons. First, ethnography examines the shared and learned values, beliefs, patterns, and behavior of participants in a particular cultural group (Creswell, 2007; Daly, 2007). Individuals who have experienced a mental illness often share similar habits, patterns of behavior, and learned 'cultural values'. These shared habits and patterns of behavior are developed through shared experiences of 
participation in mental health treatment and experiences with managing the illness. In addition, individuals with mental illness are commonly grouped together by society and share a socially positioned identity (Holland et al., 1998). Second, ethnography offers a broad and flexible design, capable of adapting to unanticipated discoveries, and is an effective means for investigating the non-personal elements of a situation (Bailliard, Aldrich, \& Dickie, 2013). Third, collaborative ethnography is an approach to ethnography that deliberately and explicitly emphasizes collaboration throughout the ethnographic process (Lassiter, 2005). Traditional ethnography relies on the experiential authority of the researcher. This experiential authority tends to squash participants' voices and further remove the observer from the lived experience of the participants being observed (Rosaldo, 2003). This idea has come to be questioned in recent anthropological work (Hinson, 2000), with a move to focus on collaboration within the ethnographic process. In collaborative ethnography, participants are co-producers of knowledge and are more overtly included in the research process. For marginalized individuals or groups, collaborative ethnography offers an opportunity to empower their voices and diminish the power differentials often inherent to research processes (Hinson, 2000). Language is important in highlighting this collaboration, which is why 'consultant' is used instead of 'participant'.

This ethnography was not purely collaborative as I did not have input from consultants in the planning phases of my research. However, the fundamental notions of consultant collaboration and empowerment served as a guide throughout planning. Various plans related to data collection and writing were intentionally left vague to allow consultants opportunities to provide input and mold the research study towards what best fit their lived experience and research needs. This approach allowed for flexibility in design to pursue unanticipated findings. In addition, I prepared myself as a partner in the research and realized that although I had ideas for how I envisioned this research would go, consultants' 
ideas and perspectives would likely shift the research process. This is a core assumption of collaborative ethnography (King, 2010).

Critical discourse analysis (CDA) was also chosen as a methodology for exploring the sociocultural mechanisms that facilitate or hinder social participation for young adults following first episode psychosis. Critical discourse analysis examines texts as they are situated in cultural, political, and historical contexts. Its philosophy encourages actively confronting discourses in an effort to challenge unjust power dynamics and reduce inequality (Cheek, 2004). Discourse is defined as an "ever changing constitution of meaning that is specific to a particular group, culture or historical period" (Gavey, 1989, p. 464). Discourses take many forms (e.g., media, photos, advertisements, government policy, etc.) and are understood to be any medium that communicates a message that can be reflected on and interpreted (Silcock, Hocking, \& Payne, 2014). Through analyzing discourse, teasing apart the language used and messages portrayed in the discourse, critical discourse analysis strives to highlight taken for granted assumptions of possibilities for action and social power. Laliberte Rudman (2013) has encouraged occupational scientists to adopt discourse analysis to examine the situated nature of occupation, factors governing occupation, and to study occupation as a broad social and relational phenomenon. Although collaborative ethnography and discourse analysis are both useful methodologies in their own regard, the combination of the two is most effective in illuminating the experiences of early psychosis and treatment. Atkinson, Okada, and Talmy (2011) claimed that ethnography allows examination of broad cultural and social beliefs and patterns, while critical discourse analysis facilitates examining how broad social messages are negotiated and processed on a micro-level via conversation and interaction. These approaches complement one another. Utilizing ethnography and discourse analysis offers a method that bridges the individual with the social to understand culture, ideas and perspectives, and 
individual and social habit more fully. The combination of ethnography and discourse analysis encourages the appreciation of how all parts of the system influence the other.

Based on the principles of CDA, a subtype of CDA was used: discourse elicitation. Discourse elicitation, which is a novel approach and application of CDA principles, was used to elicit discussions about broader social messages and expectations. There are few reports of the use of discourse elicitation in the literature. For example, it has been used in studies with individuals with aphasia or traumatic brain injury as a way for them to articulate their experiences (Hengst \& Duff, 2007; Leer \& Turkstra, 1999; Olness, Ulatowska, Wertz, Thompson, \& Auther, 2002). To my knowledge, discourse elicitation has not been used as a way to understand broader, tacit social beliefs and perceptions. In examining the illness experience, we need to examine how discourses and history position certain individuals or groups and shapes how they are viewed (Holland et al., 1998).

Discursive texts and visuals were used in this study to elicit discussion about broader social messages and assumptions that impact social participation, as well as to acquire an understanding of local social perceptions that directly impact the lives of study consultants. Examining local discourse with my consultants allowed us to collaboratively examine how language, signs, history, and symbols situate identity and facilitate or hinder opportunities for participation. It also allowed us to consider how consultants incorporated these broader social messages into their daily routines and identities. The combination of these three approaches (collaborative ethnography, critical discourse analysis, and discourse elicitation) provided an opportunity to move between levels of understanding and knowledge along the individual-social continuum.

\subsection{Consultants}

I recruited five consultants between the ages of 18-30 who had experienced a first episode of psychosis within the previous 5 years of data collection. Descriptive information about each consultant is included in Table 1, along with pseudonyms. The initial recruitment 
age was $18-25$ as the Substance Abuse Mental Health Services (SAMHSA) identified the rate of mental illness to be particularly high for this age group (SAMHSA, 2012). During the recruitment phase of the study, the upper age range was increased from 25 to 30 years of age due to recruitment challenges described below.

\section{Table 1. Consultant Characteristics}

\begin{tabular}{|c|c|c|l|l|c|}
\hline Pseudonym & Age & $\begin{array}{c}\text { Race and } \\
\text { Ethnicity }\end{array}$ & Diagnosis: & Employment: & School: \\
\hline Oliver & 22 & $\begin{array}{c}\text { Half Puerto } \\
\text { Rican, Half } \\
\text { White }\end{array}$ & $\begin{array}{c}\text { Psychosis } \\
\text { NOS }\end{array}$ & Working part-time & $\begin{array}{c}\text { Attended } \\
\text { college, did } \\
\text { not finish } \\
\text { school }\end{array}$ \\
\hline Willow & 19 & White & $\begin{array}{c}\text { Unspecified } \\
\text { Psychosis }\end{array}$ & Working part-time & $\begin{array}{c}\text { Currently in } \\
\text { school }\end{array}$ \\
\hline Leo & 30 & White & $\begin{array}{c}\text { Schizoaffective } \\
\text { Disorder }\end{array}$ & Not working & $\begin{array}{c}\text { Completed } \\
\text { college }\end{array}$ \\
\hline BB & 25 & White & $\begin{array}{c}\text { Schizoaffective } \\
\text { Disorder }\end{array}$ & Not working & $\begin{array}{c}\text { Attended } \\
\text { college, did } \\
\text { not finish } \\
\text { school }\end{array}$ \\
\hline Carly & 23 & White & $\begin{array}{c}\text { Brief Psychotic } \\
\text { Episode }\end{array}$ & Working full-time & $\begin{array}{c}\text { Completed } \\
\text { college }\end{array}$ \\
\hline
\end{tabular}

To be included in the study, all consultants must have met Diagnostic Statistical Manual (DSM-V) diagnostic criteria for brief psychotic disorder, schizophrenia, schizoaffective disorder, or schizophreniform disorders and received the diagnosis within the previous 5 years of data collection. Diagnostic criteria and date of onset were verified by written or online medical records that clearly indicated this information. Individuals were also required to be fluent and literate in English. Exclusion criteria included individuals with severe intellectual disability or individuals who were unable to adequately converse in, or read English. 


\subsection{Recruitment and Sampling}

Given the stressful time surrounding initial diagnosis and treatment, finding individuals willing to spend the time needed for an in-depth understanding of their life experiences related to FEP was an anticipated challenge. Recruitment lasted for 8 months; a total of 49 organizations were contacted over the course of those 8 months for referrals. Recruitment initially began with the OASIS (Outreach and Support Intervention Services) program, located in Chapel Hill, North Carolina. OASIS is part of the University of North Carolina at Chapel Hill's Center for Excellence in Community Mental Health. This center specializes in early identification and treatment for young people and their families at the start of a psychotic disorder. However, recruitment areas were expanded to include various mental health agencies, churches, and healthcare organizations in the Raleigh, Durham, Chapel Hill, and Greensboro area. Criterion sampling was used for recruitment. As stated above, all consultants were diagnosed with a psychotic disorder within the last 5 years, according to the diagnostic criteria from the DSM-V. Methods of recruitment included direct referral from providers/agencies, as well as posting of the IRB-approved recruitment flyers at clinics and healthcare agencies, in mental health newsletters, and around college campuses (see Appendix A). While not a predicted source for recruitment, universities and college campuses became a prime target for recruitment as the age of this population closely fit with the age of many college students. Recruitment from this source led to sampling more affluent and educated people. This was not problematic for this study because generalizability was not the objective and exploration of social factors was the primary aim.

Once initial contact was made, I met with each consultant individually to explain the research and their role in the study. Each consultant provided written consent acknowledging they understood the study and the requirements for participation (see Appendix B). Consultants were informed that they were able to withdraw from the study at any time. Consultants were each compensated $\$ 50$ for participation. Compensation was 
broken up into three payments: $\$ 15$ for each of the interview and $\$ 20$ after all observations were completed.

\subsection{Data Collection, including Benefits and Drawbacks to each Approach}

To meet study aims, the project employed participant observations, interviews, and discourse elicitation. These methods fit many recommendations in the literature regarding which factors are important to consider when studying this population. For example, Booth (1999) emphasized the importance of trust and time in building rapport with hard to reach, vulnerable study populations. This is often achieved through participant observations or 'hang outs', and emphasizing the researcher's role as a learner. These strategies shift the power dynamics within the research relationship. I incorporated these recommendations into the study design. For each method, this study identified both benefits and drawbacks to their use.

\subsubsection{Participant Observations}

The goal of the participant observations was to observe consultants in their daily life to identify and understand unspoken sociocultural factors that impacted their social participation. Data collection occurred over a 6 month time period for 4 out of 5 consultants. There were difficulties contacting one of the consultants, which led to a longer period of time required for data collection. For this consultant, data were collected over a 9 month period involving only 6 observations as compared to 12 observations over 6 months for the other 4 consultants. I anticipated that consultant observations would occur primarily on weekends, as this is a time when most community-based services are closed and expectations of social participation outside of the employment context may be higher. However, there appeared to be no specific pattern of engagement or times for specific observations (see Appendix $C$ for a list of the observations). Observation times depended on other life factors, such as employment, school, level of engagement in various social circles, and transportation resources. Consultants were asked to schedule 2 observations with me per month and each 
consultant was to call, email, or text whenever they planned on hanging out in a public arena. However, consultants rarely initiated contact to schedule observation times. It was unclear whether this was due to forgetfulness or concern about including the researcher at specific events or hang outs. At the beginning of each month, I contacted each consultant via text to remind them about the month's observations and to schedule meetings based on their monthly schedule. At least 2 other texts or phone calls were required to remind consultants about scheduling observations. Scheduling meetings proved to be a consistent challenge throughout this study.

\subsubsection{Benefits of Participant Observations}

The decision was made early on to focus entirely on 'public' observations as the goal was to examine social participation and social interaction. Public behavior or observations were defined as areas in which the subject does not have an expectation of privacy (IRB website, http://research.unc.edu/offices/human-research-ethics/); this excluded observations of the private domains of consultants' lives. While there was a possibility that certain aspects of the person's life and life roles may be missed, it was assumed that the majority of their social participation could be observed during public observations and discussions could supplement information about participation in other life domains.

The distinction between public versus private observations required ongoing discussions and reminders to consultants throughout the study. For several consultants, identifying public locations for observations was difficult. This related, in part, to how they defined 'public', as well as the underlying factors that impacted their social participation. BB mentioned several barriers to his social participation and subsequent difficulties identifying public observations:

I would say, the only part of the observation is trying to find something to do because like normally with my friends I would just go over to their house or...'d, they would come over to my house or something. So I usually don't, I don't go out. I used to go out a lot when I had money I used to go to bars. But I just don't have money right now so it's like..my... I don't know what to do a lot of times. 
This was a common report from 3 of the 5 consultants. Unexpectedly, discussions about what could be considered a public observation provided insight into the barriers that limit social participation and interaction, which was a benefit to this method. Willow stated, "I'm kind of withdrawn. And so I don't really go out into public places and do things very frequently. Especially at night." Oliver appeared to be socially engaged through work and family; however, many of his social interactions with friends consisted of hanging out at his home, smoking marijuana, and playing online video games. We discussed his virtual participation and the public arena in which he often played online video games, which led to reflections about being part of a virtual community. Oliver initially spoke fondly of his virtual gaming community and described it as a tight-knit group that had formed over years. Yet, during observations, members of this community rarely spoke of personal life issues, focusing instead on task-specific directions to win their game. Later in the study, Oliver shared that he was banned from the original group due to interpersonal issues with other team members. In this virtual community, participation was complex, as were the relationships and connections between players. Thus, in addition to being a tool for scheduling additional meetings for additional data collection, these informal discussions stretched my understandings, as well as my consultants' understandings of what could be considered 'public' versus 'private'.

These discussions encouraged consultants to consider certain domains of their lives as public when they had previously viewed them as private. Leo demonstrated his internal struggle with the public/private dichotomy in describing his social participation through social media outlets:

I think the whole, like the internet has become like such a part of participation. So, being able to accurately compare people who have a psychotic episode with society, I think you really need to make sure that you have a good understanding of society.. you know. And um...so I wonder like if..a hangout could be, I mean I know you said in a public place, but like I wonder if like an accurate depiction of my social life would be you sitting with me, we would have to go to Barnes and Noble in order to be in public, but for me to just blog or be on Facebook or something. And have that 
actually be considered social participation. Um, even though it would be weird because you would be sitting next to me, so maybe like we are on Facebook, chatting on Facebook.

In response to discussions about virtual participation, I observed several online postings of homemade music videos, gaming with an established gaming community, and postings on Facebook. These were forms of social participation and interaction that may not have been accessed through other methods. While my decision to focus solely on public observations may have limited some sites for observation, the informal discussions about the type and location of observations provided a depth of understanding that extended past the observation itself. It offered insights and knowledge about how public participation is conceived and defined and how my consultants related to this public arena.

\subsubsection{Limitations to Participant Observations}

There were some drawbacks to this method choice as well. At least two observations per month were planned with each consultant to get an in-depth understanding of their routines and engagement in social life. However, several consultants felt two observations per month was too much. They struggled with maintaining contact and scheduling observations. I do not think this was related to a lack of opportunities for observation. Rather, it seemed related to pre-planning or not wanting to incorporate the researcher into certain events or experiences. There was a feeling that observations of mundane activities were inadequate and that observations needed to consist of special events or circumstances. While the open nature to the observations was supposed to reduce anxiety and stress for consultants, this did not appear to be the case. I found that consultants worried about whether the observation would be 'good enough for the study', which Carly mentioned several times during informal discussions. They also seemed to worry about my perception of the observations themselves. Oliver provided an example of difficulties scheduling observations. Oliver only completed 6 observations during his time in the study. 
When asked why we were experiencing difficulties maintaining contact and scheduling observations, Oliver described his feelings:

I feel bad about not being able to get in touch with you more, just because, like... On my day to day it's just hard for me to like... it's hard for me to like think of good contexts to come and bring you to see me in my natural habitat you know because most of the time my natural habitat is pretty embarrassing or like dangerous (laugh).

Oliver did not delve into why he felt his natural environment would be embarrassing, although he did talk about his substance use and interactions with drug dealers as the reason for the potential danger. Consultants engaged in self-screening and pre-judgment about which observations would qualify for the study. They decided where the observations took place, who was involved, and what occupations could be observed.

My presence during participant observations unavoidably impacted my consultants' participation and their social interactions. I asked that they not plan special meet-ups for me and do as they would do if I was not there. Leo was very insightful into this and said, "Well that will never happen. As soon as you introduce an instrument in to measure something, the situation is changed". He said that participants would necessarily be different when I am around and might act differently. This notion is not new to qualitative research and is supported by the transactional perspective. Transaction suggests an "ever-present and always changing interpenetration of humans and their world" (Dickie et al., 2006, p. 88); all entities are co-defining, encompassing, and continuous; in sum, all parts affect the other parts (Boisvert, 1997; Dickie et al., 2006). Thus, just by being a part of their world during this research process, I affected my consultants' experiences as they affected mine. While this is an understood aspect of qualitative research, it became a significant drawback when consultants' expectations of a 'good observation' did not match my expectations. For consultants, observations were framed as 'events' that required pre-planning and collaboration with social networks. Carly emphasized the role of the researcher as one reason why observations felt like events: 
It feels like it needs to be an event because it's like you want to show the researcher, it feels like you have to put on a show for the researcher maybe... It's easier maybe if it's an event because it's like, I don't have to do anything. It's just like, there's all these people.

As Carly suggested, there was a level of performance involved during participant observations. I had hoped to observe the mundane aspects of each consultant's life and daily routine. However, these were not what consultants felt were most important for me to observe. It is unclear whether this related to the initial description of participant observations or the lack of structure to the type and location of observations (i.e., no set environment or context where the observations should take place), or to the tendency to perform during social interactions. It is also possible that performance is a form of identity construction wherein individuals perform certain roles as a way to depict desired identities.

In many ways, performance is a part of social life. Holland et al. (1998) claimed that people adopt and perform certain identities in particular figured worlds. These figured worlds are social and cultural constructions in which particular actors are recognized, significance is assigned to certain acts, and certain outcomes become valued over others. Continual participation in these collective worlds mediates behavior over time. Considering the research study as its own constructed figured world facilitates understanding how both the researcher and consultants take on positional identities and perform according to what they feel is acceptable and expected.

In summary, the use of participant observations for studying first episode psychosis has several benefits and a few drawbacks. Participant observation is a useful method to use with certain populations, particularly ones that are difficult to reach, marginalized or stigmatized, or have busy or disruptive daily routines that require the researcher integrate into their worlds. In addition, whereas interviews have been scrutinized for relying too much on cognition and retrospection (Paterson \& Scott-Findlay, 2002), observations uncover experiences that are difficult to articulate or may not be considered worth sharing. 
Participant observations require significant time including the development of rapport and trust between researcher and consultant. In addition, a researcher's expectations may need to shift based on what the consultant is comfortable sharing. There were events and hang outs that I was not invited to; they seemed to relate in part to the intimacy of the event and who would be present. For example, Leo identified one factor that influenced his decision to invite me to a hang out:

Um, well...one of the things that's been a factor is uh..is you. Coming into my social circle. So, it's been, I've always had to come up with a narrative about how to integrate you into my social circle. And sometimes I didn't want to include my psychotic episode as part of the narrative. Or even that you are doing a study. So how to bring you in, I mean, you know, I don't know if we are really friends.

Gaining access to participant observations in consultants' lives takes time and is dependent on the rapport and trust between the consultant and the researcher (DeWalt \& DeWalt, 2011). This is especially true for individuals with mental illness as they are keenly aware of the stigma associated with their diagnostic label. This cannot be achieved overnight. For marginalized groups, rapport and trust require more work and extended time with consultants. For the majority of my consultants, the type of observations and interactions became more varied as the study progressed. Though the actual observations completed did not match my initial expectations, the informal discussions with my consultants about the observations themselves were just as fruitful as other data gathered.

\subsubsection{Semi-structured Interviews}

In-depth, qualitative interviews are conversations that occur between a researcher and a consultant that focus on particular issues with the goal of yielding exploratory and descriptive data (Hesse-Biber \& Leavy, 2011). This method can be used as a stand-alone method or in combination with other methods; it is often a useful approach when little is known about a particular topic or population. For qualitatively examining first episode psychosis, interviews were useful in combination with other methods. 
Two formal interviews were held with each consultant: before the first observation and again near the third month of participation. A semi-structured interview guide was used to structure the interview (see Appendix D). Fundamental to collaborative ethnography is the assumption that consultants will influence the direction of inquiry, analyses, and the way the researcher relates to the study (Bailliard et al., 2013). Thus, consultants' thoughts and feedback, as well as my own thoughts and questions from the participant observations, shaped subsequent interview questions. It was important to maintain a flexible design to the interview process to build upon completed interviews as new areas of inquiry were identified. For example, throughout my observations with Leo, I began to notice that he often disclosed his mental illness far earlier when meeting new people than my other consultants who often never shared information about their mental illness. Thus, in the second interview with Leo, I expanded my interview questions to specifically ask about his tendency for rapid disclosure since it seemed to impact his ability to participate and establish relationships with others. I also shifted my second interviews with other consultants to probe other consultants' experiences and thoughts about disclosing their mental illness.

The first interview focused on each consultant's experience of social participation following FEP. This interview proved beneficial in establishing rapport with consultants, facilitating discussion about the participant observations, and integrating them more into the research process as they began to understand their role in knowledge expansion.

Discussions about how consultants spent their time and their preferences for participation in occupation helped to brainstorm potential options for participant observations. The second interview primarily focused on how local discourse had impacted consultants' participation. During the second interview, I brought two pictures that provided a discursive example of how mental illness is constructed to elicit discussions about social assumptions and expectations related to their experience of participation (see Appendix E). I completed an internet search for images of 'isolation' and chose two pieces of discourse that reflected how 
I perceived first episode psychosis and social participation. Isolation was chosen as a search term as this was the theme that represented mental illness to me, based on my clinical experiences. Searching for discourse based on my assumptions of the experience of mental illness offered an opportunity for me to reflect on my own perceptions and biases as someone who has not directly experienced a psychotic episode or mental health diagnosis. Prior to the interview, consultants were asked to bring an example of a text or image related to mental illness that they encountered and found meaningful to their experience of social participation. These discourses were incorporated into the interview and questions were asked to expand upon the meaning and impact these discourses had in the lives of my consultants. All interviews were audio recorded for subsequent transcription.

No additional formal interviews were completed; however, informal discussions occurred during participant observations that contributed useful data and explanation to further my understanding. This information was captured in field notes and a research journal. A research journal was used to document my own thoughts, feelings, and attitudes during the study. I spent time writing in this journal after each interview and observation to reflect on my experience and interactions with consultants and how these influenced my thinking about the situation. This journal served as an important reminder, in addition to fieldnotes, for how my ideas shifted during the research process.

\subsubsection{Limitations to Interviews}

As with any method choice, there are benefits, drawbacks, and practical choices that need to be made to ensure the method chosen supports the goal of the research. One particular issue that should be considered when using in-depth interviews is the researcherconsultant dynamic. Ideally, the level of division and hierarchy between the researcher and the consultant is minimal (Hesse-Biber \& Leavy, 2011); however, this division often inserts its way into the interview process unexpectedly. It is impossible to ignore who is interviewing whom and that payment is exchanged as part of the interview. In addition, differences in 
language use, education level, and socioeconomic background inherently play a role in establishing disparities in power (Elwood \& Martin, 2000; Nunkoosing, 2005). Consultants may not attempt to express complex ideas out of fear of sounding nonsensical to someone with a higher education level. Despite the intentional use of collaborative aspects in this research study, the division between myself and my consultants arose several times during our interviews. Although I assumed that consultants could shift the flow of conversation based on topics they deemed most appropriate, this did not occur naturally. Consultants required ongoing cueing and reminders to discuss topics they felt were important. For example, during our second interview, Leo made the statement, "I won't get off track during your interview." He apologized several times for taking up too much time on various topics and asked if it was ok for him to talk more extensively about certain topics. With reassurance that this was a collaborative process and joint interview, he would often continue his conversation. His need to ask permission or to question his instincts during the interview impacted the flow of the conversation and highlighted the power dynamics at play in the relationship.

There are many aspects of the interview process that generate this hierarchical division between researcher and consultant. First, the researcher tends to be the one who has developed the study and created protocols for the study, including the type of data to be collected. Thus, the researcher has already pondered the style and type of interview questions to ask. Also, the researcher often schedules the interview with the consultant. Depending on the nature of the study, the researcher may also set the location and time. Interviews tend to be temporarily distant from the phenomena being studied. Therefore, they are also less ecologically valid than observations (Cicourel, 1982). Finally, IRBs and other ethics agencies often require an interview guide be submitted with research proposals. Thus, in the early stages of research, the researcher is already moving forward without much consultant involvement. This is one reason why collaborative ethnography is a useful 
approach in research. Yet, these power dynamics are often heavily engrained, especially for young adults with mental illness who may be accustomed to clinician-patient dynamics.

These power dynamics could be applied to the researcher-participant role, especially when the research focuses on a particular health condition or experience. For instance, despite education and incorporation of collaborative approaches in this study, BB still identified a clear distinction between my role as researcher and his as consultant:

It's like...It's like you're still a part of this study, like, so you are still like that professional and I'm.. here... and like being friends with you, but...it's still kind of different..that we are being friends but there's still that, this connection...that you're like the professional observing me.

The researcher and consultant inherently play different roles in the interview process (Legard, Keegan, \& Ward, 2003). Yet, the power dynamics underlying these roles can be diminished. To do this, I encouraged flexibility in the interview location, allowing consultants to choose venues and times most convenient for them. I also encouraged them to ask their own questions during the interviews. Education was provided to consultants throughout the study regarding their role as consultants and collaborators. However, more discussion about our expectations for the interview process prior to the interviews would have been helpful in fostering comfort and ownership of the interview process. In this study, I used self-disclosure as a strategy to equalize power differentials and foster a more natural conversation during the interviews. I shared information about personal experiences (e.g., recent trips, details about my occupations, weekend events), as well as clinical experiences to validate consultants' experiences of mental health treatment and concerns with life transitions. While there continues to be ongoing debate in the research community about whether or not researchers should disclose personal details and opinions to their consultants (Legard et al., 2003), I found this strategy to be very helpful in establishing rapport with my consultants. Legard et al. (2003) acknowledged that self-disclosure and a reciprocal exchange is important to building rapport; however, they also cautioned that this approach could inhibit 
the ability to obtain a full, open response from the participant. Either the participant may hesitate sharing views or opinions that do not match that of the researcher, or they may assume the researcher understands their experiences and not delve into the desired details required for true knowledge expansion.

The decision to disclose personal opinions in response to the consultant's remarks was not an easy decision to make. I regularly questioned whether my remarks shifted the conversation, hindered the depth of responses, or diluted the role boundaries between researcher and friend. Behar's (1996) thoughts on vulnerability and self-disclosure often floated in my head during the interviews as I decided what thoughts to verbalize and what thoughts to keep to myself. Behar claimed that self-disclosure requires a good understanding of what aspects of the self are the most important based on how one perceives the world and the topic being studied. She said, "The exposure of the self who is also a spectator has to take us somewhere we couldn't otherwise get to. It must be essential to the argument, not a decorative flourish" (p. 13-14). Information or opinions the researcher decides to share must take the discussion to a depth that may not be achieved without a reciprocal, back and forth exchange of thoughts and ideas. Often this is how learning and expansion of knowledge occurs. Based on Behar's comments, sharing personal information or opinions in response to a consultant's statement does not necessarily lead the conversation or hinder what is shared. Instead, the technique of self-disclosure including how and what information is shared is most important. During interviews with my consultants, there were patterns to when I decided to share my thoughts and opinions: 1) when the consultant asked me what I thought; 2) when sensitive topics were discussed and there was an emotional response from the consultant; and 3) when I was curious about a line of questioning that may have been slightly off topic (based on something the consultant said) and felt the need to explain why I was asking a certain question. In this study, sharing my thoughts and ideas during the interview process seemed to facilitate a deeper 
understanding and connection with my consultants, even though some of the underlying power and role dynamics continued to exist.

\subsubsection{Benefits to Interviews}

While hierarchy, power differentials, and the reliance on cognitive retrospection on phenomena that are removed from the immediate situation are potential drawbacks to the use of interviews in research, there are many benefits to interviews for studying first episode psychosis. Interviews allow the researcher to explore a particular topic intensely. In addition, interviews provide an opportunity for consultants to talk openly about their illness and episode, without judgment, without the need for therapeutic goals to follow the discussion, and with someone other than a clinician or family member. For Leo, the interviews provided a chance for him to process his story in an open format:

I don't know what happened to me. And like I haven't been able to talk about this with anyone....It's been good to uh..to have somebody to hang out with and to process through my story with and someone to like help me kind of.. get that zoom out approach of like alright I had this episode last year and now I'm doing this, and now I'm doing this, and I'm doing well in this area. To have somebody to be able to dialog with who kind of knows my story. So it hasn't all been negative to try to integrate you into my life whenever you come to my hangouts because it's been, um, it's been comforting in a way. That somebody who knows me. You've said some encouraging things to me over the time that has helped me. And I appreciate that.

The interviews were one format for Leo to talk about his story and experiences, but he also spoke about the hangouts as well. It was comforting to him to have someone there who knew his story and could be a source of support when meeting new groups and interacting socially. During interviews, he often reflected on our participant observations to sort through his feelings about those observations including how he was managing his social relationships and disclosing his illness to others. The interviews granted him an opportunity to process his life and create his own narrative. In this way, data collection itself is a type of intervention that changes people.

Oliver shared similar thoughts about how interviews helped him reflect on his experiences and to process his hospitalization: 
Actually doing this is also enlightening because sometimes I don't know the answer to things about, um, questions I ask myself, and so if someone asks me and I haven't been thinking about it in a way I can articulate. Sometimes I find the answers to things while I'm articulating them...Um, because I'm hard on myself like um...going into like my life this way...Well...in some ways it definitely does give me some perspective because I wouldn't be uh...exploring it as thoroughly in my own time as I would be talking with you, you know.

The interviews provided a different lens from which to understand my consultants' experiences related to their first episode of psychosis. The interviews complemented participant observations because they provided a chance to comprehensively discuss themes and questions that could not be addressed during observations. Although the more formalized structure to the interviews (i.e., pre-scheduled, tape recorder, and semistructured questions) risked emphasizing power differentials between my consultants and I, this structure also set the stage for deep conversations and reflection to occur.

\subsubsection{Discourse Elicitation}

Discourses take many forms and are influenced by macroenvironmental and cultural factors (Laliberte Rudman, 2011; Silcock, 2013). Discourses influence what people think and subsequently influence social behavior, social expectations, and acquired identities (Silcock, 2013; Swartz, 1997). Discourse elicitation was used in two ways in this study. First, it was used during interviews with my consultants to encourage discussion of the impact of broader social beliefs and assumptions on their lives and their social participation. Second, it was used in three public venues to gain an understanding of local perceptions of mental illness from the general public and to provide a context for understanding my consultants' experiences related to social participation. This study used discourse analysis to explore how the consultants' perceptions about their own experiences meshed with the local community views through which they participate.

For discourse elicitation with consultants, each person was asked to identify one piece of discourse that reflected their experience of mental illness and participation in social life (see Appendix F). These discourses were discussed during the second interview. Oliver 
is a poet and chose to share several of his poems that spoke to his experience. One such poem, Inquisitor's Hands, was written immediately after his first inpatient hospitalization. Carly also chose written text to express herself; she chose a quote that spoke to her experience after her traumatic brain injury and brief psychotic episode. She posted the quote on her Facebook page to serve as a source of motivation and a reminder to her of her recovery journey. Willow and BB chose pictures. Willow chose a colored picture of wavelengths and used an editing program to write her thoughts over the picture. BB chose a picture of a man sitting alone at a coffee shop, which was a common location for our observations. Leo decided to draw a penciled drawing that represented his specific experience of mental illness; he drew a scene wherein he was introducing himself to someone else while his past experiences and labels related to mental illness (e.g., crazy, psychotic, trespassing, being arrested) followed closely behind him.

For discourse elicitation with the broader social environment, each piece of discourse, a total of 7 pieces including the 2 photos I contributed, were enlarged and displayed on easels in 2 public areas. A brief written description of the project and instructions were placed on a small table near the display. Passerbys were prompted to write their thoughts and feelings on a post-it note and stick it to the piece of discourse to which it referred. The first public venue was located near a local university. The large open space was picked to engage a high volume of people as they walked to restaurants or class. Given the proximity to a university, the population of people who participated were likely more affluent and highly educated, though there were several participants who did not appear associated with the university (i.e., panhandlers, court attendees). However, the makeup of the population was not important because the objective of discourse elicitation was to understand the social beliefs operating in local environments where my consultants were participating; this included a diverse population of people interacting at this venue. In a two-hour time period, the display was viewed by approximately 38 people. Thirty-one of 
those people only stopped to look at the display and read the instructions, but moved on without contributing to the display. Only seven people wrote their thoughts on post-it notes and posted it to the display. The second display occurred at a downtown area of a nearby community. The venue was chosen because it was central to many restaurants and businesses. Both sites were within communities regularly frequented by 4 out of the 5 consultants. There was very limited engagement with the local public during the second display. This was likely due to poor weather as it was cold, windy, and rainy and it was difficult to keep the display upright. Eight people passed by, and only one couple briefly glanced at the display but then continued walking. Due to limited participation in the $2^{\text {nd }}$ display, an online display was added to the study. The IRB at UNC-Chapel Hill approved this modification in the study design. The discourse was posted to a social networking and news website called Reddit. A discussion thread was created in three subreddit online communities representing the geographical areas of my consultants. Information, instructions for online users, and the discourse were posted to the subreddits for 24 hours and then the posts were removed from the site. There were 38 total views and 3 comments during this 24 hour period. All submissions were anonymous. Descriptions of the observed behavior and action surrounding the photos were noted in fieldnotes and transcribed. All post-it notes and comments were transcribed and coded as well.

\subsubsection{Benefits to Discourse Elicitation}

Discourse elicitation was an effective method to uncover underlying social beliefs for this particular topic and population. The selected discourses (two photographs chosen by me and the piece of discourse brought by my consultant) facilitated a discussion between my consultants and I about our individual views about how mental illness impacts social participation and interaction. Rather than discussing this in broader terms as in the first interview, the use of photos focused the conversation and distinctly highlighted consultants' feelings about how mental illness actually impacts their lives. I found that my perceptions of 
the impact of mental illness were often more negative than that of my consultants. For example, one of the pictures I selected was a man standing still in the middle of a crowd of people (see Appendix E) swirling around him. To me it represented feelings of isolation and separation despite the multitude of people actually around him. For Oliver, it did not represent this at all. He said, "He looks like a normal dude to me to be honest...People on their day to day...No one's obligated to go and talk to you or anything." This photograph helped me to understand Oliver's experience as someone who has had a psychotic episode as compared to my own assumptions as someone who has not. It also elicited thoughts about his expectations for social interaction in that he anticipated that people may not talk to one another as they go about their daily routine and this may be a social norm for him. Willow's interpretation of the photos were also slightly different from my own:

Um, I think both of them make me, well that one is like feeling trapped and that one is feeling like you are not on the same wavelength as other people, to me. And I think that, that...feeling trapped, I don't necessarily feel trapped. Um, I'm kind of an expert of getting out of social situations (laugh). But.. I think feeling like you are not on the same wavelength as everyone else is like definitely something that's very present for me.

The use of photos helped her to articulate her experience and compare and contrast her experience with others. Although she shared some feelings about being socially anxious and feeling 'awkward' in certain social environments during the first interview, this notion of being on different wavelengths and the deepness to which she was able to talk about her experiences through the use of discourse was starkly different.

Integrating discourse elicitation into interviews was especially useful for some consultants. BB was not very vocal during his interviews. Interviews did not appear to be a format with which he was particularly comfortable. Despite the open-ended questions, he often gave vague, short answers and seemed hesitant to delve into his story or discuss his mental illness openly. However, the use of the photos to elicit deeper ideas and thoughts from him was an effective method to structure his participation. During the second interview, 
in response to the two pictures, he expanded upon how he felt his mental illness had impacted his participation:

I feel like people are trying to put me into a box but I can still, I still try to get out of it a lot..It seems like there are more rules in my life now. Like I have to go to the doctor every two weeks. They have to watch me. I have to be on meds. My parents don't want me to drink as much. And like my doctors don't want me to drink as much. I have to go to outpatient rehab and...that was, my drinking was a way for me to get out into like the world and do stuff... But a lot of that just isn't around anymore, so it's, a lot of time l'm at home doing my own thing. And not really engaged with people outside in the world. And sometimes, some of my friends I don't talk to anymore. I don't know why. But a lot of my friends are either far away or just non-existent anymore.

Thus, one of the major benefits to use of discourse elicitation was that it elicited more complex, profound responses from individuals, such as BB, who were not as vocal or not as comfortable sharing their thoughts and perspectives.

In this study, discourse elicitation was a beneficial method for enabling trust and eliciting tacit perceptions and comprehensive knowledge about my consultants experience related to mental illness and their social participation. As mentioned above, it was difficult for consultants to incorporate me, the researcher, into their daily lives. In studying marginalized populations, rapport and trust are critical issues to facilitate comfort and sharing of knowledge and experiences (McKenzie, Tulsky, Long, Chesney, \& Moss, 1999). Discourse elicitation can be very useful with marginalized, vulnerable, and hidden populations. Focusing on the discourse offered a different way for consultants to talk about their experiences in a less threatening way that facilitated discussion and sharing of knowledge. This method also had the added benefit of allowing me to elucidate my biases and perceptions regarding my consultants' lived experiences. This impacted my data analysis and encouraged me to think about findings and concepts in broader ways (i.e., not based as much in my clinical experiences) and encouraged humility to acknowledge limitations in my own knowledge base. 


\subsubsection{Limitations to Discourse Elicitation}

During interviews with my consultants, there were no major drawbacks to discourse elicitation. BB and Willow required a little extra time to send their discourses, but with extra time and further instruction regarding the method's purpose, they found discourses that represented their experience of mental illness and participation. To garner broader social perceptions from the general public, use of discourse elicitation required more practical considerations of how to effectively deploy this approach. I encountered a significant challenge in finding an appropriate public location for the display. Several venues in the local community would not allow displays from others not affiliated with their organization. Others required a registration fee and permits. It was difficult to anticipate the locations and time periods that would elicit the most participation from the community. I envisioned people hanging around the display, examining the photos, writing deep thoughts and phrases on the post-it notes, and having conversations amongst themselves. The aim was to compare their thoughts and comments with my consultants' comments to see how they aligned. I wanted to assess whether the perspectives of people without a diagnosis reflected the perceptions of those who have had a diagnosis. I also wanted to understand the invisible local social perceptions that impacted the social participation for people with mental illnesses. In actuality, this approach did not prove to be as effective as I had imagined. At the first display, people stopped to look at the photos but few wrote comments about the photos. The comments were often very short and it was difficult to fully understand what they meant. In addition, the effort and time involved for participants to review the discourse was a factor that I had not fully considered. At both venues, people were often on their lunch break, heading to class, or out with friends and did not seem to want to stop with their group. The poor level of participation in the public displays yielded little data and did not meet the objectives I had envisioned. 
After the second public display, I concluded that online postings were likely a more effective approach for discourse elicitation with the broader social arena. While the third online display also generated limited participation, the responses were more substantial. For example, in response to the picture of the man in the glass jar, four responses were given from different people at the first display: 1) Trapped and feels like everyone is looking at them and scrutinizing them; 2) Forced to patiently accept limitations; 3) Aging vs. becoming more dependable on others; and 4) In life we all need help on becoming self-reliant. These were the longest responses offered during the full 2-hour display with 7 pieces of discourse present. In comparison, during the 24 hour online display, one person provided significantly more complex comments to the 7 artifacts:

1: is that the sun? These pictures seem esoteric in a way I don't get. But I get the impression it's far away and on a different scale of size. 2: oh no they are certainly trying to be social if they're in a cafe. This was me earlier today... 3: this looks like how it feels to be self conscious or otherwise have an attention disconnect between your inside and everything outside. 4: are they seeing themselves from an outside perspective? The glass seems like an unnecessary layer of wall or protection or something. 5: So far they all seem to me about social participation. 5 is the first to suggest mental illness, and even that's only because I see the effects of behavioral consequences and people's reactions. This one makes me sad. It seems like they want to be present and friendly and have their own identity but keep getting pulled back from it and generally not accepted. The labels are from outsiders; they don't get to share their own name let alone self identify as anything other than 'crazy'. 6 and 7 are unclear and I'm not as interested in words. I really like the pictures though, thank them and you for sharing.

These comments were detailed enough to compare different perspectives and understand the person's own perceptions and beliefs. It is likely that using online postings for longer time periods would elicit more responses with greater depth.

There are many benefits to the use of online formats for data collection: reduced cost, ease of data entry, flexibility of format options, increased participant self-disclosure, assurances of anonymity, and a greater ability to access different populations (Granello \& Wheaton, 2004). In addition, online postings offer greater temporal flexibility than most other modes of data collection. A participant can fill out the survey at any time of the day in 
whatever location they prefer. Through online postings of different discourses, consultants could engage others in an open dialogue about their experiences of mental illness with anonymity. While there are potential risks to the consultant's self-image (e.g., negative comments about mental illness that reiterate the societal stigma they already feel), this could also serve as an avenue for the consultant to take action and promote a shift in broader social perceptions and beliefs about individuals with mental illness. Two of my consultants reported that the opportunity to share their story and impact change was a significant motivator for their participation in this study. For Oliver, the idea that his thoughts and words could impact someone else was very important to him. When asked about how he felt about his participation in the study, he replied, "I mean I would be very grateful if anything about my life that I share with you wound up helping our acquisition of knowledge about people with psychiatric disorders for lack of a better term." Leo shared a similar sentiment; he stated, "This study gives me something to look forward to and a chance to tell my story." Willow also shared with her college advisor that participation in this study was one of the best things she did during her college experience, though she did not expand upon why her involvement served such an important role during her college experience. Providing these opportunities to share their story, impact broader social change, and reflect on their own experiences in a safe space were significant benefits of the chosen research methods for this study. The interviews and discourse display provided opportunities for selfexpression, reflection via conversation, and sharing of personal experiences that may not have been garnered from other research methods. Discourse elicitation and the use of online blogging could be a way to expand these benefits in future studies on first episode psychosis. 


\subsection{Data Analysis}

Data analysis began immediately following the initial interview and continued throughout the research process. While formal coding using analytic software was not completed until all data had been collected, processing and reflection occurred with my dissertation committee throughout the entire research process. Each committee member provided a wealth of knowledge related to the areas of mental health, identity, and occupational science and offered a sounding board to discuss ideas related to the study. Key themes and ideas were formulated and shared with consultants during the second interview and during participant observations to garner feedback on the accuracy of those preliminary analyses. All interviews, field notes, discourse comments, and my research journal were transcribed and coded. I decided to transcribe the data myself since a significant amount of preliminary analysis occurs during the transcription process. After all data were transcribed and coded using Atlas.ti software (ATLAS.ti 7; Friese, 2013), key themes, phrases, and contextual elements were coded and grouped. Memos were kept in the margins to begin processing my thoughts and connecting themes and ideas to larger plots.

Findings were shared with all consultants and opportunities were given to them to provide their feedback to be included alongside my own. However, the majority of the consultants did not provide feedback or changes to the findings. Given the goal of collaboration throughout the process, I was disappointed that consultants did not provide feedback when given the opportunity. Carly and Willow responded positively to the findings. Carly stated, "I thought it all looked good...I like how you put our quotes in your paper." Carly focused primarily on an observation I describe later in Chapter 4 regarding her interactions in a coffee shop. She said, "Which coffee shop was I at when I was being too loud? I have a boyfriend in my social work program and he has been helping me with that issue. He brought it up several months ago. I think it's gotten better." Although my intent was 
to garner consultants' feedback about the findings to ensure they adequately represented their experiences, Carly used the sharing of the findings as a way to reflect on her social interactions and presentation. Willow also offered positive remarks about the article, but due to life circumstances (e.g., getting her wisdom pulled), she felt she could not contribute substantial feedback to the findings presented. BB and Leo did not respond to the emails regarding the findings. Oliver seemed to feel that the additional responsibility of reviewing the research to provide feedback required too much time and energy; he stated, "If I pay you back what you gave me could I exit the study?" Additional education was provided to Oliver regarding the purpose of sharing the findings and reassurance that no additional responsibilities were required of him for this study. His response to the attempt for collaboration and discussion regarding findings was particularly disconcerting and spoke to the difficulties and limitations of collaborative ethnography.

Having presented justification for my research methods and describing the research design, the next two chapters will showcase my study findings. Chapter 4 will focus on the social factors found to support or hinder social participation for my consultants. Chapter 5 describes the role identity plays in social participation, including how occupation can be used to reshape identities and facilitate social participation. Findings were based on data collected using all methods described above; however, discourse elicitation seemed to elicit data related to identity more so than factors impacting social participation for my consultants. 


\section{CHAPTER 4: EXPLORATION OF SOCIAL FACTORS IMPACTING SOCIAL PARTICIPATION}

This study revealed seven factors that impacted consultants' social participation: 1) social norms and expectations; 2) a sense of responsibility to others; 3) consultants' occupational histories and prior routines, including their relationships prior to the illness; 4) changes in the physical and social environment; 5) the types of participation available; 6) the need for illness management; and 7) consultants' self-perception and subsequent associated perception of occupational possibilities. The impact of factors on social participation was complex and could not be categorized into supports or barriers since they could both support and inhibit participation depending on the context. Further, these factors did not operate in isolation but functioned in complex ways in a transactional relationship to impact consultants' participation. Both social and individual factors merged to generate consultants' occupational situations. Adopting a transactional perspective that employs methods that bridge macro and micro forms of action facilitated studying these complex processes.

Adequately understanding these factors required knowing how my consultants defined social participation. For my consultants, participation and social participation were one in the same; Willow reported, "I think if you are participating in anything it's kind of social". Oliver defined participation as "knowing you are a part of something, whether it is on a large scale or a small scale". The idea that participation was inherently a social process was echoed by all consultants. Consultants' definitions of social participation correlated to Hammell's (2014) review and understanding of 'belonging' in the occupational science and occupational therapy literature. Each of the seven factors listed above was united by a narrative of belonging. 
According to Hammell, belonging involves feeling connected to others, including contributing to their well-being and reciprocating support. Belonging is critical to health, wellbeing, and survival (Hammell, 2014; Wilcock, 2006). Wilcock proposed that the relationship between occupation and health is encapsulated by defining occupation as doing, being, and becoming. Wilcock (2006) expanded her original concepts of doing, being, and becoming to include belonging as critical to human survival and health. This expansion is an example of the increasing prominence of belonging as a foundational concept of occupation. In his hierarchy of needs, Maslow (1943) identified belonging as a basic human need, which selfesteem and self-actualization relied upon. Many researchers in occupational science and occupational therapy have emphasized the role of occupation in fostering belonging (Duncan, 2004; Gupta \& Sullivan, 2013; Laliberte Rudman, Yu, Scott, \& Pajouhandeh, 2000; Lyons, Orozovic, Davis, \& Newman, 2002). As with any other social concept, belonging is impacted by social factors. In my consultants' definitions of social participation, they referred to the social nature of participation in their communities. Their definitions accentuated the need to examine the social structures at play in supporting or limiting participation, including how social factors work to impact social belonging. In the following subsections, I will present findings related to each factor and detail how each factor fits within the narrative of belonging.

\subsection{Social Norms and Expectations}

According to Elder's (1999) Life Course Model, social norms and age expectations identify appropriate ages for most transitions and events in life, for example leaving home, having children, or retiring. These social expectations are often based on age cohorts, meaning that individuals around the same age are expected to engage in these transitions at shared times. In addition, these normative expectations are often accompanied by some type of social consequence of being early, on-time, or late for these transitions, such as social alienation, missed opportunities for participation, or social acceptance in the case of 
being on-time for these normative transitions. Consultants in this study referred to various age expectations and social norms they felt impacted their participation. My consultants were within an age cohort where increased independence, self-reliance, and career planning were expected. Despite those expectations, three of the five consultants had moved back in with their parents, only two consultants had a direction for their potential career path, and all five consultants still relied heavily on their parents' finances and support. All consultants spoke about the social expectations to either attend graduate school or find a career, move out of their parent's home, and be financially independent. Yet they also struggled with integrating their new diagnoses with normative expectations for this transition period. Shame and a sense of personal failure were dominant themes among three of the five consultants because they were unable to achieve the level of independence and selfreliance they felt society expected. For example, Oliver shared, "It makes me very ashamed that I had ancestors that did great things while I'm living my day to day life like a douchebag." He compared his family history and expectations for success to his daily routine of inactivity, drug use, and lack of independence.

Social norms and age expectations significantly impacted what my consultants felt they should be doing and how they compared themselves to others. When discussing her expectations for life, Carly stated, "A lot of my close friends are doing gap years, which is what I'm doing." 'Gap years' are a relatively new social concept that have become more frequent amongst college students deciding between full-time jobs and graduate school. A gap year is defined as a period of time an individual takes out of formal education, training, or the workforce prior to pursuing a longer term career trajectory (Martin, 2010). With greater social expectations for the pursuit of advanced degrees and higher learning, these gap years are more acceptable as a period of transition between college and a full-time job. Though Carly openly talked about her struggle during her undergraduate studies due to the onset of her illness, she conveyed great pride in her ability to graduate from college and 
continue along a typical life trajectory with her age cohort despite her illness. During an observation, she shared that she was significantly frustrated and annoyed that her illness had limited her: she witnessed all of her other friends graduate from college, move out of their parents' homes, and find employment. She felt limited due to her health problems. However, she said she finally felt like she was making progress and doing things with her life. Carly used her gap year to apply to graduate school. This social concept provided Carly with the language and social acceptance to take time off and reevaluate her future goals, which facilitated her acceptance of her illness and hospitalization experience. She strategically used a social norm to manage and cope with her illness. Although her situation was different than her peers due to her psychotic break, she continued to compare her life trajectory to her peers. Carly enjoyed her young adult bible study group and often talked about it because it was "a bunch of young adults going through young adult stuff":

It's funny because last week, it was like everyone was praying for a new job and then the next week, everyone was thankful because they found a new job... Everyone at this age has this problem though.

She made reference to the transitions that occur in young adulthood and how many people in the group were sharing the same experiences; she termed this period "the quarter life crisis". These comparisons reflected shared social norms and expectations and helped her feel connected to others in her age group.

Social expectations for a typical life course primarily served as motivators for social participation. They acted as motivators by providing a shared social understanding of what should be pursued at certain ages and life periods. They held consultants to a standard of participation in life and provided goals for future participation. Willow noted that social expectations encouraged her to progress towards set goals, although it was unclear whether she felt these positively or negatively impacted her participation:

I feel expected to have my own car and maybe start living off campus or something like that soon...I guess I feel very expected to be like in a relationship with someone. 
And I feel very expected to be extremely studious...I feel pressured by them and I want people to judge me in a positive way so I try to live up to their expectations.

In some ways, these expectations kept her progressing as a college student. The expectations of independence, owning a car, and moving into her own apartment could be viewed as stepping stones to full adulthood. However, participants also felt overwhelmed by social expectations and, at times, they experienced negative repercussions from such social pressures. For instance, Carly noted the stress of trying to manage her illness while keeping with social expectations for a career and independence:

It's so stressful...Around my psychotic break, I was still like I, I didn't know what I wanted to do for the rest of my life. I was freaking out....Before my brain surgery I wanted to do this but that's not reasonable anymore. What am I going to major in? What am I going to be when I grow up? I was figuring out with, during my psychosis. And I didn't know really until like maybe I was 21 . I really figured it out. So you know it took time...It was hard because of all the transitions...cause you are trying to figure out your career and, when you are at this age, it's tough.

Despite the stress associated with her psychosis and the subsequent delay in reaching certain life expectations, Carly was able to adapt her life trajectory to fit with age expectations and social norms. This implied a level of agency related to her ability to use social norms to identify acceptable areas for participation.

\subsubsection{Stuck in a Liminal Space of Dealing with Mental IIIness}

The FEP interrupted consultants' trajectories on socially expected life trajectories and caused significant uncertainty regarding their futures and how they would fit in. Leo referred to this uncertainty as a 'liminal space'. Liminality is a "state of in-between-ness and ambiguity" (Beech, 2010). Following his psychotic episode, Leo felt stuck in this space of liminality wherein he was simultaneously taken 'off track' from social norms in terms of life trajectories and having to negotiate next steps for his life. Leo was attuned to societal expectations, which influenced his personal ambitions; however, he was unable to identify a strategy for achieving those normative expectations. He was unsure if he wanted to achieve 
those social expectations, even though he felt shame and guilt about not having done so

yet:

So I'm like in this place right now. This middle space. This liminal space. It's like an in-between limbo space where I'm not committed to anything really but I'm also..not..I'm out of college..and I'm like..I'm in this intermediate space...I'm kind of stuck...in this place and that's how I feel. I feel stuck. So l'm like in the middle of the story where this stuff from my past is still going on but I'm trying to create a new story and I'm stuck in the old story. And it keeps coming up over and over. To where all I have is doctor's appointments. And the court...And I don't know how to fix it. Like I feel stuck in this place of being afraid of being stuck...So I feel like l'm torpedoing my own life and shooting myself in my foot by refusing to specialize because I'm so smart. If I could just focus on something I probably could already be independent from my parents...And that's one of the things that I'm afraid of even going back to school and trying to become independent is like, I'm afraid of the structure. That I'm not going to able to fit in the structure and submit myself to doing the homework that's assigned to me...And I feel like there is something wrong with me. Like a problem. I need to solve this. I need to figure out how to overcome this...I need to get into a structure of some kind and have a structure to my thinking and my time. But um, I'm afraid of it. I'm deeply afraid of it.

Leo chose to participate in certain occupations based on his perception of social expectations. For example, although passionate about linguistics, he shifted his academic focus to computer programming because he and his parents felt the job prospects would be better. He mentioned that his parent's encouraged him to consider a computer science degree. For Leo and his parents, his passion for learning languages became associated with his mental illness because his first psychotic episode involved excessive learning of multiple languages:

I had this dream of being a translator but I think the person that's decided that I don't want to be a translator is me. And l've always been frustrated with my languages, like why didn't I specialize? Why didn't I go abroad? And I'm looking back and I think that I'm, I don't know if I could have studied abroad with my mental illness and stuff... My world view has changed so much.

After his psychotic episode, Leo no longer felt as though he could be a career translator. He was encouraged to readjust his career goals and find a structured occupation that could lead to greater stability and independence. He took courses at the local community college and was progressing in his computer degree, but struggled with deciding whether this was the right trajectory for himself. He desired to continue learning languages but stated, "No 
one's going to pay me to be interested in Wikipedia for 40 hours per week." Without these external social motivators, Leo may not have felt pressure to identify another career path that could provide him with the independence he concurrently feared and desired. These expectations served as external motivators for action.

\subsubsection{Normative Expectations for Determining Socially Appropriate Behaviors}

Normative expectations influence what occupations are pursued and serve as tacit guides for acceptable behaviors. For my consultants, understanding what was considered socially acceptable behavior often determined how successful a consultant was with engaging in a certain occupation or with a certain community. Willow was particularly sensitive of how she was perceived by others, which made her feel different than her peers:

I'm still really awkward...Sometimes I'll think that someone will respond to something really well and the majority of people will respond to it really poorly. And I just like, in my mind the things that I view as acceptable are very different than the things most people, or the people I encounter, view as acceptable.

Consultants' comfort with their social skills impacted whether or not they would initiate participation in a given community.

Carly appeared comfortable in various social settings, especially when meeting up with older friends from college. However, she lacked awareness of some socially acceptable behaviors in public settings. She tended to be overly animated and spoke loudly when meeting with friends and was also excessively open and honest about her past experiences, which led Carly to unintentionally broadcast her personal life to strangers in public settings. She did not appear aware of it though there were several instances where I noticed others looking over to our table, giving strange glances, and in one instance, approaching me afterwards to discuss her behavior. For example, one of our participant observations was held at a local coffee shop with Carly and her friend who was visiting from out of town. The coffee shop was somewhat small, although there were approximately 15 customers seated at nearby tables. As I was walking out of the small coffee shop after our observation, a man 
walking out with me turned and said, "That was wild. I understood when she was talking about her mental illness. I said to myself, Oh ok. That's why." It was unclear what made him feel he could approach me about this interaction; perhaps it was my work nametag hanging around my neck and the possible assumption that I was a clinician. His comments made me ponder what this meant for Carly's occupation of drinking coffee and visiting with a friend in that setting. This experience made me wonder whether her participation was limited by her style of interaction. The latter might label her as 'abnormal', which could prevent others from interacting with her as they would with someone who exhibited typical social behaviors. The man's statements were also shocking given his sudden acceptance of her poor social awareness once he knew she had mental health issues (which she disclosed during her assumed private conversation with her friend). He was more tolerant of her behaviors and interaction style and he 'understood' why she acted that way, as if her interactions had nothing to do with her as a person but instead related only to her as a client with a diagnosis. With a new label to put on her, Carly could now occupy a specific social position in his mind in which such behaviors are expected.

\subsubsection{Impact of Social Norms and Age Expectations on Belonging}

Social norms and age expectations were common underlying themes throughout the study. As mentioned above, they did not operate in isolation, but were intertwined with other factors to impact consultants' social participation. Social norms and expectations served as motivators for action and social participation. Consultants were well aware of how social norms and age expectations affected their life trajectories. Bourdieu's philosophical work on social systems of hierarchy (Swartz, 1997) emphasized that entry into a social field of action requires a tacit acceptance of the rules structuring action in that field. To effectively belong to a group or community requires an understanding of the social rules and expectations that guide participation in that group. Consultants who understood and accepted those norms were able to strategically use them to find alternative avenues for belonging and social 
participation. They strategically used their resources and their available opportunities for participation to integrate with groups and communities.

Social norms served as a guide, or starting point, from which they began to reshape their lives and identify avenues for belonging. For example, consultants used social norms and expectations to compare themselves to their peers through social interaction. Though many returned to live with their parents, they knew that this was not an acceptable living situation given their age and stage in life. Thus, they worked to remedy the situation by returning to school, obtaining employment to support their independence, and searching for community groups to join. For instance, Carly joined a young adult bible study group. By belonging to this group, she could engage in age-expected occupations and discuss similar life transitions with a community of young adults. Though she was also undergoing a transition related to her mental illness, belonging to a group that fit with social norms and age expectations allowed her to access other aspects of her personhood and focus on typical life experiences.

Social norms and expectations helped consultants to identify occupational pathways and make occupational choices in line with those norms and age expectations. This is not to say that this was always feasible for all of the consultants. Several consultants were aware of expectations but were unable to make changes needed to continue on their expected life pathways. When they were unable to engage in occupations consistent with their life trajectory and age expectations, the 'liminal space of FEP' presented itself. Their inability to reengage in expected life occupations may have been limited by their inability to find groups or communities to belong to. In addition, because social norms also dictate socially appropriate behavior, ongoing symptoms and reduced self-content may have precluded consultants from seeking out communities for belonging. Those consultants who were able to identify avenues for belonging and participate socially in their communities tended to have 
fewer negative feelings about their illness. Belonging in a group and continuing to participate in occupations was important to recovery and progression on their life trajectory.

\subsection{Sense of Responsibility to Others}

Several consultants noted a sense of responsibility to fulfill social norms and expectations as an important factor encouraging their participation in social occupations. Willow is involved in her college community and identified a sense of responsibility as a motivator for her participation in her chosen organizations:

I think my sense of responsibility to others does make me get back out there just because I feel guilty if I don't contact friends that I am like good friends with... The sense of responsibility is kind of a thing that drives me to do a lot of other things, which I guess is true for a lot of people.

Going into her junior year at a local university, she is now on the leadership board of her Lesbian, Gay, Bisexual, Transgender, Queer or Questioning, and Intersex (LGBTQI) organization. She attends two meetings per week and assists with planning community advocacy events. She felt pressure to attend meetings and events even when she felt greater anxiety, depression, and paranoia about others' judgment of her. In addition to peer support and the risk that she could lose her position if she did not regularly attend the meetings, it was her sense of personal responsibility to the organization and her fellow students that encouraged her participation. She shared that others in the organization counted on her to be present; she had a lot of experience and historical knowledge about the organization that contributed to discussions and organizational decisions. Willow also felt that her regular participation in the organization helped her to "not isolate" herself and forced her to get out and be social. For Willow, her sense of responsibility to the organization and its mission kept her engaged. For Oliver, his strong sense of responsibility to his family kept him seeking employment despite multiple job losses:

My sister's here. She doesn't plan on raising her son here. So before middle school she's going to be moving and that makes me aware that I need to start producing for our family 'cause while I hope that her boyfriend will stick with it, uh, he's a convicted felon and he works hard and I believe that he wants to provide for his son, however, I 
want to make sure that that boy is taken care of because, uh... I want to make sure that he doesn't develop any of the problems that me or my sister or her boyfriend's had...I worry about my sister's situation...I want to put myself in a situation where I can provide for my sister...So l'd like to do something for her longer term...just to see that she's taken care of. Like, if I could buy my sister a house someday...that'd be awesome. I'd love that.

Oliver's desire to provide for his family served as a motivator for participation in certain occupations and as a constraint for other occupations. For example, he had plans to return to college, which happened to be located at least 3 hours from his family, but delayed those plans because he felt his family needed him in the area. Oliver lived with his mother, sister, and nephew; he would often run errands for his mother, babysit his nephew, and often mentioned the need to work to financially support his family. At one point during the study he discussed possibly beginning classes at a local community college; however, between several family issues, financial concerns, and problems maintaining consistent employment, he did not pursue any additional education.

Oliver was a second-generation immigrant whose father had returned to his home country. Oliver had a lot of traditional expectations about a male's role in the family unit. Due to his father's absence, he felt an obligation to provide financially for his family as the primary male figure in the household. However, he struggled with maintaining employment and following-through with life plans. Though he did not specifically link his employment difficulties to his mental illness, based on our discussions and my observations, it seemed his interpersonal issues, inability to attend work consistently, low self-content, and tangential life planning were related to his mental illness.

\subsubsection{Impact of Sense of Responsibility on Belonging}

A sense of responsibility to others often supported social participation for my consultants. Feelings of belonging triggered the sense of responsibility consultants felt to others. However, belonging occasionally impeded social participation in other occupations because of the sense of responsibility the consultant felt to the particular group to which 
they belonged. For example, Oliver was unable to pursue a return to college due to his sense of responsibility to his family. Belonging in one social group precluded his potential involvement in other social groups. However, he valued his belonging in his family and was able to participate in family occupations through that belonging. In addition, due to his sense of responsibility to his family, he often sought out other social occupations that fit with his role in his family unit, specifically that of employment. Similarly to Willow, belonging in a social group fostered a sense of responsibility to that group, which in turn, served to facilitate reengagement in occupation and social participation after their psychotic episode.

\subsection{Occupational History and Prior Routines}

Other factors that impacted social participation following a first psychotic episode were consultants' occupational histories and their former routines. Consultants with rich and varied occupational participation prior to their psychotic episode tended to return to participation in occupations sooner than those with limited occupational histories. Carly remarked, "I jumped back into a lot of my interests right after. They were all there because I had been doing them my whole life. I had played violin since age 7 . I had been doing these things. It was natural." Carly utilized music both within the hospital setting and afterwards to work on her recovery and reengage in social occupations. She played piano during her hospitalization and took weekly music lessons after her discharge. Carly later began tutoring others in the violin. She taught lessons, which offered both financial and social rewards: "It just helped me feel like a person again...I continued to do music throughout the entire recovery... Having a routine really helps after an episode. Like having interests and things to do."

BB and Leo also talked about their occupational participation prior to their psychotic episode. During an observation, BB and I went to a park behind his house and he built a fire in the fire pit while he shared memories of his childhood and Wilderness Camp experiences of hiking and building fires with his peers. In fact, at least 6 out of 12 observations involved 
hiking, walking around the lake, or sitting outside observing nature with peers. BB spoke fondly about these activities, which he often participated in with local friends and his father. Because his occupational history consisted of hiking and other wilderness activities prior to his psychotic episode, these were familiar and comfortable occupations that BB could easily return to after his diagnosis. They were also activities that did not require much money, which was a hindrance to other types of social participation for BB.

While in high school, Leo participated on the swim team and in the band, which offered him a daily routine and structure, as well as opportunities to develop social relationships leading to other opportunities for social participation. He did not participate in these once he began college; instead he became more involved with his campus ministry group, which also afforded opportunities to develop social relationships and expand his participation in the college environment. Unlike Carly who was able to return to her occupations quickly after her hospitalization, Leo struggled because he had graduated from college and experienced difficulty finding other social communities to participate in after graduation. In addition, due to the circumstances of his psychotic break, he was not allowed on college grounds and was forbidden from attending alumni events and felt significant shame about this, which further isolated him from prior college relationships and occupations. Because many of his occupations were team-based and centered around a specific context (i.e., school), it was difficult for him to reengage in those occupations after he graduated. Leo had to seek out new occupations to participate in, which was more difficult after his psychotic episode, in part due to his own comfort with establishing new relationships and self-stigma associated with the mental illness:

I used to hang out with people all the time. When I was going to that fundamentalist church I would hang out with friends all the time...I was always busy. And I had a job and stuff too. I had several jobs. I feel like everything has changed since I went to the hospital. And since I learned about the New World Order. Everything has changed...I've been talking about the economic downturn and the civil unrest and stuff for years and l've lost almost all of my friends over it...So I've been actively seeking these groups that have a certain kind of social participation...I think 
community is important. I think human interaction is important for health, but I don't know if society would agree.

Leo was actively seeking out groups that emphasized community among its members to meet his need for belonging and interaction. Leo noted the importance of belonging in a community and the role of social interaction for health and well-being. He actively sought groups to belong to, yet struggled with being fully included in these groups at times due partly to his changing world outlook and effects of his illness.

Oliver also struggled with reengaging in his former occupations of poetry and spoken word. Spoken word is a style of entertainment involving performance-based poetry that focuses on word play and story-telling ("Spoken word," n.d.). He continued to engage in poetry writing during and after his initial hospitalization and described the occupation as therapeutic to his recovery. However, he was unable to reengage in the spoken word community as he had prior to his hospitalization; this seemed mostly related to his own selfimage and comfort. Initially, he spoke positively about his poetry and spoken word events and we made plans to attend a few spoken word events together; however, when it was time to go to the event, he would often cancel. When asked why he did not want to attend he stated, "That was part of my old life, old self and I haven't felt connected to it like I used to." Although he continued to have friends there, he felt he could not share anything positive that would help someone else, which was important to him. This highlighted how his new diagnosis had changed his own views of himself. Oliver felt strongly that spoken word, as an art form, imparts feelings upon the audience; therefore, if he shared a piece that was not positive, he would impart negative feelings onto his listeners:

I don't think I have become what I want to see in others...I had a spoken word piece where I essentially started to get over my feelings, uh, about being in the ward...Saying it aloud to young people that can be influenced a bit more easily than adults that have a lot of experience with things like that. I didn't feel comfortable with that...Which is part of the reason why I felt as though I should seclude myself from the community. 
Although spoken word events were a prime opportunity for Oliver to participate in a familiar social occupation, he did not connect to the occupation in the same way he had prior to his illness. He had changed as a person and thus his occupations needed to change as well to fit his current situation. Oliver continued to participate in one of his past occupations but the other occupation, spoken word, no longer fit for him or his self-representation. Having a broader occupational repertoire to choose from and a history of participation in multiple arenas prior to the illness may have offered him more opportunities for reengagement after his psychotic break, as it did with Carly.

\subsubsection{Relationships Prior to the IIIness}

Another factor related to occupational history and routine that was significant to social participation was a consultant's history of relationships. Carly had a strong support network of friends and family prior to her illness. These longstanding relationships had been crucial to her success and continued progress towards recovery and participation in social occupations. Both the quantity and quality of her social relationships were important to continued social participation after her psychotic break:

A lot of times people have a social life before mental illness. It's not like those friends, if they're real friends, they are not going to ditch you over having a psychotic break. They all understand it and they had all visited me at the hospital for the brain injury. And they saw it. They knew it wasn't my fault. And I recovered really well from the psychosis. So I mean there were people that I had lived with who couldn't handle

it. But that was only a half dozen people. And I had so many other friends.

Carly noted that she lost some relationships that were lost as a result of her psychotic episode; however, she was able to maintain many other relationships. Having many friends provided more opportunities for her social participation, which facilitated her recovery after her psychotic episode. For Carly, having longstanding friendships with individuals who knew her prior to her mental illness was important because they understood who she was as a full person and did not focus on her mental illness. 
BB's primary mode of social participation involved hanging out around the lake with friends from his neighborhood, most of whom happened to attend high school with him. Due to constraints in transportation and finances, his social participation was limited. He was able to reconnect with old friends when he returned to live with his parents; at least two of his former friends also experienced mental health issues, which helped him relate to them:

I find like now that I have an illness, it's harder to relate to people. Like people they find out about it. Sometimes they don't, like my good friends they don't really mind. But other people might mind.

Leo also noted the importance of having a broad social network prior to his FEP. His closest friends were friends from high school who knew him well. Leo described himself as a "star student" in high school and very involved in many extracurricular activities which allowed him to establish friendships. These friendships contributed to his self-representation and helped him feel successful. However, Leo reported difficulty connecting with his friends after his FEP:

My friends didn't know how to relate to me for a couple of years and I lost touch with a lot of them and now they know I am on medicine and able to relate to them again...But I still feel separated from them by the psychotic episode so having a friend who has been through something similar has been really helpful.

Fundamentally, Leo's relationships changed in terms of the frequency and nature of participation. His self-perception had changed and he no longer felt he had something to offer to his friendships. In high school, he was a team player, felt positive about himself, and thought he contributed in a meaningful way to his friendship. Following his FEP, his selfperception changed and he felt more comfortable in relationships with others who shared a similar experience of FEP. Similarly, Oliver did not want to reconnect with old friends or mentors after his hospitalization because he felt "they turned their back" on him.

Willow felt that having prior relationships helped her through her hospitalization and recovery. When asked what helped her transition back into daily life after her episode, she said, "I suppose just the fact that people missed me when I was gone." Similar to Carly, 
having prior social relationships served as a motivator and support to her social participation after her psychotic episode. Both Carly and Willow had rejoined social communities and were participating more regularly than Leo and Oliver in social occupations. Perhaps they had a more positive view of their mental illness than Oliver and Leo and did not feel inhibited by it to reengage in former relationships and create new relationships that facilitated their social participation.

In addition to friends, family was a significant resource that impacted the participation of my consultants. All five consultants were deeply connected with their families and four were living with their parents at the time of the study. Strong family support prior to, during, and after the psychotic episode was vital to social participation. Carly's mom took a leave of absence from work to help her attend her outpatient appointments, took a knitting class with her to encourage participation in community occupations, and attended weight watchers with her to help lose weight brought on by her medication regimen. Due to financial and transportation barriers, BB relied on his father for most of his social participation. His father encouraged participation in hiking groups, excursions with meet-up groups, bought him skiing trips for his birthday and attended those trips with him, and took him fishing and bowling. His father attended most of our participant observations. He encouraged his son's social participation and also provided the financial means and transportation for participation. Having a supportive family member to attend events and community occupations appeared to increase Carly and BB's social participation, even outside of the family unit.

When Leo was asked about his current social participation, he said, "Gosh. I participate in my family. I hang out with my dad as soon as he gets home. And I hang out with my mom in the mornings and at night when she gets home too." After his FEP and hospitalization, Leo struggled with participating in his community due to medication side effects, issues with sleep, and self-stigma. However, he was still able to participate in family 
occupations quickly after his hospitalization, which later offered a bridge to participation in social occupations outside of his home and family. Throughout the study, Leo's social participation expanded and he seemed to spend more time volunteering, attending community college, and engaging in social occupations outside of the home. For my consultants, family was often a major support immediately after the psychotic episode and hospitalization. Leo's father initially attended community court with him, until he felt comfortable going on his own. Carly's mother helped her fill her medication box weekly and accompanied her to appointments. Willow called her mother "probably like 5 times per day" to get advice about various decisions and to help problem-solve issues in her daily routine. For example, during an observation, Willow seemed scattered and stressed. She said she had a presentation due later in the week; she needed a particular type of software to complete the presentation and had rented a room in the library that had this software. However, a class was meeting in there and she was unable to use the room. She called her mother to discuss the issue and help her problem-solve what to do. After the phone call, Willow reported significantly less stress over the issue and had renegotiated her plan to complete the assignment. When asked about their relationship, Willow acknowledged her mother was a great support for her:

Sometimes my therapist thinks though that she is too involved in my life. I think it's helpful enough that I don't want to change it so much. I'm like reluctant to change it. Even though I know that independence is good. And so when I'm still at a point where I'm going to need help from my mom for some things like advice for stuff, I usually ask her for advice for stuff. And...I don't know...I think I would need help from people consistently throughout my life.

Family support and resources were important to preventing relapse, integrating the new diagnosis into consultants' routines, and encouraging social participation in the community. Attending social events with family facilitated reengagement in the community. This appeared to be especially important immediately following a FEP or hospitalization when concern about disclosure and ongoing symptom management was higher, and additional 
support in the community was needed. Whether or not consultants chose to participate in prior occupations after their psychotic episode or connect with prior social groups, having those relationships prior to the illness and strong family support appeared to be a significant factor that encouraged participation in social occupations after the psychotic episode.

\subsubsection{Impact of Occupational History and Prior Routines on Belonging}

Having a rich and varied occupational history prior to the psychotic episode was important for reengagement in social occupations after the episode. In other words, belonging in social groups prior to the episode facilitated participation after the episode through reengagement with those groups. Through involvement in particular social groups prior to the psychotic episode, consultants had become aware of the social rules and expectations operating within those groups. These groups offered a comfortable zone for reengagement to occur after the episode because consultants were already aware of how to participate socially in these groups. In general, belonging to a variety of communities and engaging in varied occupational pursuits tended to support social participation following FEP.

This did not prove beneficial in facilitating a return to social participation for all consultants. For instance, Leo struggled to rejoin prior social groups due to a change in his social environment, legal charges, and a change in his self-concept. The change in selfperception and identity also impacted Oliver's connection to prior social groups and occupations. Leo and Oliver no longer felt a sense of belonging to their former communities, which ultimately impeded their participation in these groups after their FEP. They were unable to return to prior social groups and had to find alternative ways of belonging in their community. Leo used his occupations to identify potential groups with which he shared interests to attempt to feel a sense of connection and belonging after his FEP. In this study, a varied occupational history, including prior routines and relationships, facilitated social participation and belonging when consultants' continued to feel a sense of connection to 
their prior occupations and relationships. When consultants' self-perception or self-identity changed drastically as a result of their illness, or if their social contexts were significantly altered, this factor did not support belonging. Identifying alternative occupations and social groups to foster belonging following FEP required hard work and time. Consultants' families were consistent sources of belonging that supported a return to social participation over time. Whether or not consultants chose to reengage in prior occupations or with prior social groups after FEP, having opportunities available for reengagement was important. The family unit seemed to be one source through which opportunities were made available, which led to broader social participation as the consultant felt more able to manage their illness.

\subsection{Change in the Physical and Social Environment}

The physical and social environment played a major role in fostering or hindering social participation for the consultants in three ways: 1) the need to manage the illness often required leaving the current physical and social environment, which often led to reduced social participation; 2) being in a shared physical location led to more connections and social participation; and 3) consultants navigated towards 'comfort zones' or familiar areas where they felt able to participate in social occupations. Two of the five consultants were attending college away from home when they had their first psychotic episode. Both returned to their homes and family to receive assistance with seeking treatment, finding housing, accessing family resources, and identifying the next steps for their lives. BB shared that after moving back home to live with his parents, he was less social and engaged in fewer occupations with friends:

I moved back and now I'm under all this mental health stuff and I don't ski as much as I used to and that used to be a big part of my life. So that has been taken away and made it hard for me to cope with real life cause now I have to cope with real life and I don't have skiing to go and get away from it. 
BB went skiing twice during the study; however, both times, his father accompanied him instead of friends, in part because his father was the one who paid for the trips and provided the transportation. When asked about going skiing with friends, he said if he had his own car he would take a couple of friends, implying transportation limited his participation in skiing with friends. While BB was attending college near the mountains, skiing and hiking became important occupations for his life. The proximity of his college to the mountains facilitated his engagement in that social occupation. Transportation was not a barrier. After returning home to live with his parents in an urban environment, he no longer experienced opportunities to ski. Because of their distance from the mountains, ski trips required considerable planning, transportation by his family, and more income. In addition to the physical change in his environment, the friends he made in college were no longer accessible to him: "A lot of my friends are either far away or just non-existent anymore." As a result, he reconnected with old friends from high school, primarily due to the convenience of location. Because he did not have a car, he relied on friends with cars or friends who lived in his neighborhood. They would often meet up at each other's homes, to make music or use substances (alcohol, drugs), or walk around the park near the neighborhood. His new physical environment drastically changed his social environment and the nature of his occupational engagement. BB was still social, though the nature of his social occupations changed.

Carly also moved back in with her parents after her psychotic episode. Although she attended school locally, she was unable to return to her dorm room after her hospitalization due to interpersonal issues with her roommate, part of which revolved around her roommate's negative perceptions about mental illness. She required extra support from her parents and moved back into her family home. Carly valued her parents' support, however, felt living with her parents was not ideal for her and impacted her independence and participation: 
I didn't like living at home anymore. And I know a lot of people with mental illness, they live at home because maybe they have a hard time getting a job or they need the support from the family or financial resources. I worked it out that I could move out...I'm much happier living with people my own age and like, it's reasonable. It's like a mile from my job.

After Carly began working more and increased her financial independence, she moved out of her family's home into an apartment with two other women. Not only did moving into her own apartment offer increased opportunities for social participation with her peers, but it was also convenient for her employment and engagement in other social occupations. For example, during the study, Carly joined a local yoga gym near her apartment. She said it was convenient to her new location so she decided to give it a try. Engagement in this occupation was facilitated by her environment and the occupational opportunities of her immediate physical environment.

Being in a shared environment or location served to facilitate social participation and social relationships. After a period of recovery Carly returned to college and moved into a house with other students participating in a local religious organization on campus. Through this shared living environment, she established new friendships with peers who shared similar interests to her own. The convenience of proximity facilitated the development of these friendships. Being in a shared physical location created opportunities for happenstance encounters and spontaneous co-occupations that deepened the bonds of friendship for Carly and her housemates. In some ways, it eliminated the need to take initiative and allowed Carly to relax and let the opportunities for participation come to her. One year after graduation, she continued to meet with many of these individuals to participate in social occupations, such as fundraising events, basketball games, and other religious alumni outings.

BB's shared environment in college also led to increased social participation and the acquisition of 'rapping' as an occupation. While living with his best friend in the college dorms, who happened to be a rapper, BB participated more in rapping and rap-focused 
events. The shared environment served to expand his occupational repertoire and led to increased social participation in an occupation that he may not have pursued otherwise. Rapping and creating music are two occupations he continues to enjoy, even after returning home and away from that shared environment. However, BB now creates music primarily from his own home and the social aspect of his participation has significantly reduced. He is no longer in a shared location that facilitates spontaneous engagement in his music occupation; he now has to take the initiative to pursue this occupation socially, which is difficult in light of his financial and transportation needs. BB's primary social location during the study was a chain coffee shop near his home. Because he could walk to the coffee shop, this location provided a convenient, low-cost social setting for him to be near others. He hung out there at least 1-2 times per week, both alone and with friends, drinking coffee and observing others. During one of our hangouts, while I waited for my hot chocolate, he went over to a couple of elderly men sitting in the comfortable leather chairs by the fireplace. He spoke with them for a few minutes, they laughed and smiled and exchanged pleasantries, and then he returned to our table. The interaction appeared very friendly and pleasant, as if he had bumped into old friends. BB shared that he had come to know the men by visiting the coffee shop frequently. He reported that he and they often sit together in the leather chairs near the fire and converse. According to $B B$, he enjoys talking to them because he is "not a big talker and they don't stop talking much." It is difficult to ascertain whether BB's illness has changed his conversation and interaction style. During our observations, I noted that he rarely initiated conversation with others and tended to be brief with his responses, requiring more questions to elicit deeper interaction. The shared environment of a coffee shop generated opportunities for shared social engagement, which was important for BB's social participation, especially since his social participation was drastically limited by financial, transportation, and environmental barriers after moving back home with his parents. 


\subsection{1 'Hiding Out' in Public Places}

In addition to having a shared location for participation, a familiar environment was also important to fostering social participation for my consultants. Four of my consultants mentioned that social anxiety precluded them from returning to certain occupations and environments after their initial psychotic episode, which eliminated many opportunities for social participation. They altered their participation to incorporate locations and occupations that were familiar or offered them a chance to 'blend in to the crowd'. Leo mentioned he was "hiding out" from a church he used to attend because he had ruined his relationships there. He began attending another church that offered him the opportunity to "hide away and blend in amidst the crowd and just sit back and listen to the music and gospel." Environments that allowed for a lower level of social interaction while still being able to participate in occupation helped Leo return to social participation after an initial psychotic episode. Oliver also noted the importance of hiding in public after his hospitalization. Referring to his participation in online gaming, he reported, "The server is a public place in theory. And when I was more or less withdrawn from public interaction for a while after my stay in the hospital, I could always get on there and enjoy comfortably distant camaraderie."

\subsubsection{Comfort via Shared Experience}

For Willow and Carly, their comfort zones depended on the social relationships within those zones versus the physical environment itself. For example, although shy, soft-spoken, and self-reportedly awkward in social situations, Willow displayed boldness and selfconfidence during her participation in campus LGBTQI events. Willow was known and included in this community due to her lengthy involvement on the organization's board, her participation at events, her shared commitment to the organization's cause, and the familiar settings where most events and meetings were held. She carried on extensive conversations with peers about organization business and upcoming events, volunteered to participate in fashion shows, and openly shared her opinions during board meetings. She 
appeared comfortable with other members of this community, which seemed to dilute the social awkwardness and medication side effects she felt might have impacted her social participation. Her familiarity and lengthy involvement with this situation made it a place of comfort that she could easily navigate despite needing to manage her illness.

Similarly, Carly's comfort with expanding her social participation and engaging in new occupations was affected by social relationships in those environments. Carly was planning to move to a new state to attend graduate school. During our observations, she expressed excitement and angst about moving. Throughout our conversation, she identified several factors that helped her feel more confident in her decision to move to another state for school. She talked about the many friends she already knew at her destination. She mentioned that her dad flies there frequently for business so she would see him often. She also mentioned that her undergraduate college had many alumni organizations there, many of which she had already joined on Facebook. She had made plans to attend the organization's events during her first few months in school. To Carly, it was not as important that she had long-standing, close relationships with people in this new area; it mattered more that there was the opportunity to participate in social events with those people based on having some existing relationship with them and shared experience. For all consultants, social participation was increased when they felt comfortable in the setting and when there were opportunities for involvement through shared environments and experiences. Participation in an occupation in a shared location led to more connections with others and fostered a sense of comfort that encouraged continued engagement. Occupation was the medium for social participation.

\subsubsection{Impact of Changes in the Physical and Social Environment on Belonging}

As stated above, families and prior social groups to which consultants' belonged were places of 'comfort' that facilitated participation and belonging. The supports offered by prior occupational histories and relationships were not sustained when those occupations 
and relationships were no longer available in a given environment. Consultants could no longer participate socially in those communities, and, consequently, they lost opportunities to sustain or nurture feelings of belonging. Feelings of belonging changed along with changes in occupational participation and levels of community involvement. In addition, because consultants did not always feel a sense of belonging in the new environments, participation itself was hindered. In this way, belonging acted as both an antecedent and result of social participation.

Many of my consultants sought out 'comfort zones' of participation after their FEP. For example, Leo and Oliver initially felt more comfortable with distanced participation, wherein they could 'blend in' to the social milieu. They desired belonging and selected occupations that provided opportunities for interaction in social environments that fostered feelings of belonging. Comfort zones were important avenues for consultants to feel confident with their social participation after FEP; these zones were comfortable because they offered predictable social demands. Consultants were able to learn and predict these demands through previous experiences in similar settings. For example, Leo had participated in church services in the past and was familiar with the typical progression of a church service; thus, he was able to follow along with the congregation and blend in to church settings with relative ease following his FEP. As consultants felt more confident in their ability to participate socially, they could then explore other opportunities for belonging. This most often occurred through a shared physical environment, wherein social interaction and opportunities for participation occurred without the need for consultants to initiate it. Without a shared location, belonging and social participation were limited.

Being in a shared physical environment led to increased social interactions in those environments, which led to a greater sense of belonging and enhanced social participation. Thus, when consultants no longer shared a physical location with prior social groups, their sense of belonging diminished until they were able to identify alternative groups for 
belonging. Carly made choices to pursue certain occupations based on anticipated communities for belonging. For example, in deciding to attend graduate school, she considered the social programs and housing supports offered at each graduate school, as well as how many alumni organizations and events were offered in the surrounding location. Part of her decision related to her sense of expected comfort with alumni groups in this new location due to their shared interest and her familiarity with alumni groups in her current environment. In addition, she knew that being physically near possible social groups would likely increase her opportunities for belonging and social participation in her new environment. This had been her previous experience in shared living environments while in college (e.g., dorm, religious organization) and she could base these predictions on her past experiences.

\subsection{Types of Participation Available}

Social participation and the forms in which it occurs are shifting with the circulation of new technologies and changing cultural expectations. Leo described the changing social environment and argued we need to fully understand our assumptions about how social participation is defined and experienced:

I guess my question would be what does social participation look like in today's world? Because like...if you are going to compare people who are sitting around all day on Facebook, playing Facebook games, who like, you know, all their neighbors are just playing Facebook games too. And when you are comparing them to like a social life where people are going out and dancing or going to bars and trying to meet people or whatever...I think the whole, like the internet has become such a part of participation. So, being able to accurately compare people who have a psychotic episode with society, I think you really need to make sure that you have a good understanding of society.

Social media and other types of virtual participation played a more important role in my consultants' lives than I originally anticipated. Willow and Carly used Facebook as a way to connect with friends and stay current on social events. BB posted videos on YouTube of his music creations and ski trips. Leo blogged and journaled about his life on Facebook and maintained international pen pal connections through email. Oliver's social participation 
consisted primarily of online gaming with a group he had befriended over the course of 1-2 years. The connections with others through virtual environments were not necessarily deep connections for all of my consultants. For example, BB rarely knew who responded to his music and video posts, and Oliver knew very little about the personal lives of others in his gaming group. However, they provided an outlet for social participation and allowed consultants to feel socially connected to the outside world, albeit to a lesser degree. BB's video postings and Oliver's online gaming exemplified the importance of online outlets. Throughout the study, BB frequently referred to posted videos of his ski trips and his musical creations online. When asked why he decided to post his videos, he responded that it was not about others' comments or responses (although he admitted feeling pride in a few videos that received many comments or 'likes'). For BB, this occupation was meaningful because it allowed him to leave his legacy behind and have something online for others to see. His videos were a way of capturing parts of his life, certain moments and experiences, and sharing them with the world in creative ways. Through this venue, he was able to express himself to the world without fear of repercussion or poor social interaction. The videos also served as reminders of positive past experiences. He reflected back on each video with positive regard, which seemed to balance out negative feelings and memories associated with his FEP. His videos were a way of connecting with the world that were not limited by transportation or existing social connections. They were a way of connecting to others that was socially safe and allowed him to feel he had a positive impact on the world.

Oliver's online gaming also offered opportunities for him to participate socially in creative ways. Oliver described his online gaming clan as a very "tight-knit group of friends" that play together frequently:

The thing about the game is that it's kind of an old game so the guys that are on there all know each other and it's just, it's something...I'm not going to say it's a social atmosphere because it's a punch of nerds on the computer shooting at each other but, uh, I want to show you that bunch of trolls and how I interact with them. 
In this quote, Oliver alluded to the social norms that typically view this as a nerdy endeavor that may not fit standards for a typical social exchange. However, he viewed this occupation as social and received social benefits through participation. He acknowledged that most interactions during the game were 'chatter' related to the game with occasional jokes or remarks about one's personal life. However, he stated if he were traveling to an area where another player lived, he would not hesitate to message a clan member and set up a time to get together while he was visiting. Oliver felt a close enough connection to do this, even though they only referred to each other by their screen names. I observed him play online on two separate occasions: once with the old clan and once with a new clan he had recently joined. During the research study, Oliver was 'banned' from his old clan due to interpersonal issues with the group administrator. After he was banned, he temporarily ceased to play, but later rejoined with a new clan. Although he acted as though he was not bothered by his ban and criticized the old clan for allowing too many people to join, his tone and attitude suggested it did bother him in some manner. He was very cynical and negative when discussing the clan after his ban, as compared to earlier conversations in the study when he felt socially connected to it and expressed positive feelings about his involvement. To describe the old clan as such a close knit group of friends and then to act as though it did not bother him when he lost some of these connections through the online banning seemed contradictory. There were several instances in the study when Oliver quickly gave up occupations when he experienced interpersonal issues with others engaged in the shared occupation (e.g., spoken word, online gaming, and part-time employment). Oliver's social participation was further limited after he was banned from this online community. Although it tends to be safer and more predictable, online environments also present opportunities for rejection and alienation.

As with more physical environments, virtual environments are influenced by social norms and expectations. Social media is one source through which social norms and 
expectations are established. For example, Carly shared that she occasionally disconnects from Facebook because she becomes overwhelmed by how positive others' life posts appear. In this manner, social media can be a source of discomfort and discouragement for individuals with a recent psychotic break or a setback in life. It can serve as a painful reminder of the things one is unable to do at the moment. During a lunch with Carly and her friend, she mentioned her recent Facebook post about graduate school and her upcoming move; she bragged that 160 people liked her post. She then mentioned her friend's recent post about his internship and compared their number of 'likes'. Although he joked and responded it was not a competition, she admitted that she still sometimes compares her number of 'likes' to others. In our first interview, Carly reported she did not feel pressured by social expectations to do certain things in her life. Yet, this comparison suggested otherwise. Social norms and expectations for increased independence, progression towards a career, and need for intimate relationships were communicated to Carly through social media. The posts and online comments reminded her of the social expectations for her age group and provided a means for her to constantly compare herself to her peers.

\subsubsection{Adapting Participation Styles at Various Stages of the IIIness}

Due to the ease of access and speed of communication, social media and other forms of virtual participation can be troublesome for someone undergoing an acute psychotic episode. For two of my consultants, their posts to friends with bizarre or paranoid messages and the open display of their illness to others on social media were detrimental to the maintenance of relationships after the psychotic episode. They were embarrassed and lost friendships and connections as a result. Some attempted to apologize and explain their situation with mixed responses from their friends. In addition, a precocious self-disclosure through social media prevented consultants from strategically managing their self-disclosure when they were feeling well. For example, Carly reported that she had sent friends hyperreligious messages through Facebook. Her use of this social medium to express her 
religiosity became problematic such that her mother confiscated her laptop to prevent her sending messages until her symptoms had improved. Once her symptoms improved, Facebook and skype became important outlets for her social participation for Carly:

I feel better when I'm around people. And during my brain injury recovery I was alone a lot. And it was really tough. So I was always on skype. And I made like a fake Facebook so people would email me their skype name so I could talk to people. And my mom thought it was funny because I was always having people in the house, like on my video screen on my computer...I was skyping people and I didn't want to be alone. I have to have these connections... to like feel...like, I have to be around people.

During the study, Carly reported multiple occasions when she watched a basketball game while simultaneously talking to friends about the game on Facebook and Twitter. She emphasized that these online formats helped her maintain social relationships with friends who had moved away and were no longer physically accessible. These online formats also facilitated social participation in shared events (e.g., basketball games) from the comfort of her home. Online formats allow for participation in unpredictable environments from a comfort zone that is familiar. Leo found that blogging and sharing his story virtually helped him to feel more connected and comfortable with social participation after his psychotic episode: "One of the ways l've been interacting with people is through a pen pal website...l've been writing them and emailing them. And that's helped me with my loneliness." For consultants seeking to ease back into social participation after their FEP, online participation offered a safer and predictable mode to establish connections and interact with others in a predictable and familiar 'comfort zone'. Consultants were able to control their level of participation and interaction with others more than during face-to-face interactions.

\subsubsection{Impact of Varied Types of Participation on Belonging}

Although social norms, expectations, and rules for interaction existed in all spaces of consultants' occupational participation, virtual forms of participation encouraged social interaction and fostered a sense of belonging for consultants. Virtual forms of participation 
(e.g., social media, blogging, email) offered opportunities for connection within a social environment when participation in other environments was overwhelming. Oliver, who tended to spend a lot of time online through his gaming, felt a strong sense of belonging to his 'clan'. Although I did not sense the connection as deeply as he described it, it was evident that the gaming community offered him a sense of belonging despite illness. He easily and quickly reengaged with this community after his psychotic episode and hospitalization. It was a comfortable and predictable social environment that provided a familiar form of social participation. Consultants benefited from having alternative avenues of participation available after their FEP where social interaction could occur in a way that was comfortable to the consultant (i.e., 'comfortably distant camaraderie').

\section{6 'Managing' the IIIness}

Managing their mental illness required time and adjustments to daily habits and routines. With their new diagnosis, consultants were required to engage in new occupations that revolved around managing their illness, such as attending doctor's appointments, taking the medications as prescribed, attending court due to legal charges associated with the psychotic episode, ensuring adequate sleep and weight control, repairing damaged social relationships, and recreating the self. The need to manage the disease occasionally prevented participation in other occupations. For instance, although Leo wanted to move to Japan and teach English as a second language, he felt he needed to get his "health in order" prior to moving. Leo deferred some of his life ambitions because he felt he needed to focus on his health. He was caught in a liminal space of learning how to manage his illness.

Throughout the study, Leo's daily routine changed. Initially, he was living with his parents and had established a 7 p.m. bedtime to get ample sleep and avoid restless leg syndrome, a side effect of one of his psychiatric medications. Due to his early bedtime, he was unable to participate in young adult church events that occurred later in the evening, specifically a hangout following Sunday evening services. Later in the study, he shared that 
his routine had changed. He had not been going to sleep before 1-2 a.m. and was on a new medication that made him sleep 10-11 hours. This limited his participation in social occupations in the mornings and prevented his participation in a volunteer organization. In addition to the change in medications that affected his sleep and subsequent ability to participate in social activities in the morning, Leo also had to attend monthly court hearings due to legal charges incurred during his psychotic break. These charges also impacted his social participation and what occupations he decided to pursue after his psychotic break:

I'm not trying to get a job right now because I don't think I would pass the background check. Like there's other things I'm not doing...You know my dream is to live in California and go back to that church and be there again. And I can't do that because I have to be here in court and... also because I'm still trying to get my medicines right. We are still tweaking my meds and my sleep has been an issue.

For most of my consultants, their mental illness had taken priority over other things, including their occupations, at least during the initial period of recovery. Willow affirmed this in a statement about her participation:

I don't participate as much as people normally do...Sometimes I get so stressed out about other things in my life that I...I get so overwhelmed about mental illness that I won't even be thinking about social things. It's not my priority anymore. And I just, like, put friends on the back burner and won't even talk to anyone for like a week.

Willow's comment speaks to the barriers to social participation, which often stemmed from being overwhelmed with the activities required to manage the illness itself. Carly also pointed out that managing her illness was a barrier to returning to social participation and engagement in occupations:

It took me like a year to feel comfortable again...I started going back to my campus ministry events like a couple of months afterwards... But you have to be real slow about it... When you are recovering from psychosis you don't want to be around tons of people because you are still vulnerable and you might say weird things and freak them out...I was able to slowly jump back into things and get back to my social life.

Carly did not trust herself socially after her psychotic episode, which made her feel vulnerable. For Carly, recovery required time to reestablish comfort in social environments. Learning to reengage in occupations during her hospitalization, attending outpatient 
appointments, starting medications, and learning what was required to manage symptoms were important factors that Carly felt helped her participate in social occupations after her psychotic episode. My consultants' insights about the role their illnesses played in their lives is echoed by research from Nagle, Cook, and Polatajko (2002). Nagle et al. found that although individuals with mental illness have diverse and rich occupational histories, their occupational choices become centered on their mental illness and what occupations they feel able to do. The need to manage the illness became a new occupation that required considerable effort, both in time and cognitive energy. The time and energy required for illness management influenced present and future occupations consultants felt able to participate in based on ongoing symptoms and the need for particular habits and routines.

\subsubsection{Fear of Relapse}

The fear of relapse and the fear of disclosure also played important roles in limiting social participation for my consultants. According to Willow, "I think what I choose to participate in and do is mostly kind of governed by like fear of doing bad in things." Whether this was due to cultural expectations for high achievement or related to her self-perception, it influenced the occupations she participated in socially and the communities in which she pursued belonging. Her social engagement was limited to communities she trusted, familiar occupations, and activities in which she felt competent. She struggled with stepping outside of her comfort zone to try new occupations without external encouragement from her teachers or family. Leo also emphasized this need for security in his occupational choices: "I guess l've emphasized safety over growth." He linked his fear of relapse to engagement in a preferred meaningful occupation: learning new languages. During an observation, Leo mentioned that he had been feeling unsettled because he felt he was trying to learn too many languages. He recalled engaging in a similar occupational pattern prior to his first psychotic break when he was attempting to learn three languages at once. His parents had contacted his mental health counselor about this issue: "They worried that my excessive 
studying of the languages was related to worsening symptoms and possible relapse." He acknowledged that he was also worried, but felt better after communicating with a pen pal about his fear. His pen pal reframed the situation and reminded him that he had always had a strong interest in learning languages. Leo seemed surprised by this reinterpretation and affirmed, "This is a part of my personality. I have been learning languages and writing pen pals for 15 years...I love learning about other countries and studying languages." He shared that he was frustrated with having to second-guess himself and worry about whether his actions and the time he spent engaging in meaningful occupations was related to a possible relapse. He also expressed frustration that his engagement in such occupations was being judged in light of his mental illness, which was not the case before his episode. Thus, in addition to the trauma of having a psychotic break, being hospitalized, suffering strained relationships, and coping with many other difficult changes associated with a mental illness diagnosis, Leo was also struggling with feeling judged about his choice of occupational engagement. In his experience, the diagnosis also led to less freedom of engagement; he was now being policed and monitored closer. My consultants felt that the occupations they chose to engage in, how often they performed them, who they performed them with, and how they responded were suddenly being judged in relation to their illness and the fear of relapse. Their illness became part of their participation in all occupations, regardless of their relation to the illness itself. Their fear of relapse, by consultants and their families, precluded a return to social occupations and social participation until consultants felt their symptoms were under control and they felt comfortable with reengagement.

\subsubsection{Impact of Managing the IIIness and Fear of Relapse on Belonging}

Managing the illness became a priority for all consultants immediately following their psychotic episode. The illness presented a change to their life situation and required adjustments of habits, routines, and occupational engagement. To effectively manage the illness requires consideration of social, cultural, and physical factors that may impact a 
person's ability to manage the illness. For example, several consultants noted a 'fear' or concern with returning to certain occupations too quickly as they felt it may lead to a relapse of their illness or worsening of symptoms. Thus, initially they operated within 'comfort zones', which often involved environments focused on their mental illness (outpatient clinics, support groups, pharmacies, etc.). Though managing the illness became an occupation in and of itself and was a necessity for consultants' recovery, the need to manage the illness tended to serve as a hindrance to broader social participation and belonging in groups outside of the mental health treatment realm.

The time needed to manage the illness and the subsequent changes in habits and routines fostered participation and belonging in mental health communities and groups. It is unclear if this was a useful form of belonging for my consultants. Belonging to these groups has potentially negative implications for identity and could lead to the adoption of the 'crazy' identity (Estroff, 1981). Belonging to the 'crazy group' directly hindered feelings of belonging to other groups due to the self-stigma associated with having a mental illness. This served to prevent participation in occupations that would facilitate group belonging outside of the mental health communities.

Earlier I discussed occupational history and prior communities of belonging as beneficial in facilitating social participation after FEP for consultants who felt connected to prior occupations or communities. However, for all consultants, regardless of the prior communities to which they belonged, the need to manage the illness initially interrupted their participation in those occupations and communities. However, feeling a sense of belonging to a group appeared to facilitate a return to social participation as consultants became more adept at managing their illness. 


\subsection{Self-perception and Perceived Occupational Possibilities}

My consultants' self-perception and their perceived ability to participate in occupations were important factors that influenced their social participation. Their perceived occupational opportunities were formed by past experiences (e.g., being turned down for jobs or volunteer opportunities) and assumptions of what they were able to achieve, although those assumptions were often based on societal norms and expectations. Oliver often reflected on his life expectations and his ambition for following the traditional military career path of many of his family members. However, he felt that these opportunities no longer existed for him because of his poor GPA in college coupled with his diagnosis and hospitalization:

With my diagnosis it's harder for me to find opportunities here so I also have to, uh, sort of plan to leave the country or something, you know, because working at a University in Hungary for a couple of years will give me opportunities I wouldn't be able to get state side because my GPA dropped off so horrendously halfway through my time at school... In the position I'm in, because I want to apply myself to humanities in a meaningful way and get a good job in government or something then l'd have to go the extra mile.

Oliver had made assumptions about what opportunities were available to him and the drastic measures he needed to pursue to seize them (e.g., pursuing work overseas). He felt he needed to work harder to compensate for his illness and GPA, which implied an awareness of the stigma related to his illness. Oliver's assumptions about what he perceived possible for someone with a mental illness were shaped by discourses in the news and other media. This impacted his actions and social participation. By adopting the label of mental illness, consultants were embracing social assumptions and perceiving fewer opportunities for participation. Oliver felt he needed to achieve certain life accomplishments before he could apply to do other things:

I have a conception in my mind of how much I have to do before I'm eligible to become a father...I think that service in the military would really make it possible for me to not only be responsible for life and to understand that responsibility... Once I've had some sort of experience like that I feel like I would be uh...acceptable material to become a father. 
In his current life situation, he felt being a father was not suitable for him. He felt he had to work extra hard to achieve the level of participation in society he had envisioned for himself. His assessment was informed by limitations in his environment (e.g. family situation, socioeconomic status) and by his self-perception.

Leo was also limited by his own self-perception. During an observation, he received an email from a translation service inquiring about his interest and ability to translate for their company. He emailed them back and said he did not speak the language with enough fluency and would likely not be able to help them. He was excited that they expressed interest in him, but lacked the confidence needed to seize the opportunity for employment. He shared that one of his dream jobs had been to be a translator, but he did not know if it would happen. Later, he admitted that he regretted sending the email that downplayed his abilities. When asked why he had sent that email he responded that he was scared that he might fail. Leo had significant self-doubt about his ability to work in a full-time job, to be a good husband, and to be a father due to his low energy and ongoing symptoms. Although opportunities presented themselves to him (i.e., the translation job), Leo lacked the confidence in his ability to successfully pursue those opportunities, which further contributed to his feelings of inadequacy and being stuck in his current situation.

\subsubsection{Impact of Self-perception and Perceived Occupational Possibilities on Belonging}

Consultants tended to have diminished self-perception and feel less confident about themselves and their abilities after their FEP. This was likely due to stigma and the social norms and expectations regarding mental illness that are prevalent in societal discourse. Changes in consultants' self-perception and self-content impacted their perception of occupational possibilities in their communities. In general, self-perception and perceived occupational possibilities was found to be a barrier to social participation. However, Carly and Willow tended to reengage in social occupations faster than others and had a more 
positive outlook about their future possibilities than other consultants. This is possibly due to their ability to reconnect to prior occupations and prior relationships, which fostered a sense of belonging. As stated in the introduction to this chapter, Maslow's (1943) hierarchy of needs identified belonging as vital for self-esteem and self-actualization. Without belonging, positive self-perception and the ability to imagine new possibilities for self-actualization are limited.

\subsection{Summary of Findings}

This study identified seven factors that impacted the social participation of consultants after their FEP: 1) social norms and expectations; 2) a sense of responsibility to others; 3) consultants' occupational histories and prior routines and relationships; 4) change in physical and social environment; 5) the types of participation available; 6) the need to manage the illness; and 7) consultants' self-perception and perceived occupational possibilities. These factors transact in complex ways to impact social participation and belonging for individuals with FEP. Examining the relationship between these factors provided new insights into how individuals pursue avenues for belonging and use occupations to promote recovery and reengagement after FEP.

Factors were both supports and hindrances to participation. Social norms and age expectations and sense of responsibility to others served as motivators and supports to social participation. Managing the illness as an occupation and self-perception related to perceived occupational possibilities tended to serve as hindrances to social participation. Occupational history and prior routines, changes in the physical and social environment, and types of participation served as supports to social participation at times, but depending on other contextual factors or state of the illness itself, these equally served as barriers to participation. All factors were linked to participants' experiences of belonging via participation in occupation. This was an important factor in their recovery, health, and wellbeing. 


\section{CHAPTER 5: OCCUPATION AS MEDIUM FOR IDENTITY WORK}

For study consultants, identity was a fundamental factor impacting most areas of social participation. Analyses generated themes that supported existing research on the importance of identity work and the need to consider social factors in shaping and positioning certain identities. This study highlighted how social identities are crafted and integrated by consultants. The themes discussed below demonstrate how people with FEP understand and use occupation as a mode for identity construction and to facilitate social participation.

\subsection{Hospitalization Experience as Initial Identity Construction Period: "Feeling like a Waste to Our Society"}

The internalization of mental illness into the self as an identity happened very quickly for study consultants after their first episode of psychosis. Four out of five consultants implied that this process began during their first hospitalization period. Carly reported, "I go there and I was there for like 2 weeks...And like, before I left the hospital I knew something was like not right with me." The hospital environment is an example of Holland et al.'s (1998) figured world, where a specific language is used, specific characters function with preset roles and assumed behaviors (e.g., psychiatrist, therapist, patient), and strict rules exist for governing behaviors. According to Davidson (2007), institutions and institutional habits serve a role in creating the chronicity of mental illness. Likewise, this study found that during consultants' initial hospitalization, the identity of mental illness was already forming, or had already formed. Individuals admitted to the hospital were positioned into an identity of the 'mentally ill patient' through their interaction with other patients and hospital staff. During interviews and observations, Oliver spoke at length about his hospitalization experience and 
the toll it took on his self-perception and subsequent engagement in occupations. When discussing a poem that he wrote directly after his discharge from the hospital, Oliver reported:

The fourth poem I'm going to give you is the poem in which I sort of came to terms with what happened to me while I was at the facility. And it kind of expresses my um, my feelings of isolation. My feelings of wretchedness...I hate walking around feeling like, uh..just feeling like a waste to our society...The thing is that when you find yourself on a psych ward or you find yourself uh..becoming isolated from the things you once loved... Having people look at me like l'm crazy. I thought there was more dignity in killing myself than being treated, not like an animal, but like a crazy animal. No mental health professional is going to let a psych ward suicide walk out without a scarlet letter. I don't spend a day wishing that I hadn't spent those two weeks in jail where no one would drug you or speak to you like you're a child... I feel like if you take people out of their appropriate context and put them in a place like where I was, then labels can get attached to you that shouldn't be attached to you... And I didn't like the way that, the way in which I talked, the way in which I explained myself was picked apart the way it was...I mean I don't think I'm crazy personally. But there are plenty of crazy people that say that, so, it's anyone's guess.

Oliver was referring to the tacit habits and identities that operated within the hospital context, many of which he involuntarily absorbed prior to his discharge. Institutional habits included daily discussions between staff and patients to ascertain delusional states and analyze their speech patterns, the removal of objects and personal items due to safety concerns, suicide precautions (e.g., 15 minute room checks, limitations in activity involvement), and the shepherding of patients to and from various locations during scheduled events. These institutional habits helped to solidify the identity of 'mentally ill patient'.

This identity was further reinforced in broader social arenas by follow-up outpatient appointments, medication renewals, and other habits and occupations required to manage the illness. For example, Leo reported, "I feel like everything has changed since I went to the hospital...Because I got arrested and I have to be in court every month, there's this ongoing story of my mental illness that I have to report every month." Carly also acknowledged the role outpatient care and other illness management occupations had on habit and identity adoption: 
I had been psychotic. They didn't tell me the word psychosis until outpatient. I would ask questions on Facebook support groups. I mean like, I would go to my appointments. Go to your appointments I would say 'cause that really helps...And take your medicine obviously. Because like, if I miss a dose of something, I notice..You just follow what you are supposed to do.

Through her monthly outpatient appointments and medication renewals, Carly came to understand her mental illness identity on a deeper level. While she offered her comments as advice on how to stay well, her comments also alluded to the habits and identities she had developed through management of her illness.

Willow did not echo the trauma about her hospitalization. Through her hospitalization experience, her understanding about mental illness changed:

I didn't really want to interact with other people because I thought they weren't really like on the same level as me. But then when I was in the hospital I kind of realized that like..you can't really measure people like quantitatively...Even qualitatively...Because I met some people who were like, some of the other patients, and they were like really interesting people to be around and really good people in general and I can appreciate their struggles and stuff...There was one woman...She was very like, very crazy seeming at first. And like, I thought that she was like, like not a real person almost. I viewed her as not being a real person at all...But then when she was on medication and receiving treatment, she was a really nice person to be around...And really understandable once you knew her story.

Willow's quote highlighted the role of the hospitalization experience in facilitating a shared culture of mental illness. Willow felt a sense of connection and shared understanding through her interactions and shared environment of the hospital setting. The shared environments and occupations that constitute the figured world of the hospital generated a shared experience between Willow and the other patients. She began to identify with them and found commonalities through their shared experiences. During our interviews, she did not differentiate between herself and other patients; instead, she identified herself as part of the mentally ill community. Once discharged from the hospital, few of the study consultants interacted with peers from the hospital; however, four of the five consultants shared stories about others they met in the hospital and mentioned the impact those interactions had on their lives and how they view themselves. Oliver's interactions with another patient 
encouraged reengagement in occupations after discharge, specifically those needed to manage his illness effectively:

He's kind of a sad guy...I mean, he's had two stays on the ward. I don't ever. I...I have a lot invested in never going back, back to a place like that. However, that also requires, uh...exertion. You have to be, uh, vigilant with your health in order to avoid being in places like that.

While consultants' hospitalizations were brief, their experiences in that figured world had a significant impact on how they adopted stigmatized identities and how quickly they were able to reengage in social occupations. Their reengagement often began with occupations needed to manage their illness, which included attending follow-up outpatient therapy, obtaining medication refills from the pharmacy, participating in support groups, and maintaining proper sleep hygiene. While treatment providers often attribute poor social outcomes (e.g., social isolation, withdrawal, and the inability to interact appropriately with others) to behaviors associated with having a mental illness, this study suggests that those social outcomes are related to the positional identities forced upon individuals as they enter the figured world of the mental health system. Viewing the hospital as a figured world where patients are positioned into identities of 'mentally ill' could be important in interventions to address the issues of self-stigma and the adoption of a marginalized identity.

\subsection{Emotional Link with Identity}

There was a significant emotional component regarding how the consultants viewed themselves and their actions during and following the first episode of psychosis. Consultants identified feelings of guilt, shame, and grief as three primary emotions impacting their personal identity and social participation. Oliver felt significant shame and guilt about his life and his accomplishments after his first episode of psychosis:

It makes me very ashamed that I had ancestors that did great things while I'm living my day to day life like a douchebag...I feel guilty about my ancestry. I feel guilty about my drug habit. I feel guilty about my family...I also feel guilty about my self and the way my day to day routine is. What kind of gentleman smokes as much pot as I do for one. Um, is content with such medial things...I think that if I had applied myself a bit more earlier in life I could be, hopes for the long-term, I could be the someone 
where I won't feel guilty about myself anymore. Right now it's looking a little uhh...murky...When you look at yourself in the mirror and you think about where you're from and the people that compose you..I don't know. I work at a gas station and...I want greater things than this.

Much of Oliver's shame and guilt appeared to stem from the societal norms and cultural expectations about what a male adult his age should be doing and was supposed to have accomplished at his stage in life. Oliver also felt shame for how he spent his time and the occupations he chose to pursue in his daily routine. Oliver had formulated his expectations based on past family experiences, the history of his ancestry, and broad societal expectations. According to Brown (2006), shame is a psycho-social-cultural construct that is most often experienced as "a web of layered, conflicting, and competing expectations that are, at the core, products of rigid socio-cultural expectations" (p. 46). These sociocultural expectations, often adopted via media, advertising, and other social discourses, were narrow interpretations of how particular individuals were supposed to act, based on their prescribed identities and roles. When a person does not fit into these prescribed roles or behaves in a manner contrary to what the person feels society expects, shame is experienced (Brown, 2006). This concept is similar to Rudman's (2010) notion of occupational possibilities wherein individuals who do not engage in age-expected occupations may experience guilt and shame as a result. Oliver's engagement in occupations of substance use coupled with lack of engagement in productive occupations fostered the emotions of shame and guilt. These feelings intensified when he considered his ancestry, history, and social expectations of what a man his age should do. more:

Willow, however, identified shame as something she felt she should experience

I know there is this societal stigma and I get a lot of shit about it if somebody finds out. But it's not like, because I have an understanding of it, I'm not stigmatizing myself. So I'm not like ashamed about it. I wish I was more ashamed about it almost because other people view it so badly because they don't know the same thing about it or they just aren't paying attention in psych class [laugh]. But they have very bad reactions to me when I am too open about it, but I still, like I'm not, I always am too open about it even so just because I'm not ashamed of it in my head. 
Willow felt more confident in her identity because she was aware of societal perceptions of her illness, had educated herself about it, and could predict social responses and identify ways to address them. She had taken an abnormal psychology class and talked about reading her psychology book and attending treatments to learn about her illness. In this way, she was able to take some ownership of the identity, although she continued to feel pressure from social interactions to feel a certain way about her illness. Though Willow claimed that she did not feel shame over her illness, when a peer questioned her about my presence at one of her LGBTQI events, she was hesitant to talk about her illness. When her peer asked whether he could participate in the study, she stalled and responded he might not fit the study criteria. When he asked for the criteria, Willow hesitated long enough for her peer to realize she did not want to discuss the study. She did not mention the incident further in our discussions. There were likely many factors at play, including the open forum and social nature of the event, the status of her relationship and history with this peer (i.e., they did not appear close), and possibly the surprise element of her not expecting to disclose her illness to this person at this time. This is a good example of how the identity of mental illness can insert itself or be evoked unexpectedly during any occupations. It is ever present and a consistent threat. Willow's resistance to shame fits with Brown's (2006) shame resilience theory. According to the theory, concerns related to shame are associated with feelings of being trapped, powerless, and isolated. When a person feels connected with others, receives empathy in response to their shame experience, and feels they have a choice and possibilities for change in their lives, they are able to reduce their shame and their power to effect change increases (Brown, 2006). Willow's experience and persistence with occupational engagement facilitated her resilience. She was connected to multiple college organizations, benefited from significant family support, served as a key leader in a supportive, open-minded and inviting college organization, and enjoyed many possibilities in 
planning for life after college. She used these connections and this power to overcome the feelings of shame she felt others expected her to feel.

Grief was another emotion experienced by study consultants, particularly Leo who initiated a discussion about grief several times during our observations and interviews. He once asked me, "Have you taken into account the grief process?" He explained that he felt he was just beginning to grieve over the loss of his former self following his psychotic episode and hospitalization:

What happened was when I was diagnosed with bipolar disorder and I got labeled mentally ill, my parents spent the next few years like telling me I was mentally ill and pushing it into me. And I refused to believe it. I knew I had bipolar disorder and I took my medicine. But like my mom would leave out Bipolar Magazine for me to read. And she wanted me to like own this disease and like take it on. She would say, "You are mentally ill." And I'm like I didn't want that identity. Because I wanted to be this superstar that I had been in high school. And I wanted to be excellent. And I wanted to be successful. And I wanted to be this person that was like loved and accepted.

He stated that the first few months after his hospitalization, he was in a fog from the medication and stayed in bed for extended periods of time. At the time of the study, he was beginning to realize the impact the diagnosis had on his life and was grieving. Leo's initial perspective of the illness was one of complete negativity, in part because it differed from how he viewed himself based on past experiences and accomplishments. He viewed himself as capable, loved, and successful and associated mental illness with the opposite of those traits. Leo lacked insight into the illness itself, as well as what possibilities could still be imagined despite having a mental illness. There seemed to be a difference between having insight into one's illness and owning the identity. Notwithstanding his parent's efforts to try to increase his insight so he could manage his illness more effectively, Leo felt no sense of relief or control. Indeed, those efforts seemed to further isolate and frustrate him, facilitating a sense of ineptness and failure in his current situation. Leo specifically discussed the impact his diagnosis had on his relationships with others, his comfort in social settings where his illness could be disclosed, his daily participation, his perception of what 
he felt capable of doing (e.g., volunteer, take care of his dog), and his self-image and identity.

Throughout the study, Leo felt a pull between his 'old self' and his new self as a person with mental illness:

I'm trying to create a new story. Trying to create a new identity but the past, you know, your past is where you come from. You can't really escape your past...So I have to figure out how to cope with my past and how to be a new person that's not psychotic. That doesn't need to go to the hospital or be arrested. While still being the person that was that person...So sort of writing a new story about my life, while holding on to my old story, but my old story is following me around. And I have to, I'm trying to create a new identity but I can't just like dissociate and create a new personality that none of this stuff happened to.

Leo's grief and struggle over the loss of who he expected to be and how he viewed himself, while trying to integrate this into a new identity was best epitomized in his discussion of his bible. Leo is a religious person and was involved in many churches and bible study groups during the initial part of the study. His religious views were also deeply embedded in his experiences of psychosis, delusions about the end of the world, and what he felt God wanted him to do. During one of our interviews he brought his bible with him and talked openly about his internal struggle between disposing of his old bible and using a new bible:

I have my old bible here and I wrote a bunch of stuff in it and I was going to throw it away. I bought a new bible today. I've had this bible for a really long time and I write stuff in it and underline stuff. And I was just going to throw it away. I decided to keep it at the last minute... Because it's got so much of myself in it. I wrote all this weird stuff all over it, like stuff how I was angry at God, angry at my dad, angry at my parents. I was going to throw it away because I was just going to forget it. Just going to forget my...who I used to be.

Leo's bible was a perfect metaphor for the emotional struggle inherent to his identity work. Identities are ever-changing and constantly in flux, yet there is a foundational sense of 'I am this person' (Holland et al., 1998). Although the foundational sense of self is a conglomeration of many identities adopted throughout the lifespan, for study consultants, the experience of FEP seemed to shift this sense of self significantly. After a psychotic episode, consultants were positioned into an identity of the 'mentally ill person'. Consultants 
perceived that they were no longer the same person, though not many other aspects of the self had changed.

Emotions of shame, guilt, and grief and the level at which they impacted the lives of consultants varied significantly. Consultants who experienced significant trauma due to their psychotic episode and hospitalization seemed to experience more shame, guilt, and grief than those with positive hospitalization experiences. The implication this had for identity formation related to the mental illness identity was unclear. However, it is a useful consideration when attempting to understand stigma and self-stigma including how recovery is impacted after the psychotic episode.

Pride was another emotion consultants mentioned, however they did not internalize this emotion as they did with the other emotions, which limited the benefit this emotion had on reshaping their identity. For example, when reflecting on his experiences in court, Leo mentioned the conflicting nature of the pride others expressed in his progress and the ongoing shame he felt:

They are really proud of me and the work I am doing. So it's encouraging to go to court. It's not a negative experience when I'm there. But having to tell people I'm going and remembering being arrested and the shame that comes from that. I get reminded of that constantly. And I feel like I'm stuck in this place where that story is still my story.

Although Leo noted the pride others felt in him and his progress, it was overshadowed by the shame he felt in himself and his actions. Though pride is useful to build confidence and self-esteem, Leo did not internalize the pride expressed by his family and it did not shift his perspective about his illness. Though others felt he was working to manage his illness through his daily occupations, Leo did not feel pride through participation in occupations for managing his illness; they contributed to his shame about his illness. 


\subsection{Power to Define Oneself}

Many authors have discussed the importance of feeling a sense of power and ownership over one's identity. However, for individuals with mental illness, this power is constrained by the social and cultural contexts (Lachicotte, 2002; Thoits, 2011; Valentine \& Sporton, 2009). Oliver clearly articulated this theme:

I mean I'm not going to let something like that define me. The things that define me are, uh, the pride I have in my ancestry... and the things that I want to accomplish in my life are what I think should define me. I don't think I should be defined by anything except my actions. The actions of others, what they say, what they think or do have nothing to do with how I'm getting along... It doesn't phase me that I have a label attached to me. It's only attached to me if I make it attached to me.

Oliver's comment hinted at the shared identity of the 'mentally ill' person and how he was being positioned as a result of his diagnosis. When speaking of the actions of others, he was referring to the cycle of news and violence on the media that is often associated with individuals with a mental illness. Although it is naïve to believe that those events and existing stigma do not affect him and his participation in life, Oliver was attempting to regain a sense of control over how he was defined. He identified his ancestry and family as important for forming his identity despite his positional social identity as a 'mentally ill person'. When asked how others could experience a similar feeling of ownership and power to define themselves, Oliver responded, "I hope they have a friend or someone near them that can tell them that they don't have to let that define them, definition or selfdefinition...You're the only one with the power to do that." Other study consultants did not explicitly use the term 'defining', however, they each shared ways that they have worked to define who they are and how they own their identity. For most consultants, the power to define oneself stemmed from their engagement in chosen occupations. Carly spoke about the power of her occupations to help her feel like a real person again:

Like I just worked on myself. I took piano lessons. I played a lot of piano and violin. And that was my minor. It's funny, like the thing I studied in college directly relates to who I am. Psychology, which I'm obsessed with and I'm really interested in mental health, which I want to do for a career...I went to lessons once a week after my 
psychotic break. So it just like helped me feel like a person again and get back into my music interests.

Carly used her prior occupations and her new knowledge of the mental health system to imagine possibilities for a career in mental health. Oliver also identified occupation as a strategy for defining himself: "At the time, hip hop was pretty big to me. It was what I was doing. However, now I don't necessarily think that that's a good representation of my true self... I would rather be defined without words." Oliver distinguished between occupations that fit his conceptualization of self and those that did not. Choosing and participating in occupations that fit with consultants' perceptions of who they were and wanted to be was a powerful factor in consultants' identity work.

The ability to imagine alternative identities was another influence on consultants' identity work. Oliver spoke extensively about wanting to join the military like his grandfather and prove himself as a "real man". Through this occupational endeavor, he could redefine himself and begin to view himself in the way he wanted others to view him, as a capable person able to overcome challenge through hard work and grit. Although Oliver had not yet enrolled in the military, he was able to imagine this alternative life for himself. Imagination was one way in which consultants could assume the power to define themselves.

BB exercised the power to define himself by directly opposing social forces positioning his identity. He reported, "I feel like people are trying to put me in a box but I can still, I still try to get out of it a lot." He explained, "By putting me on medication and saying I have to do certain stuff. I can't do what I used to do. I can't hang out with this person”. When asked how he tries to escape from this 'box', he said, "I go hang out with those people anyways...Sometimes I don't take my meds or something." While not a recommended course of action when trying to manage an illness, BB used these actions to feel ownership and control of his identity and life again. He refused to stop participating in certain occupations (and at times, refused to participate in occupations needed to manage the 
illness), which made him feel a sense of control over his own life and his social participation. According to Thoits (2011), this 'challenging' is one type of resistance used by individuals positioned into the stigmatized identity of mental illness. Since BB interpreted his new diagnosis and the restrictions associated with this identity to be a harmful force to his participation in social occupations, he directly challenged those forces through his actions and participation in certain occupations.

\subsection{Role of Media in Integrating Illness Identity}

Media plays a prominent role in shaping identity and spreading social norms and expectations for behavior that impact occupational possibilities (Laliberte Rudman, 2010). According to Asaba and Jackson (2011), the media serves as the voice of the 'other' who generates shared ideas of social roles and positional identities that affect how people come to view themselves. The power of the media in shaping identity and occupational experiences came to light throughout this study. During one of our observations, Leo and I went to see a movie. Prior to the screening, a preview for a new Terminator movie aired. At this time, Leo leaned over to me and said that during his psychotic episode he thought he was John Connor (the protagonist of the film) and had studied survival skills on the internet in order to save a friend from the end of the world. I was struck by the contrast in our experiences: I was enjoying the preview and thinking that it would be a good movie while Leo was reliving his psychotic episode and the struggle he experienced at that time. His participation in this occupation reminded him of a time when he lived a reality and an identity that he later discovered was a delusion resulting from his psychotic episode. Leo often mentioned the media when describing his self-perception and his life expectations. He struggled with merging the portrayals of a 'mentally ill life' offered by the media with his own experiences. During an interview, he described one particular moment with a friend when he realized the discrepancy between real life and media depictions of life: 
I wanted to be popular and confident and loved. And I found out, like she had all this pain and stuff and she was going through all this hardship just like everybody else the more I got to know her. And so I lost my belief that there's this special elite class of people that has this beautiful life full of success and joy, singing and dancing about their life like on a Disney movie. Everything works out and you are popular and cool. But it's just like the dream just refuses to die in my heart...Part of me is afraid that there's this other part of me that's like rebellious and just doesn't want to be restrained. And wants to be like this superhero. And this part of me comes out when I watch Disney movies.

The movies Leo watched shaped his current views about himself, how he wanted to structure his life, and his expectations of reality. After face-to-face social interactions with others in his social environment, he realized that life is not always as it is portrayed in movies and in the media. Despite seeing this in real life, he still had aspirations of being popular, accepted, and a 'hero' as depicted in the movies. He continued to be caught in that liminal space of identity work where he had difficulty reconciling his perceptions of past, present, and future selves. Though he could imagine the person he wanted to be (often based on media depictions of the 'popular, heroic man'), he struggled with finding pathways to achieve this life that he believed was feasible.

Oliver also identified the media as an important factor in how others viewed him and how he interacted with peers at work:

Like on our day to day news cycle, whenever one of these horrifying news shootings happened, it's always someone that they say had a psychotic break. And I hate walking around feeling like, I don't know, like a waste of our society...I can't help but take it personally... The only thing that like bothers me is kind of feeling like a boogeyman for lack of a better word. Like when you're hanging out with people at work and you are wondering to yourself 'oh is this one of those psychotic guys'. You know what I mean. So I don't really talk about that with anyone at work.

For Oliver, media reports about violent events committed by 'psychotic' individuals impacted how he assumed the illness identity. Although he never had a violent outburst related to his psychosis, he assumed that others would presume he was violent based on frequent media accounts portraying people with mental illness as violent. It shaped what identities he felt able to share with his coworkers, as well as how much of his life he was willing to disclose. 
This impacted his participation in certain occupations and his ability to establish intimate relationships with others:

I kind of gave up on participating in spoken word... I felt pretty wretched after my experience [in the hospital] because I, I mean every time I mention it, I feel like I've got a scarlet letter on me...And at first when I was in a large social setting with a bunch of different people that I hadn't seen since before my episode happened, I just didn't bring it up at all. I just sat there. It was terrible. I felt so vulnerable.

Oliver's understanding of the mentally ill identity, shaped by media depictions, influenced his reengagement in prior occupations and the areas of occupation he felt comfortable participating in socially.

\subsection{Identity Work: Drawing Intra-group Distinctions}

In framing their identities, consultants also drew clear distinctions between their diagnoses and other mental health diagnoses. Oliver was quick and direct in explaining that he was not diagnosed with schizophrenia, but instead, a psychotic disorder. He said, “I haven't told that many people that I'm a diagnosed psychotic." He did not describe the difference he perceived between the two diagnoses; however, this was the term he preferred to use to describe his illness. He also emphasized this distinction later in the study to distance himself from other individuals he encountered in the hospital:

He's kind of a sad guy. He's a schizophrenia diagnosis. When he was there on the ward he was seeing lights and stuff. He was a philosophy major and he's a janitor at a hospital now...I wouldn't want him to think I pity him because...I mean, he's had two stays on the ward though.

Oliver distinguished himself from others based on diagnosis and the frequency of hospitalizations, which he considered an indication of chronicity and greater impairment. Oliver used language and categorization as a strategy for identity work. Leo engaged in identity work by emphasizing his diagnoses of bipolar disorder and dissociative disorder while minimizing his diagnosis of schizoaffective disorder. Indeed, he framed his experiences with these labels and terminology:

I've been diagnosed with bipolar disorder since high school. But when I learned about the New World Order I kind of lost interest in almost everything. And I started 
trying to convince everybody of the New World Order. And studying it all the time online and making connections...So just seeing more and more about the New World Order and learning more about it until I didn't talk about anything else...When I learned about it I just lost my faith in our country and the world. And I got really depressed and I was trying to change it. Trying to fight against it using this knowledge. Trying to tell other people about it. I just didn't want to be alone anymore with the information I had.

Leo mentioned his psychotic episode a few times during the study; however, when he discussed the episode, he described it in terms of the occupations he was participating in at the time, such as learning and preaching to others about the New World Order and traveling the world looking for God to heal him from his bipolar disorder. He did not refer to his psychosis as something he needed to continue to manage, rather it was an experience triggered by new knowledge and new occupations surrounding the New World Order. In other words, his symptoms and FEP stemmed from the occupations he engaged in and the knowledge he learned; this allowed him to initially avoid incorporating the illness as part of his identity. Thinking of his FEP in this way helped him to reframe the experience in a less stigmatizing way. Leo did not hesitate to refer to his bipolar disorder frequently and openly during our observations and his interactions with others. His distinction between those diagnostic labels appeared to be a strategy for negotiating how they were impacting his life and his occupational possibilities. This strategy was a form of identity work wherein he could reframe his psychotic episode in a less negative way (i.e., not related to a personal deficit, but related to his learning of a concerning world matter and responding to this knowledge), while still adopting a mental illness identity that was less stigmatizing for him.

Carly was adamant about asserting a distinction between her diagnosis and others:

I think maybe his illness is different from mine. His might be chronic and it's more of a problem and he's still dealing with the symptoms. I don't deal with the symptoms anymore because my medications work...But if you are having a chronic problem, then maybe it would help them understand you.

She separated herself by suggesting that she had a different illness, distinguishing between her acute episode and her peer's chronic impairment while emphasizing the remission of her 
symptoms. Throughout the study, Carly also stressed that the cause of her illness was different. She had a brain cyst and experienced a traumatic brain injury and post-traumatic stress disorder (PTSD) following her brain surgery. Within this time period she also experienced a brief psychotic episode. Carly felt that because her psychosis was related to an underlying physical health issue, her psychosis was different. Because of its link with a physical ailment, the psychosis did not imply something was wrong with her mental state; rather, it was a temporary side effect to an intervention to treat another physical health issue. She did not suffer from the same stigmatized identity of mental illness as other study consultants. This allowed her greater freedom to openly share her illness experience with others. Perhaps this facilitated how quickly she reengaged in meaningful occupations after her hospitalization. She did not assume the same stigmatized identity of mental illness as other consultants, although it was apparent in observations and interactions with friends that she still did not speak openly about the psychosis itself.

The distinctions consultants drew between their illness and others' mental illnesses was a manifestation of the societal stigma attached to mental illness, specifically schizophrenia. There seemed to be less stigma associated with psychosis when the episode's root cause was an environmental factor or part of another physical disease (i.e., ongoing substance use as in the case for BB, Willow, and Oliver, or had an underlying medical condition, such as Carly). When the psychosis was viewed as an innate biological characteristic where the person is said to be innately 'crazy' and fundamentally 'flawed', regardless of their environment, the psychosis was more stigmatizing. It was apparent throughout the study that the societal stigma consultants associated with certain mental illnesses had been incorporated into their perspectives and actions. Consultants developed and voiced narratives that attempted to define their identities in positive ways to allow them to continue participating in their lives. 


\subsection{Intersectionality of Identities}

While consultants spoke extensively about their illness experiences, additional identities were also expressed throughout the study. The notion of intersecting identities arose from an observation with Willow where we attended a Laverne Cox speech; Cox talked about the intersection of her identities as a transgender, black woman, daughter, and actress that made up her person. After the observation, Willow stated, "I would say definitely obviously being female would be an identity for me. And like, obviously, the one that comes across the most is that I am female and cisgender as far as everyone knows." As I examined this quote further, the word 'obvious' and phrase 'as far as everyone knows' stuck out to me. These words highlighted both the visibility and invisibility of identities, specifically the intersection and interplay between identities. It underscored the idea that some identities are more salient and visible to others:

I think being a bi-sexual person is a thing that a lot of people who know me know just because I do a lot of the photocampaigns in relation to that. And I do participate in the [organization's] stuff. People see me going into the [organization] office.

Willow's female, cisgender, and bi-sexual identities were visible based on her participation in certain chosen social occupations. Willow did not mention her mental illness when asked about her identity. Her participation in campus organizations, campaigns, and occupations centered on other identities, not her mental illness identity. Her identities affected her participation in social occupations and those occupations helped to form and sustain her identities. Willow acknowledged her diagnosis though did not pursue occupations related to this identity; however, occupations inherent to the need to manage the illness structured her day and influenced her ability to pursue occupations related to her other identities.

The intersection of identities through occupation was also evident with Leo. Referring to his love for learning languages and writing pen pals all over the world, Leo self-identified as a "charismatic Christian" and "an international person with international friends". These identities were challenged after his psychotic episode because his psychosis involved 
studying multiple languages at one time in preparation for changing world events (e.g., New World Order). When he began expressing greater interest in learning languages again, his parents and counselor questioned whether he was heading for a relapse. Leo shared his frustration with having to question himself and worry about how his other identities and associated occupations were framed in relation to his identity as a mentally ill person: "This is a part of my personality. I have been learning languages and writing pen pals for over 15 years." Since his psychotic episode, his previous identities of Christian and language academic changed due to the mental illness identity. Indeed, his other identities became part of the narrative of his illness and were reframed in relation to his mental illness. As a result, Leo has had to negotiate how his identities influence one another in his life:

From church to church where l've gone, people have always found reasons to reject me. And I think it has to do with my mental illness...So now l've started to wear the identity of the mental illness on my sleeve a little bit. To try to find like, to make peace with it, you know.

Throughout the study, Leo struggled with how to integrate his illness identity while reengaging in social occupations. His engagement in social occupations changed throughout the study, possibly in an effort to functionally coordinate his intersecting identities. Initially, he was attending several bible study groups and churches for worship, which seemed to fit with his Christian identity. Subsequently, he began volunteering with an organization that served individuals with intellectual disabilities. Leo's occupational participation in that organization fulfilled his need for acceptance and belonging. Later in the study, Leo became more involved with Al Anon, which served as more of a support group. Al Anon is a faith-based group, but they were not as religiously oriented as the churches he had previously attended. Though not explicitly stated, I questioned whether Leo's occupational choices centered on his need to integrate the illness identity amongst his other identities. 
In this study, it was apparent that it is impossible to examine a singular identity. Identities mesh together and influence each other to impact thoughts, behavior, and social participation (Holland et al., 1998). While mental illness positions individuals into an identity, this identity intersects with other identities to produce variable outcomes. Socioeconomic status, age, race, and other social factors must be examined as these factors evoke identities that intersect with one another and push individuals towards particular outcomes (Laliberte Rudman, 2002; Read \& Eagle, 2014). Thus, occupational possibilities are further impacted depending on the intersection of identities operating through the individual. This concept was most prevalent in Oliver's situation. As a second generation immigrant, Oliver identified himself as half Puerto Rican and half white. He stated his family grew up "dirt poor" and he felt pride in his father's ability to go from being poor to having a college degree and serving in the military. Oliver frequently transitioned our discussions to his family and ancestry, which seemed to be an important and influential identity impacting his life and social participation. His family identity influenced his occupational choices and plans for his future:

I've always known that I'm going to end up in the military in some regard...I think that I would find a lot of meaning in being a part of the military...Well, I, I think that's what I'm craving. I talked to the Marine recruitment officer. I really wanted to be amongst them. I was actually in ROTC for a little bit when I was in college but I was uh...I should have just gone to on campus counseling or something at the time because that would have done a lot of good for me, instead of, uh, trying to hold out on my own.

In this comment, Oliver described how his mental illness influenced his occupational possibilities. Although he envisioned a military career, his psychotic episode impacted his ability to commit to the ROTC or Army. Later in the interview, Oliver contradicted these goals and stated: "I don't identify with liberal democracy at all...That definitely influenced my decisions to not commit to the Army and ROTC because I would rather be in a place like occupy [referring to Occupy wall street] with all of those grand, gigantic fuckups where I belong." Oliver often contradicted himself in the interviews when discussing how he 
envisioned his life. This seemed to be related to his own internal struggle with identifying possible occupational pathways following his psychotic episode. While Oliver recognized his illness identity as something he had to negotiate into his daily life, he still had many other intersecting identities that factored into his social participation and shaped his occupational choices. Particularly, his socioeconomic status, family, ethnicity, and political orientation evoked different identities that operated together to impact his participation and life outcomes. Oliver attempted to negotiate his multiple identities through the occupations he chose to participate in socially. Similarly, Willow's engagement in LGBTQI events and campaigns allowed her bisexual and cisgender identities to become more salient than her mental illness identity. Leo's occupations also shifted as he worked to combine various identities in a functional way. In this study, occupation was a mode through which consultants worked to merge various identities and undergo identity work towards increased social participation.

\subsection{Positive Factors of Adopting the 'Mentally III' Identity}

Mental illness is typically not considered a positive occurrence. The illness is often associated with a negative and stigmatized identity. However, several of my consultants were able to identify positive outcomes from experiencing the illness. Willow found that her participation and social interaction improved after her hospitalization:

I actually think that after the diagnosis my participation has gotten a lot better. Like after being treated for it, I did some sort of like almost cognitive behavioral therapy with myself. Where I made myself, if I see someone that I know I will say hi to them, which I didn't do before... Like I now check to see if there are people in like a radius of me when I'm walking through a door in case I do need to open the door for someone. Which are things I never did before, like basically being hospitalized I guess.

Receiving therapy and working on skills related to self-improvement and socialization appeared to help Willow feel more confident in herself and improved her interactions with others. Oliver also referred to the role of therapy in his recovery and stated that it had given him a "great deal of self-awareness". His experience encouraged him to think creatively 
about life pathways: "Well as a result of the diagnosis, however, I don't know that I would have, uh...come across as...effective of a means of finding a career if I hadn't been thinking creatively due to my diagnosis." Carly also mentioned that the illness experience shifted her career plans in a way that she found positive. She planned to be a physician's assistant; however, with the cognitive deficits from the traumatic brain injury and academic struggles that lowered her GPA, she decided to not pursue this career path. Instead, her interactions with her providers and her hospitalization experience guided her to social work. At the time of the study, she was planning on becoming a social worker who specialized in working with individuals following a traumatic brain injury. Carly felt she would be able to help educate her clients regarding how to respond and refer them to possible treatment and community resources based on her personal experiences. Lastly, Leo also stated that his illness may have encouraged him to seek more social engagement:

I've been specifically looking for activities to get me out of the house because l've been dealing with depression...Because I've been depressed, I really need to be around people. So I wonder, um...the fact that I had this psychotic thing, and my bipolar disorder, the whole story of that, has caused me to be more active socially than other people would be maybe because l'm actively trying to find groups.

Four out of the five consultants reported positive aspects of having a mental illness. The process by which they came to see the positive aspects of their illness were unclear. It is possible that as they saw new occupational possibilities arise or new ways of being were imagined, they began to see the illness identity in a more positive light. It also seemed that insight and sense of empowerment were driving factors to viewing the illness positively.

\subsection{Summary}

It was evident in this study, that consultants who felt more ownership and control over their identities were able to remain creative and imagine new possibilities for participating in their social worlds. They used this empowerment to overcome negative dimensions of their illness. According to Lachicotte (2002), identity formation can be agentic. Through spaces of authoring, individuals integrate the voices of others inside themselves 
and modify their actions or their presentations to author to others how they see themselves. This research exemplified the positioning and placement of individuals into certain identities in particular social contexts while also exploring the agentic nature of identity formation. However, when opportunities for participation are limited or taken away as a result of the illness, the illness identity became more negative. Thus, in research and practice, it is insufficient to focus on individual performance and capabilities. Researchers must attend to how individuals experiencing early psychosis are positioned and repositioned in their figured worlds and how 'doing' changes in relation to the occupational opportunities following a diagnosis.

The social-constructivist framework to identity formation is a useful perspective for both research and clinical practice. It may be especially useful in early intervention studies and practice when identity formation surrounding mental illness is just beginning. This framework takes into account the social, cultural, political, environmental, and historical forces that shape identities in particular contexts. A social-constructivist framework with an occupational lens allows for a thorough examination of the transactions between individual and social components involved in identity work by examining the action or 'doing' involved in occupational engagement. Occupation is the medium through which identity work occurs. Many occupational scientists have already made this assertion about the power of occupation as a medium for improved health, self-making, and overall function. However, limited research has been completed to apply these concepts to broader populations. This study highlighted how consultants negotiated their identities through participation in occupation. The study also demonstrated how consultants were able to reframe illness identities in a positive light and integrate multiple identities into a functional sense of self. 


\section{CHAPTER 6: DISCUSSION}

\subsection{Summary of Findings}

\subsubsection{Social Participation and Belonging}

I began this research with the objective of exploring social factors that impact social participation for young adults following FEP. In Chapter 4, I presented findings related to my exploration of factors impacting social participation for young adults following their first episode of psychosis. Through that exploration, seven factors were identified: 1) social norms and expectations; 2) a sense of responsibility to others; 3) consultants' occupational histories and prior routines, including their relationships prior to the illness; 4) changes in the physical and social environment; 5) the types of participation available; 6 ) the need to manage the illness; and 7) consultants' self-perception and the associated perception of occupational possibilities. Though these factors were presented as separate for the purposes of abstraction, as indicated by my theoretical perspective, they are not separate. They are interrelated and function together in a transactional relationship to influence the situation of belonging.

Based on my clinical background as an occupational therapist who works primarily with individuals with longstanding mental illness, I expected to find significant barriers to social participation and belonging. As was evident by my discourse selection (see Appendix E), I presumed isolation, loneliness, and exclusion would be dominant themes of my consultants' experiences. Although loneliness and evident limitations to social participation were noted by my consultants, I did not anticipate the extent to which they sought experiences of belonging in their everyday living. Study findings suggest that the desire for belonging motivated consultants' social participation. All consultants pursued community 
and belonging in some form or another, most often through their occupations. Though there were barriers to participation and some consultants were unable to participate in desired communities or groups, they continued to strive for belonging regardless of the challenges they faced.

Occupation was the medium through which belonging occurred, in part because occupation was a means for consultants to functionally coordinate their situations following FEP. Participation in occupations facilitated social interaction and integration in varied environments, which fostered experiences of belonging. Conceiving of occupation as a facilitator of belonging has been supported in several occupational science studies. Asaba (2008) found that participation in hashi-ire, a traditional Japanese occupation, provided a way for his participants to share in a common goal and become part of a broader collective through engagement in that occupation. Participants used the occupation to become part of a group steeped in history and tradition that provided a sense of connection to others and to the past. In a study aimed at examining the meaning of occupation from the perspective of lived experience, Reed, Hocking, and Smythe (2010) stated, "It is through occupation that an avenue to Be-with others is created and meaning is revealed that is more than the occupation itself" (p. 145). Lastly, Ekelman, Bazyk, and Bazyk (2013) found that university students with disabilities sought out opportunities for occupational engagement to help them feel connected with other students and establish a sense of belonging. They also noted that when participants' occupational engagement did not foster a sense of belonging, participants felt like 'outsiders', which negatively impacted their self-esteem.

Though occupational science has successfully emphasized the role of occupational engagement in facilitating a sense of belonging and connection, occupational science has not sufficiently emphasized the primacy of this concept in understandings of occupational participation or models for therapeutic intervention (Hammell, 2014). They have not clearly defined belonging or fully articulated the processes through which it is nurtured or 
extinguished. Despite its centrality to the human experience and participation in occupation, there is a paucity of scholarship in occupational science and occupational therapy that captures the role of belonging in occupation (Hammell, 2014). To date, no study in occupational science has illuminated the factors influencing belonging and the role occupation serves to facilitate social belonging for individuals with FEP. This research study offers insights into the theoretical makeup of belonging, including how social factors impact belonging.

According to Jones and Krzyzanowski (2008), if we understand belonging as a social process, it is vital that we consider how power, individual action, and social factors affect this process. Though social participation and belonging are interconnected and depend on one another for successful social integration, there is a deepness to belonging that surpasses that of social participation. Belonging implies inclusion. Several questions arose during this study that revolved around the concepts of tolerance, acceptance, and inclusion. In returning to Carly's situation at the coffee shop, I wondered, is tolerance of certain behaviors enough to support participation? Or is acceptance of differences what is needed to support social participation, and can we fully accept differences when social norms and expectations are so prominent in social life? How can we resituate the problem of FEP away from the individual and create social situations that foster belonging? I think these are important questions to ponder. For occupational science to fully address social participation and belonging, the discipline must address questions of this nature.

When I began this study, I characterized social participation as the ability to engage in social activities wherein individuals achieved some level of connection within social groups. Though I assumed individuals needed a level of intent to engage and interact with others, inclusion was not necessarily a required component. This seems to be the distinction between social participation and belonging. In other words, a person can socially participate but not be included as part of a community. Carly was socially participating in sharing coffee 
with her friend. Yet, she was not included in the broader social community; her behaviors were 'tolerated' by the man once he found out she had a mental illness. Thus, a problematic situation was created, though the ill fit of the situation was not Carly's responsibility. Rather, this was a situational mismatch where her behaviors were not congruent with the social processes operating through that situation. For individuals with FEP to feel a sense of belonging, which is vital for health and well-being (Hammell, 2014; Wilcock, 2006), inclusion and integration with the social environment are required. Yet, there are barriers along the individual-social continuum that impact inclusion for individuals with mental illness. This belonging, or inclusion, is the area researchers and clinicians need to attend to.

I anticipated findings would primarily relate to specific social factors as I assumed that these social elements were the primary limiting factors to individual participation and recovery; however, it was impossible to tease apart the individual and social factors that impacted participation and belonging as they each influenced the other in a transactional relationship. Per findings from this study, individuals' prior exposure and participation in occupations before the illness impacted perceived avenues for belonging after FEP; consultants with more varied occupational histories and connections with social groups prior to the illness were able to reengage more quickly after their FEP. Media depictions that communicate social expectations to broader social groups and position certain groups of people impact occupational possibilities for individuals with FEP and influence individuals' emotional connection and identity related to the illness. Lastly, changes in the physical and social environment, available types of participation, and the time and energy needed to initially manage the illness before reengagement impacted opportunities for inclusion, and ultimately belonging. In all of the factors identified, there were elements of individual and social involvement that served to support and hinder social participation. Thus, for clinicians or researchers attempting to facilitate social participation and belonging, implementing interventions or examining the 'problem' while isolating individual factors from the social 
environment is counterproductive and harmful. This serves to narrow the scope of intervention, blame the person for an issue that is situational, and ignore important processes that must be addressed to change the fundamental structure of the situation. Study findings suggest that the individual should not be the focus of intervention; rather, the situation itself must be examined and intervened upon. For example, targeting the discourses that frame the situation is one avenue for intervention to promote belonging for individuals with FEP. Reframing the experience of FEP in this way could facilitate recovery and belonging, as well as reduce the adoption and impact of the illness identity itself. Leo and Oliver spoke extensively about the impact of the diagnosis in their lives. Though they engaged in identity work to reduce the negative impact of the illness in their lives, they still experienced negative reactions to their diagnosis. If FEP was reframed as a 'problematic situation' requiring situational interventions rather than individually-based interventions, their experience of mental illness and the identity may be very different.

Despite the identified barriers, it was evident from this study that consultants also exhibited significant agency amidst the obstacles and limitations that impacted their participation and belonging. As stated above, they continued to strive for belonging by pursuing occupations and social groups to acquire connection with others. Though they started in 'comfort zones', most often within their family units where belonging was expected and predictable, they pursued wider avenues for social belonging as they became more adept at managing their illness and were able to integrate their illness into their identity and daily routines. In other words, they were able to 'functionally coordinate' (Fesmire, 2003) their illness with other aspects of their person and with their social situation.

Social occupations that fit with expected social norms and age expectations facilitated social engagement for consultants. Though not explicitly acknowledged by the consultants, it was evident from our conversations and observations that they sought out occupations and avenues for engagement that fit with expected social norms and age 
expectations (e.g., employment, graduate school, independent housing). For example, Carly moved out of her parent's home, joined a young adult bible study group where life transitions were discussed, and completed a gap year while applying to graduate school, which was an acceptable social path many of her college friends had also completed. She pursued occupations that connected her with others in socially accepted ways.

Though all consultants continually pursued occupational participation and belonging, not all were able to find available avenues for belonging; feelings of rejection and isolation resulted. They were unable to functionally coordinate their illness with their situation, which further limited their participation and fostered negative notions of the illness and a negative sense of self. In addition, their ability to handle unfamiliar environments, establish new social relationships, and recreate a positive sense of self immediately following the episode limited their engagement in communities of practice outside the world of mental health treatment. The lack of social support for functional coordination of the 'FEP situation' and inability for consultants to participate in broader social groupings impacted their sense of belonging. Even when consultants were engaged in other communities, the illness experience had a tendency to interrupt the occupational experience and associated feelings of belonging. Belonging to the community of mental illness was an ever-present shadow over all forms of occupation. For instance, Leo's occupation of studying languages were reframed by his parents to be part of his mental illness after his FEP even though he had been engaging in this occupation for many years before his FEP.

Leo and Oliver tended to think more negatively about the impact of the illness in their lives and struggled with finding stable communities for belonging following their first psychotic episode and hospitalization. Oliver changed jobs often, was banned from gaming clans due to interpersonal conflicts, and did not feel connected to prior spoken word communities, which were a source of belonging for him prior to his FEP. Leo sought out many religious communities for belonging and struggled with finding a constant place where 
he felt supported and connected to others. The figure below presents a model that describes consultants' experiences of 'spaces of belonging' (see Figure 1. Spaces of Belonging).

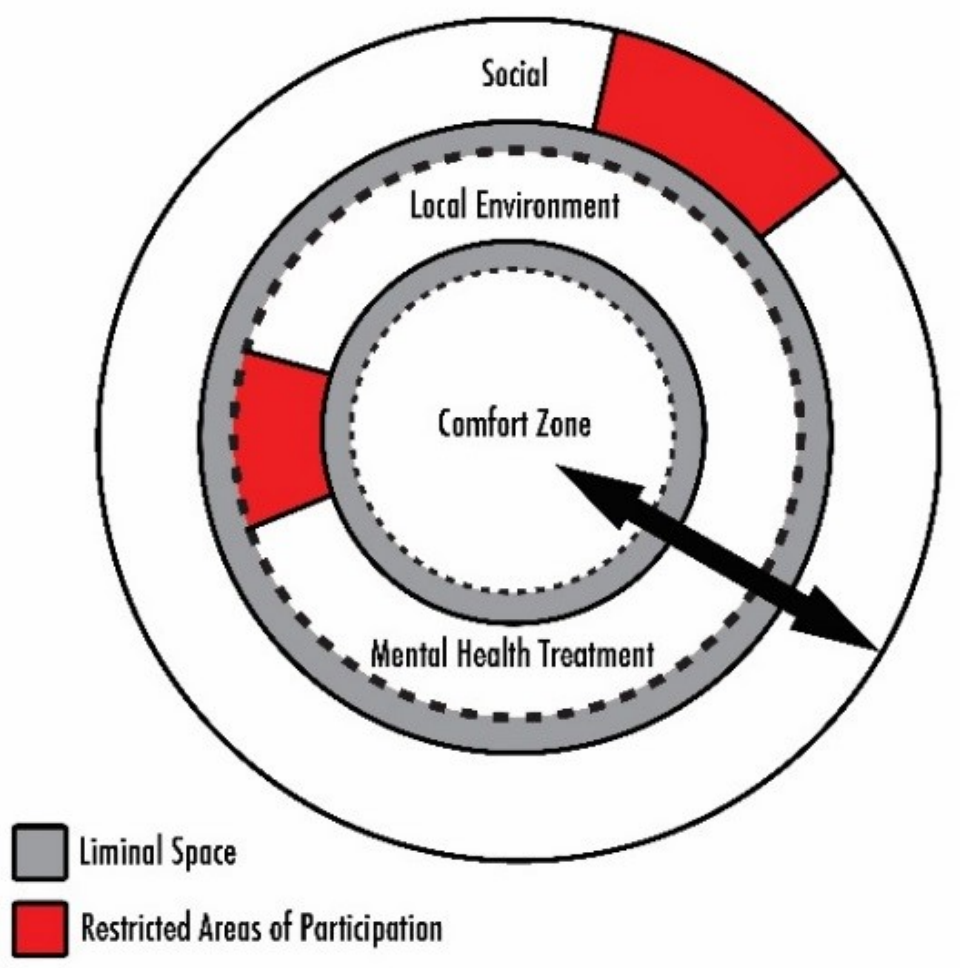

\section{Figure 1. Spaces of Belonging}

This model emphasizes the importance of examining the physical and social environments of individuals following FEP to determine how belonging differs in certain social spaces and how individuals move through spaces of belonging. Following their first psychotic break, the physical and social environments consultants occupied changed drastically. Their participation was initially limited to 'comfort zones', or areas from their occupational histories that were most familiar and fostered a prior sense of belonging. For most consultants, family occupations were in their comfort zone. Belonging to a family unit and having family supported movement out of the comfort zone over time. In a study with individuals with mental illness who were homeless, Fields (2011) found that 'kin ties' helped 
participants feel more connected to neighborhoods outside of the ones in which they lived. Her findings imply that family and kin ties facilitated movement into broader social environments. As participants in Fields' study began to manage their illnesses more effectively, they were able to move into broader spaces of social participation. Comfort zones were important for study consultants following their first psychotic episode. These spaces of familiarity and predictability helped to reestablish a sense of belonging amidst difficult life changes. Family support and engagement in family occupations were useful methods to facilitate participation in comfort zones while consultants regained control of their lives and prepared to pursue engagement in broader spaces of belonging.

Consultants in my study moved through their local environments, as well as through mental health treatment environments, primarily consisting of outpatient mental health appointments, support groups, and local pharmacies. Certain social spaces were not available to them following their FEP due to lingering effects of their psychotic episodes (i.e., lost relationships, forbidden access to areas due to trespassing charges), a loss of personal connection with certain environments and occupations following the illness, or a diminished self-concept and ability to perceive possibilities for belonging and occupational engagement. Restricted areas of participation are represented by red blocks in the model.

Over time, consultants felt more confident moving into broader social environments, (i.e., graduate school in new states) that were unfamiliar and less predictable. These broader social environments, or macro social spaces, are represented by the exterior circle ('social') in the model. This larger circle encompasses the local environment and comfort zone spaces to represent the consultants' migration into broader social environments over time. Though comfort zones and local environments are both social spaces, social norms and expectations, the predictability of the space, and opportunities for change in participation differed between comfort zones, local spaces of practice, and broader social environments. 
For most consultants, transitioning to broader social spaces of belonging took a considerable amount of time after the FEP. Consultants needed to functionally coordinate their actions in each social space. Some of my consultants were stuck and unable to move between these spaces of belonging. For instance, Leo was unable to pursue volunteer work in certain settings due to background checks that would highlight his trespass charge and likely disclose his FEP experience. These spaces are denoted with the smaller circles, labeled 'liminal spaces'. The dashed circle illustrates that these liminal spaces are spaces of transition within each space of belonging; they are not separate spaces entirely. Liminal spaces, though part of each space, differ slightly in that consultants' are intentionally acting to move to broader social spaces in these circles. For example, Leo established a routine after his discharge from the hospital that included attending support groups, his outpatient appointments, going to bed at an early hour to prevent medication side effects, and participating in family occupations. As the study progressed, it was evident that he had progressed beyond these occupations and was beginning to pursue broader avenues for participation, including returning to community college and volunteering with a local disability organization (i.e., the local environment). However, he had to adapt his routine, establish new community connections, and continue to manage his illness to progress to the next space of belonging; in other words, he had to functionally coordinate his illness with his new situation. It was not an immediate step and required action to transition to this space of belonging. All consultants moved through these liminal spaces as the illness itself required transitioning and reforming anticipated life trajectories and views of themselves. For some, these spaces were a source of transformation, growth, and identity transformation. For others who become stuck in liminal spaces, these spaces became a source of anxiety, stress, and social isolation that impeded a sense of belonging and subsequent social participation. Feeling stuck in the liminal space negatively impacted consultants' identity and perceived opportunities for participation in broader social environments. 
Time is also important to understanding the model; time is denoted with a bidirectional arrow spanning each of the environmental layers. Though consultants hoped to move into broader social environments for participation, where more expansive opportunities for social participation and community integration existed (i.e., the outer circles), movement did not always occur in this way. Reoccurring psychosis, recurrent hospitalizations, or changes to the physical environment and communities available in those environments could cause consultants to return to comfort zones briefly before again moving back into broader social spheres. The seven themes identified in Chapter 4 serve to either support or hinder movement between these spaces of belonging.

\subsubsection{Rethinking the Experience of FEP Relative to Belonging}

This study has caused me to question my own assumptions about how social participation and belonging occur for individuals following FEP. While this study revealed factors that impact social participation and belonging, the factors themselves could not be delineated as clearly social. In fact, the factors impacting belonging operated along the individual-social continuum. The transaction of individual and social factors is complex. This finding highlights the idea that factors typically thought of as individual factors (e.g., prior experiences, intersecting identities, motivation) are in fact inseparable from social experience; thus, they must be treated together, as a relationship that impacts the full situation of FEP.

In returning to the discourse I chose to represent my own assumptions of participation and mental illness (i.e., picture of man standing alone in a crowd), isolation and loneliness are no longer words I would use to discuss the experience of FEP related to social participation. While I continue to think that isolation and loneliness exist, especially in the period immediately following FEP or hospital discharge, my consultants have helped me to realize that individuals with FEP also exude power to reshape their experience,

functionally coordinate their illness into their identity and new situation, and pursue avenues 
for belonging for themselves. As stated in Chapter 3, Oliver had a very different reaction to the discourse than I had; he expressed a more positive view of the man, stating "He looks like a normal dude to me." At the early stage of analysis, Oliver's statement encouraged me to question my own biases, as well as offered insight into Oliver's assumptions of social interactions. However, I continued to conclude that Oliver expected poor social engagement due to his experiences rather than questioning my own understandings of social participation and belonging. As my analysis has developed, I have come to adopt some of Oliver's understandings of the picture. Perhaps the man standing alone in the crowd is evaluating his options and deciding which spaces of belonging or social groups he plans to pursue. Perhaps he is imagining new possibilities for himself. Pursuit and imagination, rather than isolation and loneliness, are words that now represent that picture.

\subsubsection{Reframing FEP as a Problematic Situation}

Examining FEP as a problematic situation emphasizes the relational nature of this illness. It shifts the focus from the individual or the social, instead encouraging an exploration of how various factors operate together to influence the overall situation. As has already been stated, focusing on either the individual or the social is ineffective for addressing belonging related to FEP. Separating the individual or the social and treating them as separate entities, or entities that interact rather than transact with one another, would discount my consultants' greatest identified need: the need to harmoniously integrate with the environment, or to fit and belong.

Viewing FEP as a problematic situation also encourages creative thinking about how to functionally coordinate the situation of FEP and improve belonging following FEP. According to Dewey, the ability to imagine possibilities for action is integral to a person's ability to integrate with the environment, or functionally coordinate following a change in their situation (i.e., the problematic situation of FEP). However, helping a person to imagine new possibilities is not enough. The situation itself must change (i.e., social perceptions, 
discourse, transportation limitations, disability system, laws, etc.) since situational factors are equal partners in creating the problematic situation of FEP and hindering belonging for individuals with FEP.

As consultants moved through life, they operated along anticipated or expected life trajectories. These trajectories were shaped by social norms and age expectations. After their FEP, consultants faced transitions in their identities and expected life trajectories (i.e., the liminal space of FEP). Though they could continue to progress along anticipated life trajectories, four out of five consultants were unable to do so and needed to adapt their trajectories. They attempted to identify alternative avenues for belonging and alternative occupations to restructure their trajectory to again comply with social norms and expectations; some were able to do this more quickly than others depending on the social supports, knowledge of avenues for inclusion, and resources available to them. As life situations change due to disability, illness, or new life circumstances, the occupational situation also changes. Imagination was a way in which consultants could assume the power to redefine themselves and adapt life trajectories and avenues for belonging. However, this required the ability to perceive possibilities for occupational engagement and belonging and the availability of occupational opportunities in the broader social environment. Social discourses related to mental illness (e.g., media depictions, history of mental health treatment, social language and labels) operated through environments and influenced what consultants felt was possible after FEP. Functional coordination following FEP requires a change in social discourse regarding FEP experiences, a change in what is socially expected and considered 'normal', and a change in what is perceived to be desirable life trajectories. Though consultants demonstrated agency in pursuing social participation and belonging, they continued to face hindrances because we have yet to conceive of FEP as a relational problem that requires intervention on the situation as a 
whole. Researchers and clinicians need to start with the situation of FEP and address the social broadly to foster recovery and belonging for individuals with FEP.

In sum, belonging is not facilitated solely via social policies and laws that promote inclusion, interventions focused on social skill building, or individuals' ability to imagine new possibilities for themselves. Rather, belonging requires all of these elements. The ability to

functionally coordinate one's actions following FEP to achieve belonging and social inclusion requires opportunity, the ability to perceive possibilities for action, the capacity to pursue alternative avenues for engagement and alternative occupations, and the expansion of social awareness and support towards inclusion of individuals with FEP. The situation of FEP is quite complex with many fluctuating parts; however, consultants demonstrated that functional coordination and achievement of belonging does occur after the illness. To facilitate social participation and belonging requires a reframing of the experience of FEP and an understanding of the array of factors along the individual-social continuum that influence the situation of FEP. This study has begun to identify those factors and highlighted the need to assist individuals following FEP with functionally coordinating their new situation to facilitate belonging and inclusion.

\subsubsection{Belonging and Identity}

Identity and identity work were integral to belonging. To belong to a group implies identifying with that group. For consultants, their identities influenced their selection of occupations, which in turn, influenced their participation and belonging in specific social communities. Occupation was a tool consultants employed to construct their identities construction and facilitate their social participation and belonging. If identity is formed, changed, and perpetuated by participation in occupation, then changes in participation will effect changes in identity. Consultants who had access to a variety of groups experienced more options for pursuing occupational engagements after their FEP, which fostered a sense of continuity of belonging. In addition, because they had more opportunities to 
continue their former occupational participation, they also had more opportunities to preserve former identities. This allowed for more continuity in their conceptualization of self and therefore, their overall self-concept was not as threatened by the mental illness. They adopted a more positive identity of mental illness as compared to those consultants who struggled with finding connection and belonging after their FEP. They used their occupations and history of engagement to pursue avenues for belonging and connection in larger social groups. Their ability to belong and consequently shape their own identity was dependent on social factors.

Consultants were invariably positioned into a social identity of the 'mentally ill person' during their initial hospitalization and were unavoidably integrated with the mental health community because of their need to manage the illness and participate in related occupations. Belonging to this community hindered their ability to belong to other groups. Occupations of managing the illness prevented participation in occupations that fostered belonging in other groups, which further limited opportunities to develop identities related to those groups. By extinguishing opportunities for developing or maintaining other group identities, the illness identity gained further prominence. For example, Leo was required to attend court and court-appointed treatment due to events during his psychotic episode. As a result, he was unable to move away and pursue career goals and missed volunteer outings. Several consultants in the study exercised power to define themselves through oppositional identity work (i.e., refusing to engage in mental health recommendations for treatment, distinguishing themselves from other mentally ill persons) and by adopting other identities beyond that of the illness. They chose to belong to other groups and used their group membership to actively reshape their social identities and self-perception. For example, Willow belonged to a LGTBQI group, which became her primary identity rather than her mental illness. Consultants who were unable to identify other groups for belonging, or whose occupational opportunities were limited in social spaces, adopted the identity of 'mentally ill' 
to a greater extent and integrated deeper into the mental health treatment community, a group to which they felt they belonged.

Jones and Krzyzanowski (2008) argued that the notion of 'belonging' offers a useful way to examine an individual's relation to a collective: "Belonging allows the fluid, constructed nature of many of the processes associated with identity to be analyzed and understood in a more rigorous way" (p. 38). They emphasized that belonging is about the relationship between personal identity and collective identity; thus, when an individual feels a sense of belonging in a community, their personal and collective identities become connected. Individuals with mental illness who do not have personal identities that relate to their collective environments struggle with movement through spaces of belonging and social participation. If they adopt or are positioned in the identity of a 'mentally ill person', this shapes their sense of belonging and hinders their ability to move through liminal spaces to broader social spaces for belonging. Since belonging is integral to health and wellbeing (Hammell, 2014), encouraging participation in occupations that foster belonging to social groups is a useful intervention to scaffold community integration and positive identity development for persons with FEP. In addition, fostering belonging through occupation could prevent being stuck in liminal spaces.

\subsubsection{Liminal Space of FEP: Importance to Identity Work and Social Participation}

The liminal space was a notion identified initially by Leo, though all consultants discussed a space of uncertainty and transition after their FEP. Liminality, a space of inbetween-ness, provided a way for consultants to discuss the period immediately following their FEP and reframe their experience. Leo and Oliver were able to use this concept to illustrate their feelings of being 'stuck' and unable to move beyond their FEP diagnosis, while Willow and Carly were able to talk about the liminal space as a space of personal growth and transformation. The concept offered common language to discuss consultants' experience of FEP and social participation following FEP. 
The concept of liminality has been used in other social sciences, particularly anthropology to explain cultural experiences, social dynamics, and ways of being (Jackson, 2005; Kelly, 2008; Lewis, 2008; Turner, 1967). The concept has rarely been applied in occupational science, though it holds promise in illuminating the role of occupation in facilitating belonging through liminal spaces into spaces of inclusion and recovery.

A liminal space is a space of in-between-ness. It is to be neither here nor there; it is to be in limbo (Kelly, 2008). This concept has been applied to grief, loss, and uncertainty in response to terminal illnesses (Kelly, 2008; Little, Paul, Montgomery, \& Philipson, 1998), as well as pain (Jackson, 2005) and mental illness (Barrett, 1998). In a study of experiences of loss and grief associated with AIDS dementia, Kelly (2008) found that individuals often lived 'within' a liminal space of loss where uncertainty prevailed and individuals did not know when or if a loss would occur related to their health. Her participants were "between social roles, cultural expectations, and status" (Kelly, 2008, p. 336). Consultants in my study echoed similar experiences. Each consultant referred to the experience of first episode psychosis, and the period of time immediately following the episode, as a transitional moment in their lives. Though some framed their illness in a more positive light than others, each consultant talked about the changes the illness had in their lives and the time needed to incorporate the illness into their identities and daily routines. This was a space of uncertainty, not knowing if they would be able to regain their prior level of function, regain past relationships, or achieve their anticipated future life goals. There was a sense of loss in this space of liminality; loss of past relationships and communities of practice, as well as loss of perceived identities. For some consultants, this sense of loss was more extensive and severely disrupted their social participation and sense of belonging in their community. For others, they were able to move through the liminal space and had a reduced sense of loss; they were able to find avenues for belonging more easily. This was the 'liminal space of FEP'. 
Through his anthropological study of Ndembu rites of passage, Turner (1967) introduced a three phase framework to describe the liminal state and the various transitions that occur between states. Turner found that rites of passage were marked by three phases: separation, liminality/transition, and incorporation. According to Turner, the separation phase is necessary to detach from a previous state of being; this occurs at a fixed point marked by a cultural event or change in social structure. Once detached, an individual assumes an ambiguous identity; this state of in-between-ness is the liminal phase.

Reflection and transformation can occur during this state of detachment and uncertainty. In the third phase, incorporation, an individual's identity is reshaped and a new role in society is adopted. Turner's three phase framework is applicable to the experience of FEP and explains the role of occupation in moving individuals through liminal spaces (see Figure 2).

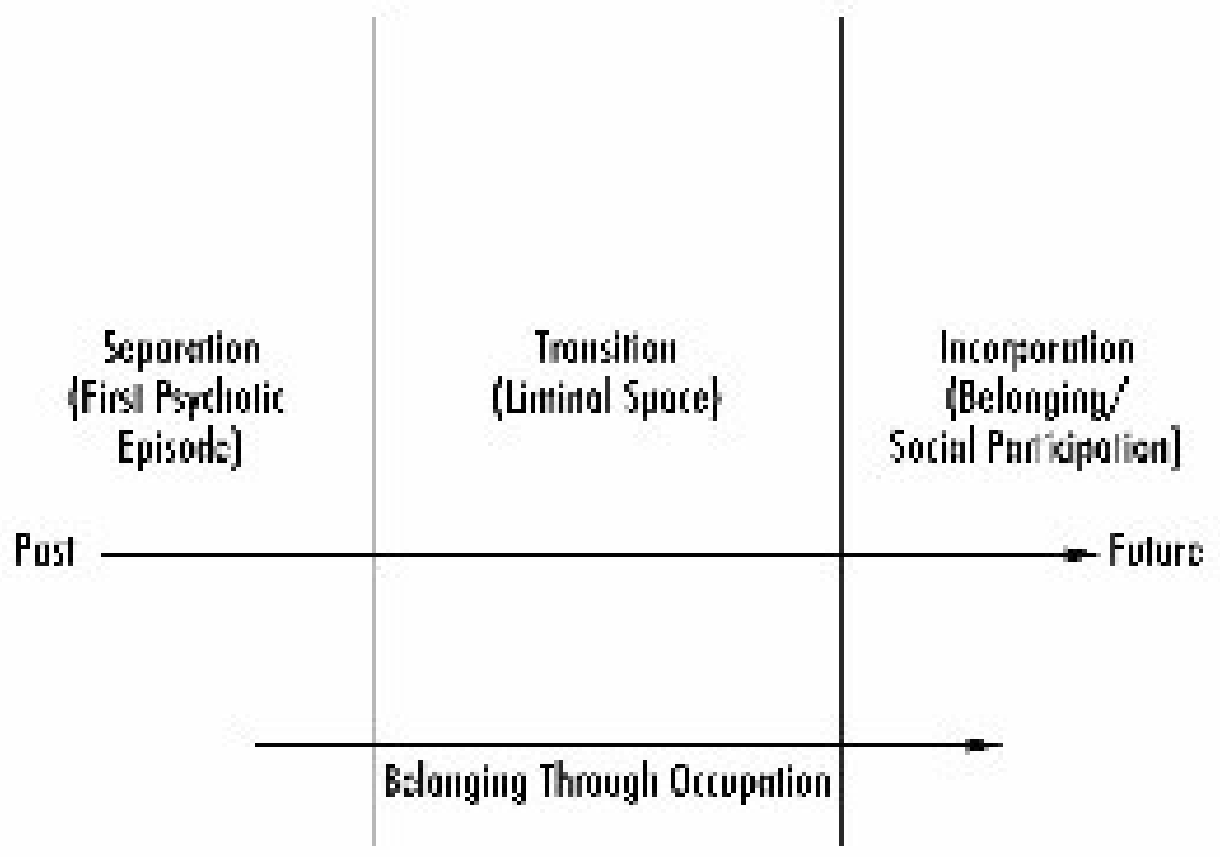

Figure 2. Liminal Space of FEP: Belonging Through Occupation (adapted from Turner, 1967) 
The separation phase occurs when an individual experiences their first episode of psychosis. At this moment, consultants underwent unfamiliar experiences, detaching from prior identities and self-perceptions, and were unsure of how to effectively integrate their experiences with their cultural and societal contexts. This was the separation phase. Consultants then moved into the liminal space of FEP. A hospitalization experience may mark the beginning of this phase. Consultants identified the hospital experience as a specific point at which they began to assume the identity of mental illness and process their experience. During this liminal space, consultants began to learn how to manage their illness, adopted occupations needed to manage their illness, and took the time to reevaluate their life trajectories. The third phase involved reintegration into social occupations. In the third phase, consultants integrated the illness into their identity and were able to reshape their identities, as well as identify alternative life trajectories that fit with their experience and personhood after FEP. They identified avenues for belonging and social participation that fit with their new self after FEP. Again, some consultants were unable to identify alternative avenues for belonging and social participation and remained stuck in the liminal space of FEP. Consultants used occupation as a way to pursue alternative avenues for belonging even if they were restricted or unable to achieve their desired sense of belonging in chosen communities of practice. In this way, belonging was found to be both an antecedent and a result of participation. All consultants belonged to social groups prior to their FEP; some were more connected to a multitude of community groups than others. Consultants who were able to sustain engagement in prior occupations and communities of practice during the liminal phase were able to progress through this phase into the incorporation or belonging phase. This phase involved integration of their illness into their identity and was a phase where belonging to broader social environments occurred. Participation in social occupations served as a way to facilitate belonging for consultants. 
The ability of consultants to move through the liminal space was influenced by the seven factors identified in Chapter 4. Social norms, age expectations, and sense of responsibility encouraged movement through the liminal space. Social norms and age expectations defined possible occupational pathways for individuals to follow. These pathways served as guides as consultants integrated the illness into their routines and selfidentity. For some consultants, social norms and typical life trajectories drew attention to their inability to move beyond the liminal space as they were unable to progress towards their desired life trajectory. For example, Leo shared that he felt he should have a career and a relationship due to his age. He felt his FEP precluded his ability to acquire these things and thus, he felt stuck in the liminal space of FEP. A sense of responsibility to others encouraged consultants' reengagement in a community of practice and required their intentional participation to fulfill those responsibilities associated with community membership (e.g., Oliver's continued efforts to obtain employment to support his family, Willow's attendance at LGTBQI meetings despite her anxiety). In addition, changes in physical or social environments both supported and hindered transition through liminal spaces. This depended on the types of participation available in new physical environments, the proximity of opportunities for social participation, and the consultants' perceptions of occupational possibilities. Virtual forms of participation offered a comfortable outlet for social participation after FEP, though success with virtual participation required some level of symptom management and stability as did other participation environments. Consultants who felt a more negative effect of the illness on their identity and self-perception dwelled in the liminal space after FEP for an extended period of time and struggled with identifying avenues for belonging in new social environments. These factors operated in a complex, transactional way to influence belonging, identity formation, and the progression towards future life goals. These factors were difficult to tease apart because they impacted one another throughout the FEP experience. 
Managing the illness was one of the most influential factors impacting a consultant's ability to move through the liminal space of FEP. Managing the illness became a predominant occupation after the episode. Engagement in this occupation detracted from participation in other social occupations. For example, Leo was initially unable to attend evening bible study events due to concerns that if he did not go to sleep by a predetermined time, his symptoms would worsen. He was unable to adapt his routine because of his motivation to manage his symptoms. Consultants often deferred the future to manage the illness and limited occupational pursuits in certain environments. At times, they became 'stuck' in this space of transition (i.e., liminal space of FEP), which influenced both their social participation, inclusion, and identity. For some consultants, managing the illness became a full-time endeavor and required reduced social participation in communities of practice thereby offering fewer opportunities to experience belonging in those communities. An extended period of time in the liminal space dominated by illness management could contribute to a state of chronicity. Several consultants became 'stuck' in the liminal space of negotiating their identity between their past self and new self after FEP. However, reducing social alienation and heightening community integration could facilitate movement through the liminal space and promote recovery.

Though three of the five consultants identified this liminal space as a negative space in their lives during which they were unable to progress on their expected life trajectory, two consultants portrayed it as a space of positive transformation and growth. Researchers have studied spaces of liminality as places of transformation. Lewis (2008), in a study examining Westerner's use of Ayahuasca, found that liminal spaces were both spaces of crisis, vulnerability, and anxiety and spaces for transformation and growth. She found that Westerners who used Ayahuasca without an appropriate cultural 'backing' (i.e., cultural beliefs and supports to frame their experiences effectively) were left in a liminal state, a period of crisis filled with anxiety and vulnerability. Barrett (1998) found that individuals with 
schizophrenia who were unable to reframe their experiences with adequate cultural backing and support also experienced anxiety and vulnerability. Though Barrett (1998) and Lewis (2008) described the anxiety and vulnerability associated with liminal spaces, Lewis also found that participants who were able to work through the experience and reframe the experience using culturally-accepted beliefs, emerged from this liminal period with a changed, transformed identity. Similarly, consultants in my study who struggled with finding avenues for belonging and cultural support following their FEP tended to have a negative perception of their illness and struggled with moving through liminal spaces. Examining psychosis as a non-culturally sanctioned experience that often fosters feelings of distress and isolation for individuals who experience it may shift treatment and societal beliefs about the illness and help to reframe the illness for patients. Willow's ability to educate herself about mental illness helped her to reframe her illness and functionally coordinate her illness identity with her situation following FEP. Addressing factors that facilitate progression through liminal spaces, such as fostering belonging, is a promising avenue to assist people with FEP to achieve wellbeing through social participation. However, this requires intervention along the individual-social continuum (e.g., advocacy events, public health/educational campaigns about inclusion, adaptation to media depictions and social discourse).

Consultants who felt a sense of belonging and were able to sustain prior community membership throughout their FEP experience viewed the liminal space as space of growth. In occupational science, Mondaca and Josephsson (2013) identified liminal spaces as spaces for growth. In their research with elderly survivors of human rights violations, Mondaca and Josephsson found that liminal spaces were spaces of transformation, wherein "things are about to be defined" (p. 82). They argued that occupation allowed participants to bridge past and current life experiences and provided opportunities for multiple "emplotments" or life narratives to exist. This study echoes and supports viewing occupation 
as a medium through which individuals with FEP move through the liminal space of FEP. However, findings also demonstrate that liminal spaces are not always spaces of positive transformation and can be detrimental to health and wellbeing. Liminal spaces themselves are social spaces that are socially constructed and shaped via history and past events, current social policies and laws, societal beliefs, and social discourse. For example, events such as school shootings and media depictions of mentally ill offenders shift citizen rights (e.g., ability to purchase a gun) for individuals with mental illness. This in turn shapes future possibilities for action and social participation (e.g., hunting, joining the military) and further reduce opportunities for belonging related to these occupational endeavors. This particular example was identified by Oliver as shaping his perceived opportunities for action, and thus functional coordination. Social factors and perceptions of the illness impact whether these spaces are sticking points versus spaces for positive transformation. It is also important to realize that because liminal spaces are social spaces, constructed by a variety of social elements, they will change over time. Individuals with FEP will need to shift their actions to functionally coordinate with the changing social context of the liminal space in order to move beyond the liminal space of FEP. It is important for occupational scientists to examine how occupation can be harnessed in intervention to ensure these transitional spaces are opportunities for growth and recovery.

\subsection{Limitations}

The sample of consultants for this study was small with limited diversity. Though the purpose of qualitative research is not generalizability, the lack of diversity in the sample may limit application of the findings for broader clinical applications if broad sociocultural factors were taken into account (e.g., socioeconomic status, education, cultural background). In addition, as the focus of the study was on sociocultural factors that impact social participation, diversity in race, ethnicity, socioeconomic status, and geographic location may have offered perspectives that may have been missed by this study. As I was studying a 
population with a specific Western perspective, it is important to note the cultural implication of this research. By adopting a social constructivist framework, it is likely that studying this issue for different populations around the world or even within the United States would yield different results. Thus, I would like to caution against generalizing these findings to other cultural groups or applying the clinical implications to all populations.

Since people with mental illnesses are a marginalized and hidden population, recruitment was difficult. It is possible that individuals with first episode psychosis who were not as psychiatrically stable or who were more limited in their participation may have been missed with this study. In addition, the time commitment involved may have limited their willingness to participate. Future research should consider partnering with existing mental health clinical environments to aide in recruitment efforts. Research should also consider creative methods to understand complex phenomena in ways that do not require the extended time needed for ethnographic research.

As noted in Chapter 3, this study utilized collaborative ethnography for data collection. While the intent of this approach was to foster a partnership with my consultants, as well as to ensure they shared an equal voice and role in the research process, it is questionable whether this partnership fully matured during the study. Consultants did not seem to understand their role as co-collaborator and often looked to me for direction throughout the study. When given opportunities to provide input in analyses and the subsequent write-up, few consultants responded. In addition, two consultants felt overwhelmed by the invitation to provide feedback and participate in sharing of the research findings. Instead of viewing the invitation as an opportunity to shape the research and share their voice equally with me, they viewed it as another responsibility that required their time and energy. Overall, the mission of collaborative ethnography is beneficial and useful, however, the efficacy of this approach with young adults following FEP is questionable. 
Lastly my background and ongoing clinical work with individuals with mental illness shaped my perspective. As the principal investigator, I was responsible for data collection and analysis. Having worked primarily with individuals with chronic mental health issues on inpatient mental health units when they are not psychiatrically stable, I assumed participation would be more restricted. However, this did not appear to correspond to the experiences of young adults following their first episode of psychosis. Though this finding presented itself despite my prior assumptions, there is the possibility that I may have overlooked other ideas and prior assumptions that may have influenced my findings. Different ideas and viewpoints may have been garnered by someone without a clinical mental health background. However, through ongoing consultation with my research team, I tried to ensure my clinical lens did not interfere with my analysis.

\subsection{Implications for Future Research}

\subsubsection{Future Avenues for Research}

To build on the findings of this study, occupational scientists should further study the process of developing belonging through occupation. Such exploration should include how belonging differs in various social spaces and whether occupations affect belonging differently in different spaces of participation. It is anticipated that as belonging differs in each space of practice, occupation must also change to accommodate the need for belonging in those spaces. Thus, attempting to use occupation in broader social environments would be different than using occupations in the smaller, local, comfort zone areas. Research is also needed to determine whether facilitation of belonging in one area can limit belonging in other areas. In clinical practice, such knowledge would be critically important to ensure therapists understand the relationship of belonging in various communities and how belonging impacts belonging in other communities. 
Occupational science should also further explore liminal spaces-inherent to life as spaces of transition- including how occupations facilitate or impede moving through these spaces. This research argued that belonging through shared occupation was a critical factor to help consultants move through liminal spaces. However, there may be other ways to use occupation to help transition individuals through liminal spaces. It is important for occupational science to examine how liminal spaces are created and persist to elucidate processes of social change including what supports or hinders social action, social movements, and engagement in social occupations.

Further research is also needed to examine gender related to FEP. Carly and Willow, the two female consultants in this study, tended to have a more positive experience related to their FEP, were able to incorporate the illness identity with other identities, identify alternative life trajectories, and recognize avenues for belonging more quickly after their FEP. It is unclear if, or how, their gender affected these outcomes. Examining the gendered nature of occupational choice and occupational engagement, in conjunction with the FEP experience could provide greater insight into how to use occupation to facilitate belonging. In addition, because gender is a social construct itself, examining gender could be important to greater depth in understanding the FEP experience for young adults.

Lastly, families were a salient, but underemphasized part of this study. This study did not intend to examine familial roles related to FEP and social participation; however, family proved to be a prominent factor in facilitating social participation and movement into broader social spaces of belonging. All consultants discussed aspects of their family life during observations and interviews. However, families themselves were not interviewed and a thorough depiction of family life and daily routines was not investigated. Exploring family relationships as ascribed rather than prescribed relationships and how individuals with FEP navigate and use these relationships would be a beneficial avenue for future occupational science research. 


\subsubsection{Recommendations for Research Methods for Examining First Episode Psychosis}

This research study aimed to explore the sociocultural mechanisms that impact the experience of social participation for young adults following their first episode of psychosis and ultimately to contribute to the literature on first episode psychosis. The innovative combination of interviews, participant observations, and discourse elicitation provided a holistic exploration of the study question. These methods garnered both knowledge of the social factors that impacted consultants' social participation, as well as how social factors influenced consultants' perceptions of available opportunities for participation. In addition, incorporating collaborative ethnographic techniques with critical discourse analysis served to reduce power differentials to encourage authentic self-disclosure.

For future studies examining the experience of individuals following their first episode of psychosis, there are changes I would make to my research protocol. First, I would not limit participant observations to public arenas. I feel that certain aspects of my consultants' lives were missed by not observing the private occupations that occurred in their home or in friends' or family's homes. Given findings related to virtual participation as a source of social participation and family occupations as a bridge to broader social participation, observations in consultants' homes and private spaces of belonging may have offered more insights into how social participation occurs.

Second, I would incorporate methods to understand consultants' use of time and space into the study. For example, time use diaries and weekly calendars might paint a better picture of how consultants spend their time and reveal the more mundane aspects important to the examination of social participation, including how they structure their time to pursue belonging in social communities. Time use diaries and weekly calendars might also be useful to elicit discussion about time spent in certain locations. The model of spaces of belonging implies that consultants begin participating in comfort zones immediately after 
their FEP and slowly branch out into broader social environments. Data about the amount of time spent in public social settings as compared to more private locations would be useful information for expanding research knowledge and translating this knowledge into effective clinical interventions. Similar to discourse elicitation, time use diaries, weekly calendars, and spatial tracking could be useful ways to elicit discussion about social participation and belonging, including what factors hindered or supported participation and belonging.

Third, I would make greater use of online formats in data collection. The benefits of online data collection were discussed in relation to discourse elicitation. I think that online data collection could be expanded further to examine social participation for young adults following their first psychotic episode. Retroactive data from social media or other online mediums could be collected, examined, and compared to current time use data and current descriptions of participation to determine what aspects of participation shifted following their initial psychotic break. For example, past emails, Facebook messages, blogging, and photos posted to Instagram or other social media sites could be examined and analyzed as part of discourse analysis.

Though discourse elicitation in the local social environment did not have the impact I intended, I continue to feel this is a viable research method that could elicit abundant knowledge about societal beliefs and perceptions. I was quite disappointed in the amount of participation and the difficulty in obtaining public space to elicit discussion. Due to the restrictions in setting up displays in many public locations, my ability to elicit a full understanding of social beliefs in certain social spaces (perhaps important spaces of belonging for my consultants) was limited. In the future, use of scheduled forums may be a beneficial way to elicit discussions about social discourse. I also think that online displays may be a more useful form to take for discourse elicitation. Online discourse elicitation would eliminate many of the limitations discussed in Chapter 3, including allowing for greater anonymity, possibly reaching a broader audience, and overcoming time limitations and 
restrictions to public space. It is also possible that linking discourse elicitation with existing social campaigns could be beneficial. For example, media campaigns to shift social perceptions of mental illness could capture a wider audience and then apply discourse elicitation to gain knowledge about the social perceptions they are attempting to change. In conclusion, there are a variety of ways to examine the experience of first episode psychosis. This research study utilized participant observations, interviews, and discourse elicitation in a collaborative format to examine social participation as it has impacted the lives of young adults who have had a first episode of psychosis. As Boydell et al. (2010) stated, there is ample need for more qualitative research examining first episode psychosis; they stated, "Research in early psychosis needs to draw on different perspectives and methodologies to generate breadth of knowledge and depth of understanding" (p. 8). The novel methods used in this study should encourage the critical appraisal of traditional methods used in this area, as well as innovative development of new methods to tackle new and complex research questions. 


\section{CHAPTER 7: CONCLUSION}

\subsection{Conclusion}

The focus of this study was to explore social factors that impact social participation for young adults following FEP. Occupational science has not sufficiently explored the sociocultural processes that influence the social participation of young adults with FEP. There is a gap in the literature examining the transactions of social and individual forces that impact the identities and feelings of belonging for this population. Through this research study I hoped to fill a gap in knowledge and offer new insights for how occupational science and occupational therapy can expand research and practice. Findings from this study have filled some of these research gaps and also provided preliminary data to inform early intervention practice for occupational therapy.

This study identified seven social factors that impacted social participation for young adults with FEP: 1) social norms and expectations; 2) a sense of responsibility to others; 3) consultants' occupational histories and prior routines and relationships; 4) changes in physical and social environment; 5) the types of participation available; 6 ) the need to manage the illness; and 7) consultants' self-perception and perceived occupational possibilities. For the ease of analysis and articulation, each theme was separated and discussed in detail. However, it is vital to understand that these factors do not impact participation unilaterally but operate in a complex interpenetration. In addition, the social factors transact with individual factors and operate along the individual-social continuum. Thus, though some factors were may begin from a social construct, they transact with the individual experience to influence the occupational situation and belonging. Social factors 
cannot be teased apart from individual factors and must be examined and intervened upon simultaneously; the relationship of these factors must be the point of intervention.

Findings demonstrated that social participation and belonging were greatly connected, though belonging implied social inclusion and acceptance. Belonging served as both an antecedent and result of social participation. The need for belonging served to motivate the pursuit of occupations in various social environments. In addition, when opportunities for participation were provided, belonging was facilitated. Findings identified factors that influenced social participation and participants' feelings of belonging.

Researchers in occupational science and occupational therapy have acknowledged that belonging is crucial to health and well-being (Hammell, 2014; Wilcock, 2006). However, the discipline and the profession have not sufficiently studied belonging to elucidate its primacy in occupational participation. Achieving a full understanding of belonging and its relationship to occupation is a promising avenue to identify new treatment approaches for individuals with mental illness. This research contributes to such understandings by identifying factors that impact experiences of belonging.

For young adults following FEP, a period of transition existed after their hospitalization: the liminal space of FEP. During this time, both participation and associated feelings of belonging were inhibited. Consultants primarily participated in 'comfort zones' with family or familiar groups with which they had shared interests and occupations. As consultants reshaped their identities, reframed the illness experience and reimagined alternative life trajectories, they expanded their occupational pursuits and participation into broader social arenas. They were able to pursue avenues for belonging through their occupations, which in turn, helped to promote their social participation in broader social environments.

This research provided insights into the identity demands for young adults with FEP. The study found that consultants were positioned into the social identity of the 'mentally ill' 
person during their first hospitalization. Consultants engaged in identity work throughout their hospitalization and afterwards to incorporate their new identity with their existing identities and to reframe or redefine their selves. Consultants' connection with the mentally ill identity depended on their social circumstances, including what groups or communities they belonged to prior to their illness, what groups they were able to maintain relationships with after their FEP, their prior occupational histories, and whether or not they were able to imagine alternative life trajectories and avenues for social participation after their FEP. There existed a liminal space between consultants' past selves and their visions of their future selves. Each consultant passed through the liminal space as a space of transition and possible transformation. The liminal space of FEP became a 'sticking point' for consultants who were overwhelmed by the need to manage the illness. In such cases, they deferred their future plans to devote their time and energy to manage their illness. The ability to move through liminal spaces was influenced by the above-mentioned seven factors identified earlier. Occupation was a conduit for positive identity work which allowed consultants to integrate their illness into their existing identities. This was an important finding that should encourage clinicians to move beyond a focus on symptom-reduction in FEP treatment. Individuals who are unable to move beyond the liminal space of FEP may develop a 'chronic mentally ill' identity wherein participation in social life, sense of belonging, and functional recovery are continually limited. I continue to wonder whether chronicity develops through extended periods of closed opportunities. As this study has demonstrated, opportunities for social participation is important for belonging to occur, which is needed for health and recovery. This study also highlighted the agentic nature of consultants as they pursued belonging after their FEP. However, when opportunities are not offered for belonging and individuals are unable to identify alternative life trajectories, it is possible that they continue to participate in communities of practice related only to their mental illness as this is an open avenue for belonging. This further engrains the illness identity into their self- 
concept, their daily habits and routines, may reduce their comfort with pursuing belonging in broader social spaces, and limit their imagination of alternative ways to participate over time.

This study identified other implications for clinical practice and avenues for future research. This study emphasized and identified important sociocultural factors that impact social participation for individuals following their first psychotic episode. This study suggests that social factors should be addressed in therapy and by broader social interventions as they impact belonging and social participation, which are integral to recovery. Understanding and acknowledging factors that support or hinder social participation is necessary but insufficient. Occupational scientists must also study how to address those factors to support social participation for individuals following their first psychotic episode. The findings suggest that occupational therapy practice should address social integration, participation in communities of practice, and belonging in clinical interventions. For instance, therapists should help clients with FEP to envision a future life trajectory that is feasible and matches the demands of their social environments. Social institutions (e.g., government organizations, healthcare facilities, clinical settings, and the media) influence life patterns and provide structures that determine which life trajectories are available and which decisions are costly or rewarding (Diewald \& Mayer, 2009; Elder, 1999; Humphry \& Womack, 2014). Yet, these social determinants of health are often left unaddressed, with the emphasis of interventions primarily focused on the individual (Schon, Denhov, \& Topor, 2009). This may be due to lack of awareness of social determinants, how they impact the clinical expression of mental illness, or how to address them in clinical practice. With its emphasis on participation in occupation, occupational therapy can fill a significant gap in early intervention services for first episode psychosis. In addition, through the use of occupation as a medium for social change, occupational therapy can make a unique contribution in addressing areas of social participation and belonging. 
Occupational therapy should be involved in early intervention for FEP as the discipline has much to offer. Utilizing occupation to facilitate positive identity work, belonging, and social participation could be useful modes for early intervention for FEP. Working to include belonging as a component in the DSM-V as important to health and wellbeing is influential in shaping individual's function and recovery is important. It is crucial that occupational therapists understand how belonging is impacted along the individual-social continuum. Because belonging and liminal spaces exist and are shaped by social constructs, it is important that research continue to examine the experience of FEP and monitor the social environment to determine how to support belonging.

This study also identified an important need for clients with FEP: the need to imagine alternative life trajectories and avenues for engagement that help clients move through liminal spaces of FEP. Occupational science can further support occupational therapy practice and early intervention for FEP by elucidating the process of developing belonging through occupation, researching collective occupations, expanding understandings of social participation, and examining spaces of belonging including how belonging differs in varying social spaces. 


\section{APPENDIX A: RECRUITMENT FLYER}

\section{First Episode Psychosis: Exploring Social Participation}

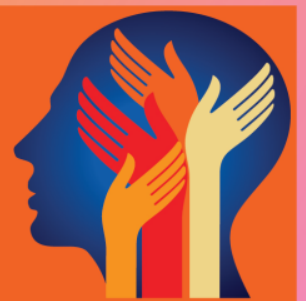

What: A study exploring participation in social life for young adults following their first psychotic episode

Why:

To further our understanding of how to improve social participation and inclusion for individuals who have a mental illness

Who: Individuals between the ages of 18 - 30 who have been diagnosed with a psychotic disorder within the last 5 years

If you or someone you know have experienced a psychotic episode within the last 5 years, we want to hear from you!

Contact: Valerie Fox

Division of Occupational Science

University of North Carolina - Chapel Hill 252.213.0744

valerie_fox@med.unc.edu

Participants will receive $\$ 50$ compensation for study completion. 


\title{
APPENDIX B: INFORMED CONSENT
}

\section{Consent Form}

\author{
University of North Carolina-Chapel Hill \\ Consent to Participate in a Research Study \\ Adult Participants \\ Social Behavioral Form
}

\author{
IRB Study \# 14-1313 \\ Consent Form Version Date: 5/27/2014 \\ Title of Study: An Exploration of Social Participation for Young Adults Following a First \\ Psychotic Episode \\ Principal Investigator: Valerie Fox \\ UNC-Chapel Hill Department: Department of Allied Health Sciences, School of Medicine \\ UNC-Chapel Hill Phone number: (919) 966-2451 \\ Email Address: Valerie_fox@med.unc.edu \\ Faculty Advisor: Antoine Bailliard, PhD \\ Funding Source and/or Sponsor: None \\ Study Contact telephone number: (252) 213-0744 \\ Study Contact email: Valerie_fox@med.unc.edu
}

\begin{abstract}
What are some general things you should know about research studies?
You are being asked to take part in a research study. To join the study is voluntary.

You may refuse to join, or you may withdraw your consent to be in the study, for any reason, without penalty. Research studies are designed to obtain new knowledge. This new information may help people in the future. You may not receive any direct benefit from being in the research study. There also may be risks to being in research studies. Details about this study are discussed below. It is important that you understand this information so that you can make an informed choice about being in this research study. You will be given a copy of this consent form. You should ask the researchers named above, or staff members who may assist them, any questions you have about this study at any time.
\end{abstract}

What is the purpose of this study?

The purpose of this research study is to learn more about the ways participation in social life is impacted following a mental health diagnosis. The ability to continue to participate in social life and engage in desired roles is important to health and recovery. However, for some individuals, the ability to participate in social life changes following an illness. There is currently a gap in our understanding of the factors that impact social participation following a first psychotic break. This knowledge is important in developing needed interventions targeting social integration and participation.

How many people will take part in this study?

If you decide to be in this study, you will be one of approximately five people in this research study.

How long will your part in this study last?

This is a qualitative study, which seeks to understand the experience of the participants in the study. To fully understand those experiences requires frequent conversations and 
observations with participants. Your participation in this study will require approximately 14 hours over a 6 month period. This includes at least 2 interviews (approximately 1 hour each) and at least 2 observation sessions per month. Interviews and observations will be tailored to your needs. These time estimates may vary substantially depending on what activities you would like for me to observe or how involved you would like to be in the study.

\section{What will happen if you take part in the study?}

If you decide to take part in this study, there are three components that you will be involved in:

1. Interviews: We will establish a time to conduct two formal interviews (lasting about 1 hour each). The first interview will focus on your experience of participation in social life following your first psychotic episode. For the second interview, I will ask you to bring a text or item (i.e., photograph, book, quote, article) related to mental illness and participation that you find important or meaningful. I will also bring an item and we will discuss these together. Additional interviews may be requested for clarification of thoughts and ideas.

2. Observations: At least 2 observations will be completed each month, for a minimum of 6 months. These observations must occur in public locations (i.e., picnics, parks, stores, etc.). You will decide where you would like the observations to occur. I will 'tag along' where you would like for me to so I can observe your participation in social life to gain a better understanding of social participation.

3. Photo Elicitation: You will choose 1 photograph that reflects your own experience of mental illness and participation in social life. This image, along with the 4 other participants' images, will be enlarged and displayed on easels in a crowded setting. Passerbys will be asked to write their thoughts and feelings as it relates to the photograph on a post-it note. The purpose of this activity is to better understand how society views mental illness and participation.

\section{What are the possible benefits from being in this study?}

Research is designed to benefit society by gaining new knowledge. The study aims to provide knowledge that will facilitate the development of social interventions that target social inclusion and integration, which has been a notable concern for individuals with mental illness. It is hoped that you will also benefit from participating in this study by identifying avenues for social advocacy and broader social change related to mental illness.

\section{What are the possible risks or discomforts involved from being in this study?}

There is the potential that you may feel some emotional distress and discomfort when discussing social perceptions related to mental illness. To reduce this risk, a safety plan will be established with you during the initial meeting; this might include emergency contact numbers, decision about whether to contact your provider in the case of an emergency, and potential triggers or warning signs I need to be aware of. In addition, my phone number will be provided if you need to talk or decompress feelings related to this study. A handout of crisis numbers and local support groups will also be provided. There may also be uncommon or previously unknown risks. You should report any problems to the researcher.

\section{How will your privacy be protected?}

To ensure your privacy is protected, you will be assigned a unique identification number with the master list linking names and ID numbers stored separately from the data. Only the Principal Investigator will have access to the master list linking names and ID numbers; this list will be stored separately from the data. As soon as possible, after data collection, all 
personal identifiers will be removed from all data files and the tracking files will be destroyed to further prevent the possibility of identification of individuals and/or disclosure of confidential data. Access to all forms of study data (electronic and hardcopy) will be restricted to research staff only. All data will be protected on a secure, password protected database and all hardcopies of data will be stored in locked filing cabinets. Any oral or written reports drawing on the study data will contain no identifying information that would link individuals to specific counties or survey data. Participants will not be identified in any report or publication about this study. Although every effort will be made to keep research records private, there may be times when federal or state law requires the disclosure of such records, including personal information. This is very unlikely, but if disclosure is ever required, UNC-Chapel Hill will take steps allowable by law to protect the privacy of personal information. In some cases, your information in this research study could be reviewed by representatives of the University, research sponsors, or government agencies for purposes such as quality control or safety.

All audio tapes of interviews will be transcribed. Audio tapes will be stored in the same location as the other hard copy data (i.e., fieldnotes) and locked in filing cabinets. At study completion, the audio tape will be erased and destroyed. Audio recordings may be requested to be turned off if you do not wish to be recorded.

Check the line that best matches your choice:

OK to record me during the study Not OK to record me during the study

What if you want to stop before your part in the study is complete?

You can withdraw from this study at any time, without penalty. The investigators also have the right to stop your participation at any time. This could be because you have had an unexpected reaction, or have failed to follow instructions, or because the entire study has been stopped. Due to the nature of qualitative study and ongoing data analysis, it is requested that the data that has been collected to date still be used as part of the study, even if you decide to withdraw from the study.

Check the line that best matches your choice:

OK to keep the data that has already been collected

Not OK to keep the data that has already been collected.

\section{Will you receive anything for being in this study?}

You will be receiving $\$ 50$ for taking part in this study.

Will it cost you anything to be in this study?

There will be no costs for being in the study.

\section{What if you are a UNC student?}

You may choose not to be in the study or to stop being in the study before it is over at any time. This will not affect your class standing or grades at UNC-Chapel Hill. You will not be offered or receive any special consideration if you take part in this research.

\section{What if you are a UNC employee?}

Taking part in this research is not a part of your University duties, and refusing will not affect your job. You will not be offered or receive any special job-related consideration if you take part in this research. 


\section{What if you have questions about this study?}

You have the right to ask, and have answered, any questions you may have about this research. If you have questions, complaints, concerns, or if a research-related injury occurs, you should contact the researchers listed on the first page of this form.

\section{What if you have questions about your rights as a research participant?}

All research on human volunteers is reviewed by a committee that works to protect your rights and welfare. If you have questions or concerns about your rights as a research subject, or if you would like to obtain information or offer input, you may contact the Institutional Review Board at 919-966-3113 or by email to IRB_subjects@unc.edu.

Title of Study: An Exploration of Social Participation for Young Adults Following A First Psychotic Episode

Principal Investigator: Valerie Fox

\section{Participant's Agreement:}

I have read the information provided above. I have asked all the questions I have at this time. I voluntarily agree to participate in this research study.

$\overline{\text { Signature of Research Participant }} \overline{\text { Date }}$

Printed Name of Research Participant

$\overline{\text { Signature of Research Participant's Guardian (if applicable) }}$ Date

$\overline{\text { Printed Name of Research Participant's Guardian (if applicable) }}$

Only include the following section if consent obtained in-person.

$\overline{\text { Signature of Research Team Member Obtaining Consent }}$ Date

$\overline{\text { Printed Name of Research Team Member Obtaining Consent }}$ 


\section{APPENDIX C: LIST OF CONSULTANT OBSERVATIONS}

Oliver:

- Mr. Diplomat, Improv Comedy show

- Played CounterStrike, virtual military game

- Local bar; supposed to be spoken word event but decided not to go.

- Working at local restaurant during lunch shift

- Played CounterStrike, virtual military game; new server/clan

- Barnes and Noble for study close-out

Willow:

- Group meeting to complete class project/presentation

- Executive committee session of organization

- Library studying for last exam

- Orange is the New Black 'watch party'. Free style hangout at organization

- Laverne Cox show and meet and greet backstage.

- Gender-neutral pole dancing class, fitness event with organization

- Performing in gender-diverse fashion show, at event with organization

- Library preparing for upcoming class presentation

- Library doing homework

- Grocery shopping, recently moved into new apartment

- Yoga class through school

- Anatomy class 
Leo:

- Hanging out in café talking with friend

- Sunday morning church services with friend

- Assisted with getting back to his home to pick up spare key, then studying at library

- Watched American Sniper movie and debriefed after at Barnes and Noble

- Volunteering at local site. Attended 2 classes, lunch, and bowling with the group.

- Evening church services at separate church

- Monthly courthouse session for CRC

- Young adult bible study

- Cookout with bible study group, neighbors, and friends

- Volunteer location; lunch and resume class

- Al Anon weekly meeting, speakers meeting

- Al Anon weekly meeting

BB:

- Meteor shower at lake with meetup group.

- Sat on benches outside Starbucks, walked around lake near house

- Sat on benches outside Starbucks, walked around lake near house, built fire on fire pit

- Meetup group, 5 mile hike at lake

- Bowling with he and dad

- Hang out at Starbucks

- Sunday mass

- Familiar bar for darts, walked down main street

- Outside Starbucks, watched his posted videos online

- Hiking 
- Attended WRAL Freedom balloon festival

- Walked around lake near house

Carly:

- Sunday Chapel Service, helping with passing out hymns and assisting with finding right hymns, as well as transport to and from the service back to rooms.

- Weekly bible study, social night, appetizers and board games.

- 'Gentle' yoga session, morning class

- Weekly bible study, met at coffee shop

- Sunday Chapel Service, helping to pass out hymn books

- Watching UNC-Duke game with friend at local bar

- Meeting with visiting friend at coffee shop, catching up.

- Auction

- Eating lunch with friend

- Weekly bible study, intervention with other member

- First visit to Women's Group bible study

- Eating lunch with friend following church 


\section{APPENDIX D: SEMI-STRUCTURED INTERVIEW QUESTIONS}

\section{First Interview:}

1. How would you define participation?

a. What about social participation?

2. Tell me about your participation.

3. What do you do during the day? What do you participate in?

4. When you think of the things you do that involve other people, what has influenced what you do?

5. Are there things you would like to be doing with other people that you are not currently doing? Why do you think you are not doing these things?

6. Describe how your social participation has changed over the past 5 years.

a. What has led to these changes?

b. How do you think your diagnosis has, or has not, contributed to these changes?

c. What aspects of your social participation have not changed much over the past few years?

d. Why do you think this is?

\section{Second Interview:}

1. In thinking about your time in the study, what thoughts have you had about the study itself?

a. What have you found difficult about being in the study?

b. What have you found helpful or to be the easiest, if anything?

2. Tell me what you think about this piece of discourse (referring to the discourse I brought). 
3. Tell me about the piece of discourse you brought.

4. What did you think about when choosing this piece?

5. Tell me what you think about how these pieces of discourse relate to social participation. 
APPENDIX E: PHOTOS USED DURING DISCOURSE ELICITATION
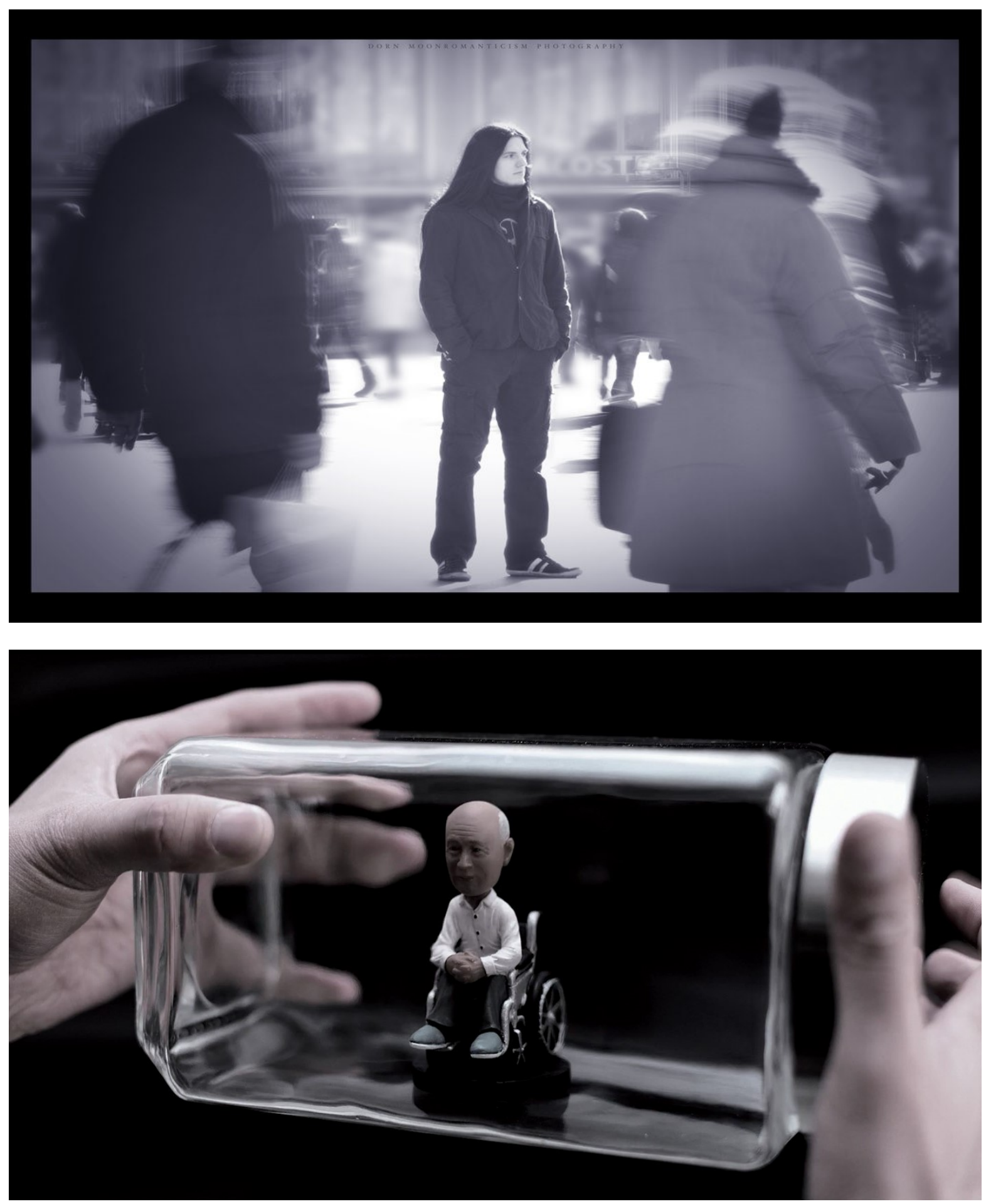


\section{APPENDIX F: CONSULTANT IDENTIFIED DISCOURSE}

Oliver:

\section{Inquisitor's Hands}

The martyrs only do it for attention.

In lighting as dark as the night in which we kill the Buddhas

one Enlightened spinal column at a time.

Death is the truth you grasp for

like a blind, deaf, mute

reaching into themselves wondering whether the senses can be trusted.

Show me what was written in the sanguine solitude of suburban cell blocks silent but for the screaming of sullen billions.

Are you a narcissist?

Are you happy?

Walking into tomorrow hoping the loveless forgive your tip-toeing.

Don't look at me.

I'm not what I want you to become.

I'm the rung of the ladder into the truth you grasp.

Laughing and crying inside and out,

the tortured clown

filled with zeal and doubt.

Staggering on the stage

as light as a feather,

as heavy as the page.

As free as the day you awoke

meaning less than dew or dust.

Trusted, once you've lost a few toenails

to everyone's favorite traitors but who is the more deluded?

The oath keeper or me?

Censored like the embers you don't want to hear burning flesh,

or all that's left to pay off the debt with while honor immolates houses of usury

like heretical houses of worship

who reached inside you with Inquisitor's hands

that shake for want of a subject to deliver piecemeal to the truth of truths.

Hallelujah!

Does a good mother smother or soothe?

Hallelujah!

Trapped within this night in me

unleashed into the night in you.

Hallelujah!

It's an affliction, it's an oath,

it's a welcome to what you wouldn't do as if you even could.

Here's to watching the firemen burning down the neighborhood.

Policemen escorting the organized criminals for whom every trial is theater, every law a joke.

Comedy for the comatose, tragedy for the lethargic.

Poetry recitation for the plenipotentiary plantation hands

whose masters lock their doors at night and sleep soundly.

If you found me flying towards the truth

with dried tears on my cheeks and a smile on my face, 
finally not feeling disjointed, out of place,

like something that should be erased.

Ask yourself, is this the message I should be sending?

Or does it take something real for a happy ending?

Carly:

'What is your scar tissue? What does it look like? Feel like? Taste like? What have you chosen to cover your wounds, your pains, your Invisible Monster? Your answer determines when your pain ends and when your life resumes'

-Kara Swanson

Willow:

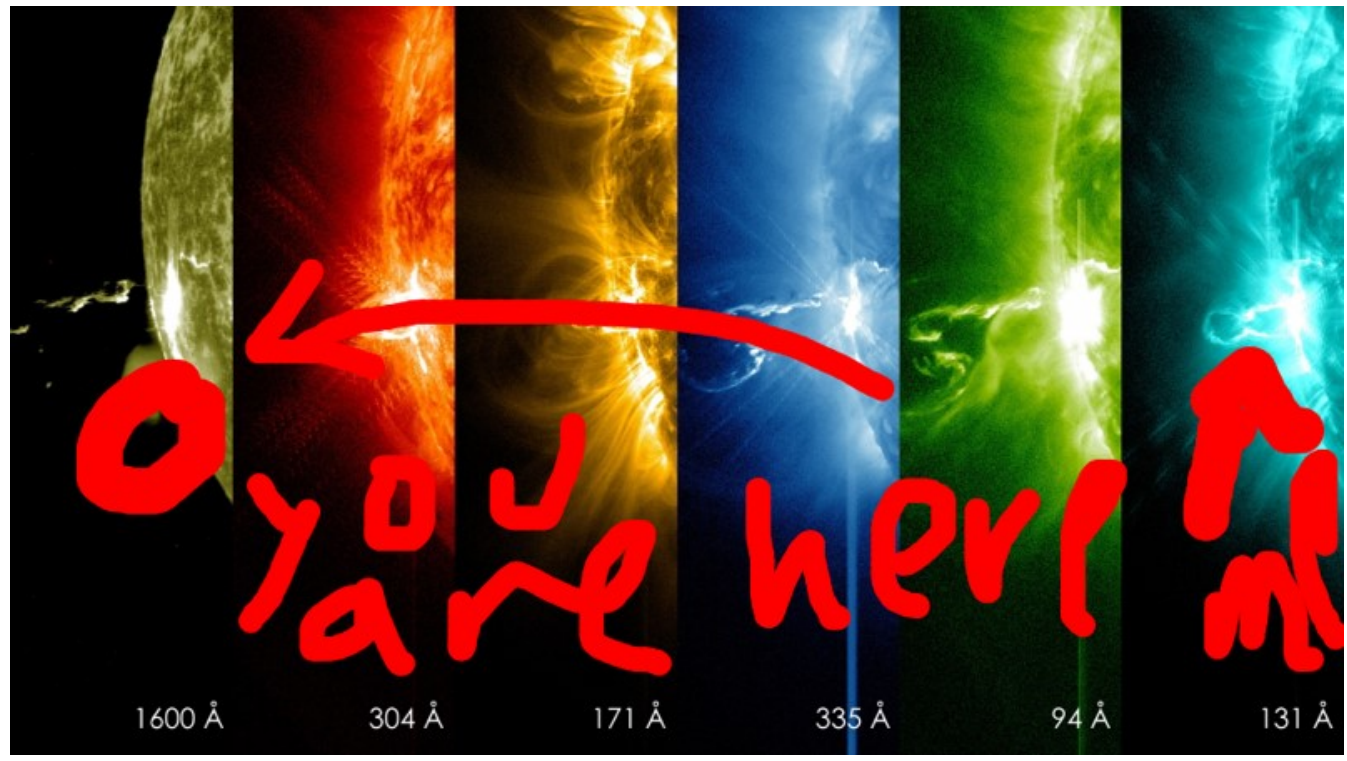


BB:

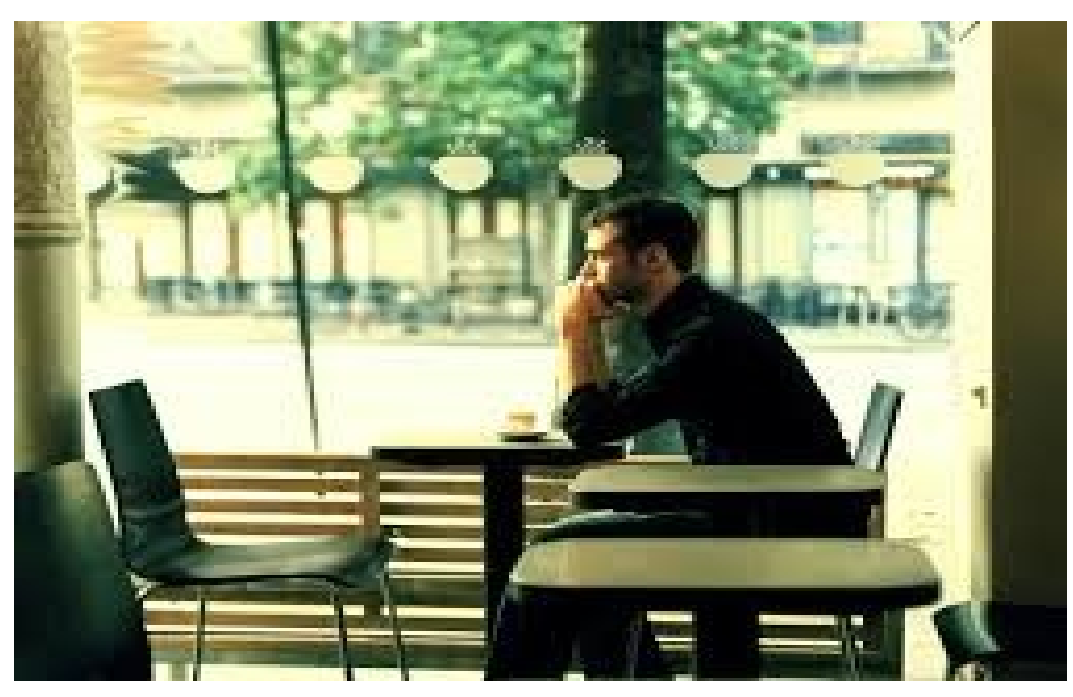

Leo:

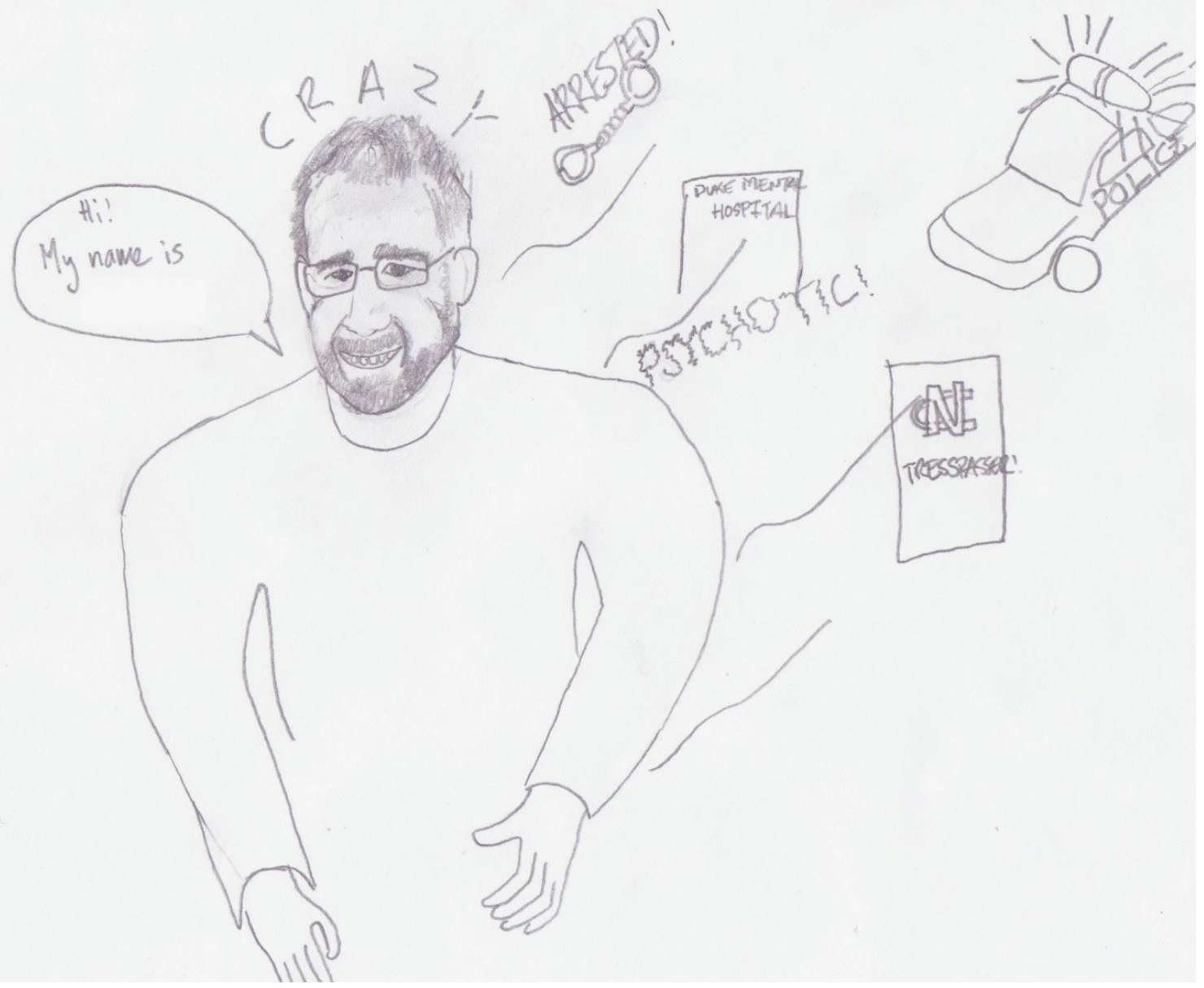




\section{REFERENCES}

Aldrich, R. (2008). From complexity theory to transactionalism: Moving occupational science forward in theorizing the complexities of behavior. Journal of Occupational Science, 15 (3), 147-156.

Aldrich, R., \& Cutchin, M. (2013). Dewey's Concepts of Embodiment, Growth, and Occupation: Extended Bases for a Transactional Perspective. In M. Cutchin and V. Dickie (Eds.), Transactional perspectives on occupation (pp. 13-23). New York, NY: Springer.

Asaba, E. (2008). Hashi-ire: Where occupation, chopsticks, and mental health intersect. Journal of Occupational Science, 15(2), 74-79.

Asaba, E., \& Jackson, J. (2011). Social ideologies embedded in everyday life: A narrative analysis about disability, identities, and occupation. Journal of Occupational Science, 18(2), 139-152.

Bailliard, A., Aldrich, R., \& Dickie, V. (2013). Ethnography and the transactional study of occupation. In M. Cutchin and V. Dickie (Eds.), Transactional Perspectives on Occupation (pp. 157-168). New York, NY: Springer.

Barrett, R., (1998). The 'schizophrenic' and the liminal persona in modern society. Culture, Medicine, and Psychiatry, 22(4), 465-494.

Bassett, J., Lloyd, C., \& Bassett, H. (2001). Work issues for young people with psychosis: Barriers to employment. British Journal of Occupational Therapy, 64, 66-72.

Beech, N. (2010). Liminality and the practices of identity reconstruction. Human Relations, 64(2), 1-18.

Behar, R. (1996). The Vulnerable Observer: Anthropology That Breaks Your Heart. Boston, MA: Beacon Press.

Bishop, R. (2007). Methodological holism and methodological individualism. In The Philosophy of the Social Sciences: An Introduction (pp. 151-167), New York, NY: Continuum International Publishing Group.

Blumer, H. (1969). Symbolic Interactionism: Perspective and Method. Los Angeles, CA: University of California Press.

Boisvert, R. (1997). John Dewey: Rethinking our time. Albany, NY: State University of New York Press.

Booth, S. (1999). Researching health and homelessness: Methodological challenges for researchers working with a vulnerable, hard to reach, transient population. Australian Journal of Primary Health, 5(3), 76-81.

Borell, L., Asaba, E., Rosenberg, L., Schult, M., \& Townsend, E. (2006). Exploring experiences of "participation" among individuals living with chronic pain. Scandinavian Journal of Occupational Therapy, 13 (2), 76-85. 
Boydell, K., Stasiulis, E., Volpe, T., \& Gladstone, B. (2010). A descriptive review of qualitative studies in first episode psychosis. Early Intervention in Psychiatry, 4, 7-24.

Bratun, U., \& Asaba, E. (2008). From individual to communal experiences of occupation: Drawing upon Qi Gong practices. Journal of Occupational Science, 15(2), 80-86.

Breitborde, N., Srihari, V., \& Woods, S. (2009). Review of the operational definition for firstepisode psychosis. Early Intervention in Psychiatry, 3, 259-265.

Brown, B. (2006). Shame resilience theory: A grounded theory study on women and shame. Families in Society. The Journal of Contemporary Social Services, 87, 43-52.

Brown, C., \& Lloyd, K. (2001). Qualitative methods in psychiatric research. Advances in Psychiatric Treatment, 7, 350-356.

Burr, V. (2015). Social constructionism ( $3^{\text {rd }}$ ed.). New York, NY: Routledge.

Cheek, J. (2004). At the margins? Discourse analysis and qualitative research. Qualitative Health Research, 14, 1140-1150.

Christiansen, C. (1999). Defining lives: Occupation as identity: An essay on competence, coherence and the creation of meaning. American Journal of Occupational Therapy, $53,547-558$.

Cicognani, E., Pirini, C., Keyes, C., Joshanloo, M., Rostami, R., \& Nosratabadi, M. (2008). Social participation, sense of community and social wellbeing: A study on American, Italian and Iranian university students. Social Indicators Research, 89, 97-112.

Cicourel, A. (1982). Interviews, surveys, and the problem of ecological validity. The American Sociologist, 17, 11-20.

Creswell, J. (2007). Qualitative inquiry and research design: Choosing among five approaches $\left(2^{\text {nd }}\right.$ ed.). Thousand Oaks, CA: Sage Publications.

Crotty, M. (1998). Constructionism: The Making of Meaning. In The Foundations of Social Research: Meaning and Perspective in the Research Process (pp. 42-65). Thousand Oaks, CA: Sage Publications.

Cutchin, M. (2007). From society to self (and back) through place: Habit in transactional context. OTJR: Occupation, Participation and Health, 27, 50-59.

Cutchin, M., Aldrich, R., Bailliard, A., \& Coppola, S. (2008). Action theories for occupational science: The contributions of Dewey and Bourdieu. Journal of Occupational Science, 15(3), 157-165.

Cutchin, M., \& Dickie, V. (2012). Transactionalism: Occupational science and the pragmatic attitude. In G. Whiteford \& C. Hocking (Eds.), Occupational Science: Society, Inclusion, Participation (pp.22-37). West Sussex, UK: Blackwell Publishing. 
Cutchin, M., Dickie, V., \& Humphry, R. (2006). Transaction versus interpretation, or transaction and interpretation? A response to Michael Barber. Journal of Occupational Science, 13, 97-99.

Dalgard, O., \& Lund, L. (1998). Psychosocial risk factors and mortality: A prospective study with special focus on social support, social participation, and locus of control in Norway. Journal of Epidemiology and Community Health, 52 (8), 476-481.

Daly, K. (2007). Methodology: Links among ontological assumptions, theory, and forms of inquiry. In Qualitative Methods for Family Studies and Human Development (pp. 83128). Los Angeles, CA: Sage Publications.

Davidson, L. (2007). Habits and other anchors of everyday life that people with psychiatric disabilities may not take for granted. OTJR: Occupation, Participation and Health, 27, 60S-68S.

Dewalt, K., \& DeWalt, B. (2011). Participation observation: A guide for fieldworkers ( $2^{\text {nd }}$ ed.). Lanham, MD: AltaMira Press.

Dickie, V., Cutchin, M., \& Humphry, R. (2006). Occupation as transactional experience: A critique of individualism in occupational science. Journal of Occupational Science, 13, 83-93.

Diewald, M. \& Mayer, K. (2009). The sociology of the life course and life span psychology: Integrated paradigm or complementing pathways? Advances in Life Course Research, 14, 5-14.

Drake, R., Green, A., Mueser, K., \& Goldman, H. (2003). The history of community mental health treatment and rehabilitation for persons with severe mental illness. Community Mental Health Journal, 39(5), 427-440.

Ekelman, B., Bazyk, S., \& Bazyk, J. (2013). The relationship between occupational engagement and well-being from the perspective of university students with disabilities. Journal of Occupational Science, 20(3), 236-252

Eklund, M., Hermansson, A., \& Hakansson, C. (2012). Meaning in life for people with schizophrenia: Does it include occupation? Journal of Occupational science, 19(2), 93-105.

Elder, G. (1999). The life course and aging: Some reflections. Proceedings from Distinguished Scholar Lecture for Section on Aging in American Sociological Association.

Elwood, S., \& Martin, D. (2000). "Placing" interviews: Location and scales of power in qualitative research. Professional Geographer, 52(4), 649-657.

Estroff, S. (1981). Making it crazy: An ethnography of psychiatric clients in an American community. Los Angeles: California: University of California Press.

Fesmire, S. (2003). John Dewey and Moral Imagination. Bloomington, IN: Indiana University Press. 
Fields, D. (2011). Emotional refuge? Dynamics of place and belonging among formerly homeless individuals with mental illness. Emotion, Space and Society, 4, 268-267.

Friese, S. (2013). ATLAS.ti 7 user manual. Berlin, Germany: ATLAS.ti Scientific Software Development $\mathrm{GmbH}$.

Fritz, H. (2014). Improvisational Theater and Insights into the Function of Habit in Occupation. Journal of Occupational Science, 21(2), 161-172.

Furimsky, I., Cheung, A., Dewa, C., \& Zipursky, R. (2008). Strategies to enhance patient recruitment and retention in research involving patients with a first episode of mental illness. Contemporary Clinical Trials, 29, 862-866.

Garrison, J. (2001). An introduction to Dewey's theory of functional "trans-action": An alternative paradigm for activity theory. Mind, Culture, and Activity, 8, 275-296.

Gavey, N. (1989). Feminist poststructuralism and discourse analysis. Psychology of Women Quarterly, 13, 459-475.

Gioia, D. (2006). Examining work delay in young adults with schizophrenia. American Journal of Psychiatric Rehabilitation, 9, 167-190.

Goering, P., \& Streiner, D. (1996). Reconcilable differences: The marriage of qualitative and quantitative methods. Canadian Journal of Psychiatry, 41, 491-497.

Goffman, E. (1963). Stigma: Notes on the management of spoiled identity. Englewood Cliffs, NJ: Prentice-Hall Inc.

Granello, D., \& Wheaton, J. (2004). Online data collection: Strategies for research. Journal of Counseling and Development, 82, 387-393.

Hammel, J., Magasi, S., Heinemann, A., Whiteneck, G., Bogner, J., \& Rodriguez, E. (2008). What does participation mean? An insider perspective from people with disabilities. Disability and Rehabilitation, 30, 1445-1460.

Hammell, K. (2004a). Dimensions of meaning in the occupations of daily life. Canadian Journal of Occupational Therapy, 71(5), 296- 305

Hammell, K. (2014). Belonging, occupation, and human well-being: An exploration. Canadian Journal of Occupational Therapy, 81, 39-50.

Hasselkus, B. (2002) The meaning of everyday occupation. Thorofare, NJ: Slack Incorporated.

Hecht, H., \& Wittchen, H. (1988). The frequency of social dysfunction in a general population sample and in patients with mental disorders: A comparison using the social interview schedule (SIS). Social Psychiatry and Psychiatric Epidemiology, 23, 17-29. 
Heinemann, A. W., Lai, J.-S., Magasi, S., Hammel, J., Corrigan, J. D., Bogner, J. A., \& Whieneck, G. G. (2011). Measuring participation enfranchisement. Archives of Physical Medicine and Rehabilitation, 92, 564-571.

Hengst, J., \& Duff, M. (2007). Clinicians as communication partners: Developing a mediated discourse elicitation protocol. Topics in Language Disorders, 27, 37-49.

Henry, A., \& Coster, W. (1996). Predictors of functional outcome among adolescents and young adults with psychotic disorders. American Journal of Occupational Therapy, 50(3), 171-181.

Hesse-Biber, S., \& Leavy, P. (2011). The practice of qualitative research ( $2^{\text {nd }}$ ed.). Thousand Oaks, CA: Sage Publications.

Hinson, G. (2000). Stepping around experience and the supernatural. In Fire in My Bones: Transcendence and the Holy Spirit in African American Gospel (pp. 327-334). Philadelphia: University of Pennsylvania Press.

Hocking, C. (2009). The challenge of occupation: Describing the things people do. Journal of Occupational Science, 16(3), 140-150.

Holland, D., Lachicotte, W., Skinner, D., \& Cain, W. (1998). Identity and agency in cultural worlds. Cambridge, MA: Harvard University Press.

Hopper, K., Wanderling, J., \& Narayanan, P. (2007). 'To have and to hold: A cross-cultural inquiry into marital prospects after psychosis'. Global Public Health, 2(3), 257-280.

Howe, K., \& Eisenhart, M. (1990). Standards for qualitative (and quantitative) research: A prolegomenon. Educational Researcher, 19(4), 2-9.

Humphry, R., \& Womack, J. (2014). Transformations of occupations: A life course perspective. In E. Crepeau, E. Cohn, \& B. Schell (Eds.), Willard and Spackman's Occupational Therapy. Philadelphia, PA: Wolters Kluwer Health/Lippincott Williams and Wilkins.

Huxley, P., \& Thornicroft, G. (2003). Social inclusion, social quality and mental illness. British Journal of Psychiatry, 182, 289-290.

IRB and Office of Human Research Ethics. Retrieved from http://research.unc.edu/offices/human-research-ethics/

Iyer, S., Mangala, R., Thara, R., \& Malla, A. (2010). Preliminary findings from a study of firstepisode psychosis in Montreal, Canada and Chennai, India: Comparison of outcomes. Schizophrenia Research, 121, 227-233.

Jackson, J. (2005). Stigma, liminality, and chronic pain: Mind-body borderlands. American Ethnologist, 32(3), 332-353.

Jones, P., \& Krzyżanowski, M. (2008). Identity, Belonging, and Migration: Beyond Constructing "Others". In G. Delanty, R. Wodak, \& P. Jones. (Eds.), Identity, belonging and migration (pp. 38-54). Liverpool, UK: Liverpool University Press. 
Judge, A., Estroff, S., Perkins, D., \& Penn, D. (2008). Recognizing and responding to early psychosis: A qualitative analysis of individual narratives. Psychiatric Services, 59, 96-99.

Kelly, A. (2008). Living loss: An exploration of the internal space of liminality. Mortality, 13(4), 335-350.

Keshavan, M., \& Schooler, N. (1992). First-episode studies in schizophrenia: Criteria and characterization. Schizophrenia Bulletin, 18(3), 491-513.

Kessler, R., Walters, E., Forthofer, M. (1998). The social consequences of psychiatric disorders, III: Probability of marital stability. American Journal of Psychiatry, 155, 1092-1096.

Kielhofner, G. (2002). Model of human occupation: Theory and application (3rd ed.). Baltimore, MD: Lippincott Williams \& Wilkins.

King, M. (2010). Documenting traditions and the ethnographic double bind. Collaborative Anthropologies, 3, 35-67.

Lachicotte, W. (2002). Intimate powers, public selves: Bakhtin's space of authoring. In J. Mageo (ed.). Power and the self (pp.48-66). New York: NY: Cambridge University Press.

Laliberte Rudman, D. (2002). Linking occupation and identity: Lessons learned through qualitative exploration. Journal of Occupational Science, 9, 12-19.

Laliberte Rudman, D. (2010). Occupational terminology: Occupational possibilities. Journal of Occupational Science, 17, 55-59.

Laliberte Rudman, D. (2011). Understanding political influences on occupational possibilities: An analysis of newspaper constructions of retirement. Journal of Occupational Science, 12(3), 149-160.

Laliberte Rudman, D. (2013). Critical discourse analysis: Adding a political dimension to inquiry. In M. Cutchin \& V. Dickie (eds.), Transactional Perspectives on Occupation (pp. 169-181). New York, NY: Springer.

Lassiter, E. (2005). The Chicago Guide to Collaborative Ethnography. Chicago, IL: University of Chicago Press.

Lee, H.Y., Jang, S., Lee, S., Cho, S., Park, E. (2008). The relationship between social participation and self-rated health by sex and age: A cross-sectional survey. International Journal of Nursing Studies, 45, 1042-1054.

Leer, E., \& Turkstra, L. (1999). The effect of elicitation task on discourse coherence and cohesion in adolescents with brain injury. Journal of Communication Disorders, 32(5), 327-349.

Legard, R., Keegan, J., \& Ward, K. (2003). In-depth interviews. In J. Ritchie \& J. Lewis (eds.), Qualitative Research Practice: A Guide for Social Science Students and Researchers (pp.138-169). Thousand Oaks, CA: Sage Publications. 
Lewis, S. (2008). Ayahuasca and spiritual crisis: liminality as space for personal growth. Anthropology of Consciousness, 19(2), 109-133.

Lieberman, J., \& Fenton, W. (2000). Delayed detection of psychosis: Causes, consequences, and effect on public health. American Journal of Psychiatry, 157, 1727-1730.

Little, M., Jordens, C., Paul, K., Montgomery, K., \& Philipson, B. (1998). Liminality: A major category of the experience of cancer illness. Social Science and Medicine, 47 (10), 1485-1494.

Link, B., Cullen, F., Struening, E., Shrout, P., Dohrenwend, B. (1989). A modified labeling theory approach to mental disorders: An empirical assessment. American Sociological Review, 54(3), 400-423.

Malla, A., \& Payne, J. (2005). Psychopathology, quality of life, and functional outcome. Schizophrenia Bulletin, 31(3), 650-671.

Martin, A. (2010). Should students have a gap year? Motivation and performance factors relevant to time out after completing school. Journal of Educational Psychology, 102(3), 561-576.

Maslow, A. (1943). Maslow's Hierarchy of Needs. Psychological Review, 50, 370-396.

McCay, E., Beanlands, H., Leszcz, M., Goering, P., Seeman, M., Ryan, K, Johnston, N., \& Vishnevsky, T. (2006). A group intervention to promote health self-concepts and guide recovery in first episode schizophrenia: A pilot study. Psychiatric Rehabilitation Journal, 105-111.

McGorry, P., Killackey, E., \& Yung, A. (2007). Early intervention in psychotic disorders: Detection and treatment of the first episode and the critical early stages. Medical Journal of Australia, 187, S8-S10.

McKenzie, M., Tulsky, J., Long, H., Chesney, M., \& Moss, A. (1999). Tracking and follow-up of marginalized populations: A review. Journal of Health Care for the Poor and Underserved, 10(4), 409-429.

Nagle, S., Cook, J., \& Polatajko, H. (2002). I'm doing as much as I can: Occupational choices of persons with a severe and persistent mental illness. Journal of Occupational Science, 9(2), 72-81.

Nunkoosing, K., Pearls, pith, and provocation: The problems with interviews. Qualitative Health Research, 15(5), 698-706.

Olness, G., Ulatowska, H., Wertz, R., Thompson, J., \& Auther, L. (2002). Discourse elicitation with pictorial stimuli in African Americans and Caucasians with and without aphasia. Aphasiology, 16 (4-6), 623-633.

Ornstein, R. (2015). The Sociology of Young Adulthood: An Introductory Study of the Unknown. Life History and the Media Project. 
Paterson, B., \& Scott-Findlay, S. (2002). Critical issues in interviewing people with traumatic brain injury. Qualitative Health Research, 12(3), 399-409.

Penn, D., Waldheter, E., Perkins, D., Mueser, K., \& Lieberman, J. (2005). Psychosocial treatment for first-episode psychosis: A research update. American Journal of Psychiatry, 162, 2220-2232.

Perry, B., Taylor, D., \& Shaw, S. (2007). "You've got to have a positive state of mind": An interpretive phenomenological analysis of hope and first episode psychosis. Journal of Mental Health, 16(6), 781-793.

Peters, S. (2010). Qualitative research methods in mental health. Evidence Based Mental Health, 13(2), 35-40.

Petticrew, M., \& Roberts, H. (2003). Evidence, hierarchies, and typologies: Horses for courses. Journal of Epidemiology and Community Health, 57, 527-529.

Phelan, S., \& Kinsella, E. (2009). Occupational identity: Engaging socio-cultural perspectives. Journal of Occupational Science, 16(2), 85-91.

Phelan, S., \& Kinsella, E. (2014). Occupation and identity: Perspectives of children with disabilities and their parents. Journal of Occupational Science, 21(3), 334-356.

Piskur, B., Daniels, R., Jongmans, M., Ketelaar, M., Smeets, R., Norton, M., \& Beurskens, A. (2014). Participation and social participation: Are they distinct concepts? Clinical Rehabilitation, 28(3), 211-220.

Pottick, K., Bilder, S., Vander Stoep, A., Warner, L., \& Alvarez, M. (2008). US patterns of mental health service utilization for transition-age youth and young adults. Journal of Behavioral Health Services and Research, 35(4), 373-389.

Prince, P., \& Gerber, G. (2005). Subjective well-being and community integration among clients of assertive community treatment. Quality of Life Research, 14, 161-169.

Ramsay, C., Broussard, B., Goulding, S., Cristofaro, S., Hall, D., Kaslow, N., Killackey, E., Penn, D., \& Compton, M. (2011). Life and treatment goals of individuals hospitalized for first-episode non-affective psychosis. Psychiatry Research, 189(3), 344-348.

Read, J., \& Eagle, D. (2014). Intersectionality and identity: An exploration of Arab American women. In L. Keister \& D. Sherkat (Eds.), Religion and inequality in America: Research and theory on religion's role in stratification (pp. 75-94). New York, NY: Cambridge University Press.

Reed, K., Hocking, C., \& Smythe, L. (2010). The interconnected meanings of occupation: The call, being-with, possibilities. Journal of Occupational Science, 17(3), 140-149.

Romano, D., McKay, E., Goering, P., Boydell, K., \& Zipursky, R. (2010). Reshaping an enduring sense of self: The process of recovery from a first episode of schizophrenia. Early Intervention in Psychiatry, 4, 243-250. 
Rosaldo, R. (1993). After objectivism. In Culture and Truth: The Remaking of Social Analysis (pp. 46-67). Boston, MA: Beacon Press.

Ryff, C.D., \& Singer, B. (1996). Psychological well-being: Meaning, measurement, and implications for psychotherapy research. Psychotherapy and Psychosomatics, 65, 14-23.

Sakiyama, M., Josephsson, S., \& Asaba, E. (2010). What is participation? A story of mental illness, metaphor, and everyday occupation. Journal of Occupational Science, 17(4), 224-230.

Schon, U., Denhov, A., \& Topor, A. (2009). Social relationships as a decisive factor in recovering from severe mental illness. International Journal of Social Psychiatry, 55(4), 336-347.

Schulenberg, J., Sameroff, A., \& Cicchetti, D. (2004). The transition to adulthood as a critical juncture in the course of psychopathology. Development and Psychopathology, 16(4), 799-806.

Schwalbe, M. (2008). The Sociologically Examined Life. (4 ${ }^{\text {th }}$ ed.). New York, NY: McGrawHill.

Schwalbe, M., \& Mason-Shrock, D. (1996). Identity work as group process. Advances in Group Processes, 13, 113-147.

Schwalbe, M., Godwin, S., Holden, D., Schrock, D., Thompson, S., \& Wolkomir, M. (2000). Generic processes in the reproduction of inequality: An interactionist analysis. Social Forces, 79(2), 419-452.

Sharma, T., \& Antonova, L. (2003). Cognitive function in schizophrenia. Deficits, functional consequences, and future treatment. Psychiatric Clinics of North America, 26, 2540.

Silcock, M., Hocking, C., \& Payne, D. (2014). Childhood constructions of contemporary technology: Using discourse analysis to understand the creation of occupational possibilities. Journal of Occupational Science, 21(3), 1-14.

Snow, D., \& Anderson, L. (1987). Identity work among the homeless: The verbal construction and avowal of personal identities. American Journal of Sociology, 92(6), 1336-1371.

Spoken word. (n.d.). In Wikipedia. Retrieved from https://en.wikipedia.org/wiki/Spoken word

Stoep, A., Beresford, S., Weiss, N., McKnight, B., Cauce, A., \& Cohen, P. (2000). Community-based study of the transition to adulthood for adolescents with psychiatric disorder. American Journal of Epidemiology, 152(4), 352-362.

Substance Abuse and Mental Health Services Administration. (2012). Results from the 2010 National Survey on Drug Use and Health: Mental Health Findings. Retrieved April 29, 2012, from http://www.samhsa.gov/data/nsduh/2k10MH Findings/2k10MHResults.htm 
Swartz, D. (1997). Culture and power: The sociology of Pierre Bourdieu. Chicago, IL: University of Chicago Press.

Thoits, P. (2011). Resisting the stigma of mental illness. Social Psychology Quarterly, 74, 628.

Townsend, E. (2012). Boundaries and bridges to adult mental health: Critical occupational and capabilities perspectives of justice. Journal of Occupational Science, 19, 8-24.

Turner, V. W. (1967). The forest of symbols: Aspects of Ndembu ritual. Ithaca, NY: Cornell University Press.

Valentine, G., \& Sporton, D. (2009). 'How other people see you, it's like nothing that's inside': The impact of processes of disidentification and disavowal on young people's subjectivities. Sociology, 43, 735-751.

Van Dijk, T. (2003). Critical Discourse Analysis. In D. Schiffrin, D. Annen, \& H. Hamilton (eds.), The Handbook of Discourse Analysis (pp. 352-371). Malden, MA: Blackwell Publishing.

Wenger, E. (1998). Communities of Practice: Learning, Meaning, and Identity. Cambridge, UK: Cambridge University Press.

Whiteford, G. (2000). Occupational deprivation: Global challenge in the new millennium. British Journal of Occupational Therapy, 63(5), 200-204.

Whiteford, G., \& Hocking, C. (2012). Occupational Science: Society, inclusion, participation. Oxford, UK: Wiley-Blackwell.

Wilcock, A. (2006). An occupational perspective of health (2 $2^{\text {nd }}$ Edition). Thorofare, NJ: Slack Incorporated.

Woodside, H., Krupa, T., \& Pocock, K. (2007). Early psychosis, activity performance and social participation: A conceptual model to guide rehabilitation and recovery. Psychiatric Rehabilitation Journal, 31, 125-130.

Wortham, S. (2006). Learning identity: The joint emergence of social identification and academic learning. New York, NY: Cambridge University Press. 